Florida International University

FIU Digital Commons

FIU Electronic Theses and Dissertations

University Graduate School

$10-3-2014$

\title{
The relationship among serum levels of manganese superoxide dismutase and mtDNA 8-hydroxy-2'- deoxyguanosine, and dietary antioxidants intake in Type 2 Diabetes
}

MICHAEL ANDREW MCLEAN

mmclean0612@aol.com

DOI: $10.25148 /$ etd.FI14110702

Follow this and additional works at: https://digitalcommons.fiu.edu/etd

Part of the Dietetics and Clinical Nutrition Commons

\section{Recommended Citation}

MCLEAN, MICHAEL ANDREW, "The relationship among serum levels of manganese superoxide dismutase and mtDNA 8-hydroxy-2'-deoxyguanosine, and dietary antioxidants intake in Type 2 Diabetes" (2014). FIU Electronic Theses and Dissertations. 1573.

https://digitalcommons.fiu.edu/etd/1573

This work is brought to you for free and open access by the University Graduate School at FIU Digital Commons. It has been accepted for inclusion in FIU Electronic Theses and Dissertations by an authorized administrator of FIU Digital Commons. For more information, please contact dcc@fiu.edu. 


\section{FLORIDA INTERNATIONAL UNIVERSITY}

Miami, Florida

THE RELATIONSHIP AMONG SERUM LEVELS OF MANGANESE

SUPEROXIDE DISMUTASE AND MITOCHONDRIAL DNA 8-HYDROXY-2'-

DEOXYGUANOSINE, AND DIETARY ANTIOXIDANTS INTAKE IN

TYPE 2 DIABETES

A dissertation submitted in partial fulfillment of the

Requirements for the degree of

DOCTOR OF PHILOSOPHY

in

DIETETICS AND NUTRITION

by

Michael Andrew McLean 
To: Dean Michele Ciccazzo

R.Stempel College of Public Health and Social Work

This dissertation, written by Michael Andrew McLean, and entitled The Relationship among Serum Levels of Manganese Superoxide Dismutase and mitochondrial DNA 8hydroxy-2'-deoxyguanosine, and Dietary Antioxidants Intake in Type 2 Diabetes, having been approved in respect to style and intellectual content, is referred to you for judgment.

We have read this dissertation and recommend that it be approved.

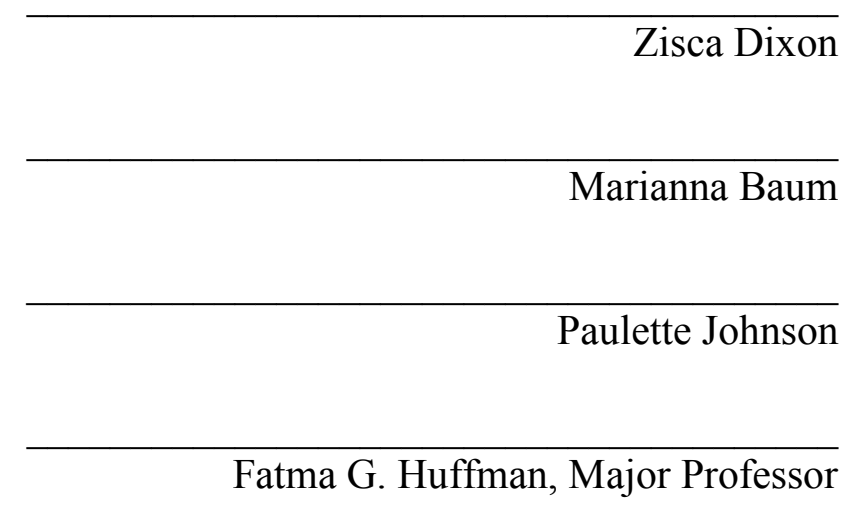

Date of Defense: October 3, 2014

The dissertation of Michael Andrew McLean is approved.

Dean Michele Ciccazzo

R.Stempel College of Public Health and Social Work

Dean Lakshmi N. Reddi
University Graduate School

Florida International University, 2014 
(C) Copyright 2014 by Michael Andrew McLean

All rights reserved. 


\section{DEDICATION}

I dedicate this dissertation to my wife Zunilda, my daughter Kasey Diana, my two sons Adrian Luis and Michael (AJ), and my parents. Without their sacrifices, understanding, motivation, and encouragement the completion of this project would not have been possible. 


\section{ACKNOWLEDGMENTS}

I would like to thank the members of my dissertation committee, Dr. Fatma Huffman, Dr. Paulette Johnson, Dr. Marianna Baum, and Dr. Zisca Dixon. Without their guidance and the support from my wife and family, I would not have been able to complete my dissertation. Additionally, I would like to express my deepest and most sincere gratitude to my mentor and advisor, Dr. Fatma Huffman. Her unrelenting guidance and encouragement have been instrumental in every step towards the completion of my research. In the past several years, Dr. Huffman has successfully developed my intellectual background in the study of vitamins, minerals, and carbohydrates. I would also like to thank Dr. Paulette Johnson for her infinite wisdom in the statistical analysis, even when she was in her retirement phase of career.

I would be remiss if I did not acknowledge Gustavo Zarini for his guidance and coordination of the recruitment of the participants. His willingness to provide insight and management of the data for my study is infinitely appreciated and priceless. His willingness to always help and give me his best suggestions goes beyond the friendship that we have developed throughout these years.

My parents, Percival and Curdella McLean, have provided an enormous amount encouragement. They made huge sacrifices when they migrated from Jamaica to the United States to ensure that my sisters and I receive the best education and career opportunities. The conferment of my doctorate in Dietetics and Nutrition has made them proud of their decision and vision. I would like to thank my sisters and their family for their support and best wishes. Finally, I want to thank my wife Zunilda for her wonderful 
encouragement and understanding. She always stood with me throughout the good and bad times and for sacrifice and understanding when I was away from the family, whether I am at the university or at the library. And of course, my daughter the princess Kasey Diana McLean and my two sons Adrian Luis McLean and Michael McLean (AJ) who were the men of the house when I am away working on my dissertation. 


\begin{abstract}
OF THE DISSERTATION
THE RELATIONSHIP AMONG SERUM LEVELS OF MANGANESE

SUPEROXIDE DISMUTASE AND MITOCHONDRIAL DNA 8-HYDROXY-2'-

DEOXYGUANOSINE, AND DIETARY ANTIOXIDANTS INTAKE IN
\end{abstract}

TYPE 2 DIABETES

By

Michael Andrew McLean

Florida International University, 2014

Professor Fatma G. Huffman, Major Professor

Oxidative stress plays a key role in the development of Type 2 Diabetes (T2D).

This cross-sectional study examined the relationship among serum levels of manganese superoxide dismutase (MnSOD), 8-hydroxy-2'-deoxyguanosine (8OHdG), dietary antioxidant intakes and glycemic control in African Americans $(n=209)$ and Haitian Americans $(n=234)$ with and without T2D.

African Americans had higher BMI (32.8 vs. $29.3 \mathrm{~kg} / \mathrm{m}^{2}$ ), higher energy intake (2148 vs. $1770 \mathrm{kcal}$ ), and were more educated as compared to Haitian Americans; all variables were significant at $p<.001$. Serum levels of $80 \mathrm{HdG}$ and MnSOD for African Americans $(1691.0 \pm 225.1 \mathrm{pg} / \mathrm{ml}, 2538.0 \pm 1091.8 \mathrm{pg} / \mathrm{ml}$; respectively) were significantly higher than for Haitian Americans $(1626.2 \pm 222.9,2015.8 \pm 656.3 \mathrm{pg} / \mathrm{ml}$; respectively). $8 \mathrm{OHdG}$ was negatively correlated with $\operatorname{MnSOD}(r=-.167, p<.001)$ in T2D. Having T2D was negatively correlated with $\operatorname{MnSOD}(r=-.337 ; p<.01)$ and positively correlated with $8 \mathrm{OHdG}(r=.500 ; p<.01)$. African Americans and Haitian Americans with T2D had fasting plasma glucose (FPG) levels of $143.0 \pm 61.0 \mathrm{mg} / \mathrm{dl}$ and 
$157.6 \pm 65.5 \mathrm{mg} / \mathrm{dl}$, and $\mathrm{A} 1 \mathrm{C}$ of $7.5 \pm 1.8 \%$ and $8.4 \pm 2.4 \%$, respectively. African Americans and Haitian Americans without T2D had FPG levels of $95.8 \pm 13.2 \mathrm{mg} / \mathrm{dl}$ and $98.7 \pm 16.9 \mathrm{mg} / \mathrm{dl}$, and A1C of $5.9 \pm 0.4 \%$ and $6.0 \pm 0.5 \%$, respectively. Dietary intakes of vitamin C and vitamin D were negatively correlated with FPG $(r=-.21 ; r=-.19, p<$ $.05)$ respectively. Carotenoids negatively correlated with A1C $(r=-.19, p<.05)$. Lower levels of MnSOD were associated with lower levels of zinc, $r=.10, p<.05$, and higher levels of carotenoids $r=-.10, p<.05$. Higher levels of $8 \mathrm{OHdG}$ were associated with lower levels of Vitamin $\mathrm{D}, r=-.14, p<.01$, and carotenoids, $r=-.09, \mathrm{p}<.05$.

The results demonstrate greater oxidative mtDNA damage in persons with T2D compared to those without T2D and in African Americans compared with Haitian Americans. The inverse relationship between dietary intake of antioxidants and oxidative stress implies a potential to reduce oxidative stress with diet. 


\section{TABLE OF CONTENTS}

CHAPTER

PAGE

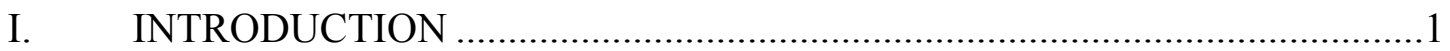

Statement of the Problem.........................................................................4

Justification of the Study ....................................................................4

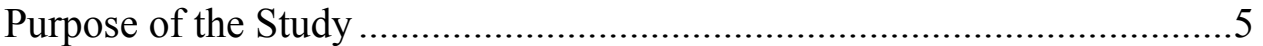

Hypotheses and Specific Aims ............................................................6

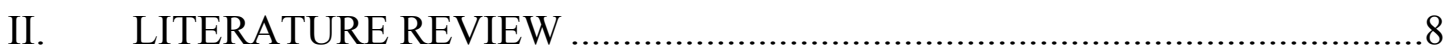

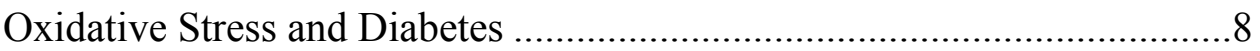

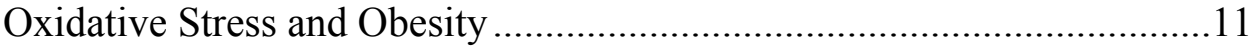

Oxidative Stress and Dietary Antioxidants .........................................11

Oxidative Stress and Biochemical Mechanism....................................14

Diabetes and Manganese Superoxide Dismutase (MnSOD) .....................17

Diabetes and 8-hydroxy-2'-deguanosine (8OHdG) ..............................21

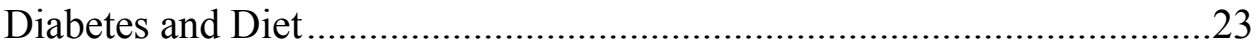

Serum Levels of MnSOD and Oxidative Stress .....................................25

Serum Levels of $8 \mathrm{OHdG}$ and Oxidative Stress ......................................27

Oxidative Stress and Glycemic Control among Ethnic Groups................28

Ethnicity and Dietary Antioxidant Intake ........................................29

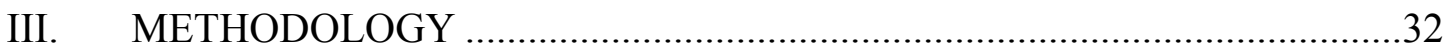

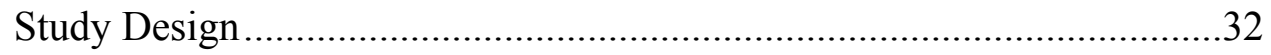

Anthropometric Measurements.................................................... 32

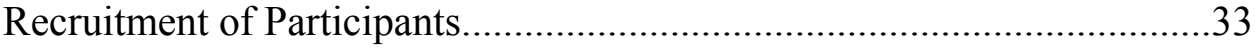

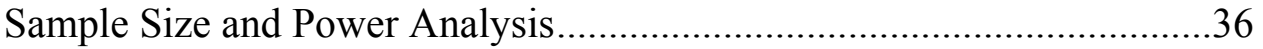

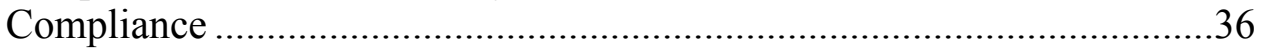

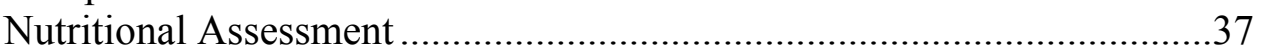

Blood Collection and Biochemical Assessment .....................................37

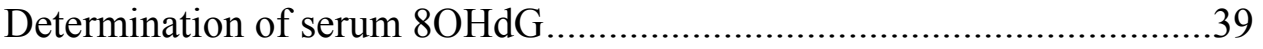

Determination of serum MnSOD .......................................................41

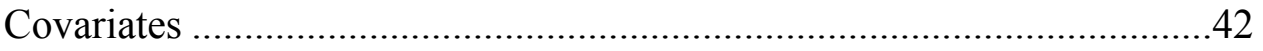

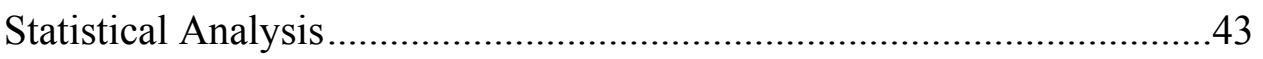

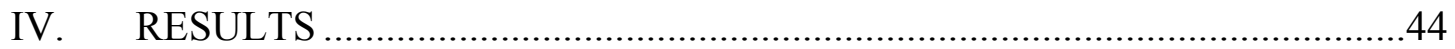

Section 1: General Characteristics of Participants...................................44

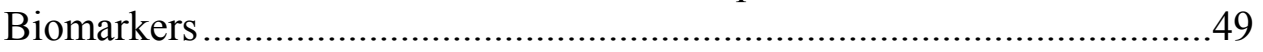

Macro and Micronutrients..................................................................54

Energy Intakes of Participants by Ethnicity and Diabetes Status ..............57

Protein, Carbohydrate, and Fat Intakes............................................57

Vitamin and Mineral Intakes ................................................................57

Section 2: Correlations......................................................................60

Correlation of Oxidative Stress with Socio-demographics......................60

Correlation of Oxidative Stress with Study Variables ..............................60 
Section 3: Hypotheses Testing ..................................................................65

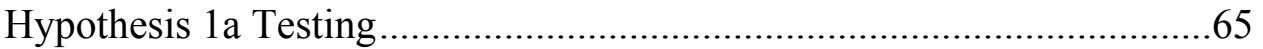

ANCOVA on Manganese Superoxide Dismutase (MnSOD) .....................65

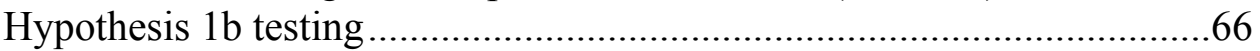

ANCOVA on mtDNA 8-hydroxy-2'-deoxyguanosine (8OHdG)...............66

Hypothesis 1c Testing.........................................................................67

Multiple Linear Regression of MnSOD with 8OHdG ...............................67

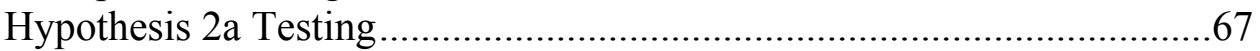

Multiple Linear Regression of 8OHdG on dietary antioxidants.................68

Hypothesis 2b Testing........................................................................69

Multiple Linear Regression of MnSOD on dietary antioxidants ...............69

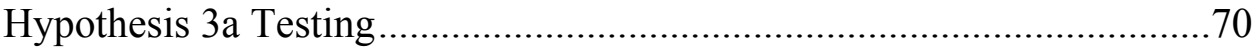

Multiple Linear Regression of Hemoglobin A1C......................................71

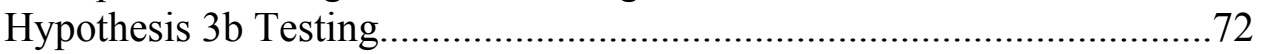

Multiple Linear Regression of FPG .......................................................72

Summary of Hypotheses Testing ...........................................................73

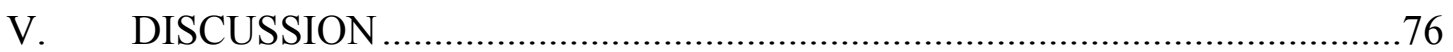

General Characteristics of participants ....................................................76

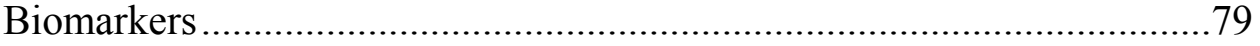

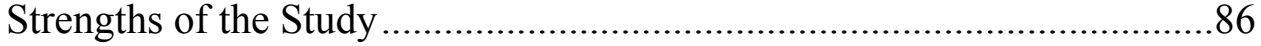

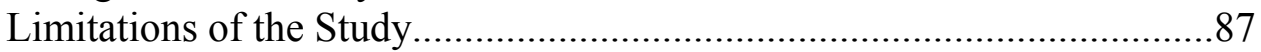

Conclusions and Recommendations .......................................................8

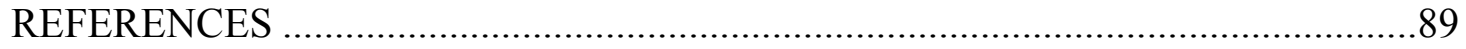

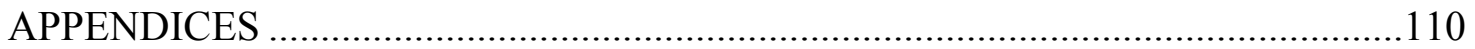

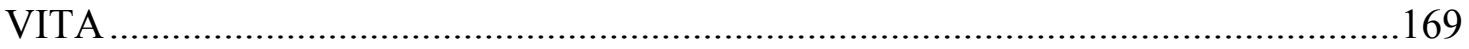




\section{LIST OF TABLES}

TABLE

PAGE

1. General Characteristics of Participants by Ethnicity ..................................45

2. General Characteristics of Participants by Diabetes Status ...........................47

3. General Characteristics of Participants by Ethnicity and Diabetes Status.......48

4. Biomarkers of Glycemic Control and Oxidative Stress of Participants by Ethnicity

5. Biomarkers of Glycemic Control and Oxidative Stress of Participants by

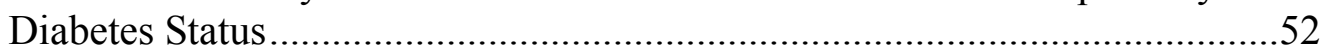

6. Biomarkers of Participants by Ethnicity and Diabetes Status .......................53

7. Macro and Micronutrients Intake of Participants by Ethnicity.......................55

8. Macro and Micronutrients Intake of Participants by Diabetes Status...............56

9. Macro and Micronutrients Intake of Participants by Ethnicity and Diabetes Status.

10. Pearson's Correlations of Oxidative Stress Biomarkers with Study Variables

11. Pearson's Correlations of Oxidative Stress Biomarkers with Study Variables

12. Pearson's Correlations of Glycemic Control with Study Variables in Individuals with T2D

13. Results of Hypothesis Testing .74 


\section{CHAPTER I \\ INTRODUCTION}

The United States Census Bureau (2009) reported that the Haitian American population in the United States (U.S.) is approximately 830,000, two thirds of whom live in Florida and New York. An intensive search of the literature resulted in very little health care information about the population of Haitian descent and it is unclear how their glycemic control, dietary intake of antioxidants, and oxidative stress biomarkers compare with African Americans. African Americans have higher mean A1C (Kirk et al., 2006; Manickham et al., 2013), lower dietary antioxidants plasma biomarkers (Arab et al., 2011), and increased oxidative stress biomarkers and inflammation (Feairheller et al., 2011; Cook et al., 2013) than whites. There are no studies on glycemic control, oxidative stress biomarkers, or dietary antioxidant in Haitians. In addition, there are no studies that compared African Americans with Haitian Americans with and without Type 2 Diabetes (T2D) as investigated by this study.

Diabetes is of epidemic proportions, and T2D accounts for $90 \%-95 \%$ of all diabetes cases (Centers for Disease Control [CDC], 2011; O’Brien, Patrick, \& Caro, 2000). According to the American Diabetes Association (ADA), there are 23.6 million children and adults in the United States who are afflicted with diabetes, with approximately $50 \%$ of whom are not aware that they have the disease. It is estimated that $5-10 \%$ of these patients have Type 1 (T1D), or insulin-dependent diabetes, and that the remaining have T2D, or non-insulin dependent diabetes mellitus (NIDDM; ADA, 2013; Demmer et al., 2013). T2D is the focus of the current research. 
The prevalence of diabetes in the United States is $8.3 \%$, of which $12.6 \%$ of those diagnosed with T2D are of African descent (ADA, 2013; Demmer et al., 2013). In 2007, Rosen et al. investigated the prevalence of T2D in the Haitians. The investigators used fasting glucose to determine the prevalence of $\mathrm{T} 2 \mathrm{D}$ and found that the prevalence of $\mathrm{T} 2 \mathrm{D}$ was 33\% (Rosen et al., 2007) in Haitians in the Miami-Haitian community. A report prepared by The Health Council of South Florida for the Miami-Dade County Health Department (2008) documented that death rates for Blacks were twice that of Whites and Hispanics with T2D. It is clear that health disparity exist between African Americans and Whites. There are gaps in scientific literature regarding health biomarkers in Haitians and it is imperative to investigate the differences observed in the prevalence of T2D in African Americans and Haitians.

Diabetes is clinically diagnosed by the use of a fasting plasma glucose (FPG) test or oral glucose tolerance test (OGTT), and a diagnosis of diabetes is made when the fasting plasma level of glucose is greater than or equal to $126 \mathrm{mg} / \mathrm{dl}$ (ADA, 2013). The symptoms that are associated with diabetes are frequent urination, excessive thirst, extreme hunger, unusual weight loss, increased fatigue, irritability, and blurry vision. Diabetes risks may be categorized as either modifiable or non-modifiable. The modifiable risk factors associated with diabetes are high blood glucose, obesity, hypertension, abnormal lipid metabolism, smoking, physical inactivity, and inflammation (ADA, 2013). The non-modifiable risk factors are age, ethnicity, gender, and family history (Vanuzzo, Pilotto, Mirolo, \& Pirelli, 2008; Giovannucci et al., 2010). 
Oxidative stress plays an important role in the progression of complications associated with diabetes and the severity of the complications may be reduced with dietary antioxidant supplements (Gopaul et al., 2001; Kiss \& Szabo, 2005; Rains \& Jain, 2011; West, 2000; Daien et al., 2013). Montonen, Järvinen, Knekt, and Reunanen (2004) studied dietary antioxidant intakes and the development of T2D and found a negative relationship between T2D symptoms and dietary intake of antioxidants in the form of food or supplements.

High levels of glucose contribute to an increase in reactive oxygen species (ROS) that up-regulate 8-oxoguanosine DNA glycosylase (OGG1) and decrease manganese superoxide dismutase (MnSOD), both of which are indicators of enzymatic antioxidants (Bolajoko et al., 2008; Ruchko et al., 2011). This effectively induces mtDNA damage, whereby there is an increase in the byproduct mtDNA 8-hydroxy-2'-deoxyguanosine (8OHdG; Bolajoko et al., 2008). $80 \mathrm{OHdG}$ is a byproduct of the DNA repair mechanism, which has been used worldwide as a non-invasive method of identifying oxidative DNA damage that can occur both in vivo and in cell cultures (Harri et al., 2007; Patel, Bevan, Mistry, \& Lunec, 2007; De Iuliis et al., 2009). The mitochondrion also produces superoxide via reverse electron transport, and the body will normally up-regulate the antioxidant enzyme MnSOD to neutralize its damaging effects (Ceriello, 2003; Abraham et al., 2013).

Other studies have shown that riboflavin (Cobianchi et al., 2008; Schramm et al., 2013), n-acetylcysteine (Deneke, 2000), and vitamin E (Clarke, Burnett, \& Croft, 2008; Niki, 2013) may all down-regulate the production of reactive oxygen species and assist 
the body's antioxidant defense system. As such, the therapeutic use of antioxidant nutrients as food or supplements can prevent oxidative damage (Jat et al., 2013; Landete, 2013).

The mechanism of DNA damage appears to be directly associated with oxidative stress and impairment of mitochondrial oxidative phosphorylation (Lee \& Pervaiz, 2011; Suzuki et al., 1999). This impairment and defect results in the generation of the byproduct $8 \mathrm{OHdG}$, which has been documented as a sensitive biomarker of oxidative stress, associated with a biochemical damaging effect on mitochondrial DNA (Ishikawa, Fujioka, Ishimura, Takenaka, \& Fujisawa, 2007; Johnston et al., 2010). 8OHdG is the most frequently studied and validated biomarker of oxidative stress damage of the mitochondrial DNA (Cooke, Henderson, \& Evans, 2009). 8OHdG has been shown to be stable in blood circulation and is measureable by the Enzyme-Linked Immunosorbent Assay (ELISA) methodology using serum (Breton, Sichel, Bianchini, \& Prevost, 2003). There is a strong relationship between serum $8 \mathrm{OHdG}$ and creatine, but there is no relationship between serum levels of $80 \mathrm{HdG}$ and urinary $8 \mathrm{OHdG}$ (Soini et al., 2011). It is believed that $8 \mathrm{OHdG}$ excretion from the urine may be dependent on kidney function, which would justify not using urinary $8 \mathrm{OHdG}$ analysis in the T2D population (Soini et al., 2011).

\section{Statement of the Problem and Justification of the Study}

The prevalence of T2D in the general population is well documented, and research shows a disproportionate prevalence in ethnic/minority groups (Kim \& Caprio, 2011; Richard, Alexandre, Lara, \& Akamigbo, 2011), who experience poor outcomes and 
increased rates of complications associated with T2D (Richard et al., 2011). There are no studies, however, that looked at $8 \mathrm{OHdG}$ and MnSOD in African Americans and Haitian Americans, two ethnically different groups that are normally grouped together. This study provides data on the serum levels of $8 \mathrm{OHdG}, \mathrm{MnSOD}$, dietary antioxidant and A1C in African Americans and Haitian Americans. The relationship between these variables was also determined. The literature provides strong evidence of a protective effect of MnSOD on cell apoptosis. Improvement in the deficient level of MnSOD may provide an ameliorative effect on diabetes complications resulting from programmed cell death (Kannan \& Jain, 2000; Kowluru, Atasi, \& Ho, 2006; Kaminski et al., 2012).

This study also investigated the levels of dietary intake of antioxidants in African Americans and Haitian Americans, in addition to establishing a relationship between dietary intake of antioxidant nutrients and the serum levels of MnSOD. Finally, this study provides valuable information for potential intervention studies on therapeutic approaches (Li \& Zhou, 2011) to reduce progressive disorders associated with T2D.

\section{Purpose of the Study}

The purpose of this study was to determine the relationship between oxidative stress biomarkers that included mitochondrial DNA damage and serum MnSOD and to explore the relationship between these parameters of oxidative stress and dietary antioxidant intake. Another purpose was to identify whether there are ethnic differences in these biomarkers in participants with and without T2D. The study provides information on dietary intakes of antioxidant nutrients and their relationship with circulating oxidative stress biomarkers in persons with and without T2D. 


\section{Hypotheses and Specific Aims}

Aim 1: To determine differences in the serum levels of MnSOD and 8OHdG by diabetes status and ethnicity.

Hypothesis 1a: Serum levels of MnSOD will be lower in participants with T2D as compared to those without T2D, independent of ethnicity.

Hypothesis 1b: Serum levels of $80 \mathrm{OHdG}$ will be higher in participants with T2D when compared to those without T2D, independent of ethnicity.

Hypothesis 1c: There will be an inverse relationship between serum levels of MnSOD and $8 \mathrm{OHdG}$ in participants with T2D, independent of ethnicity.

Aim 2: To determine the relationships of serum MnSOD and $80 \mathrm{OHG}$ with various dietary antioxidants by diabetes status and ethnicity..

Hypothesis 2a: Serum $8 \mathrm{OHdG}$ levels will be negatively associated with dietary intake of antioxidants, independent of diabetes status and ethnicity.

Hypothesis 2b: Serum MnSOD levels will be negatively associated with dietary intake of antioxidants, independent of diabetes status and ethnicity.

Aim 3: To examine the relationships of glycemic control (A1C) and fasting plasma glucose levels with various dietary antioxidants in T2D by ethnicity.

Hypothesis 3a: There will be no relationship of A1C with any dietary antioxidants in T2D independent of ethnicity. 
Hypothesis 3b: There will be no relationship of fasting plasma glucose level and any dietary antioxidants in T2D independent of ethnicity. 


\section{CHAPTER II}

\section{LITERATURE REVIEW}

\section{Oxidative Stress and Diabetes}

The literature shows that oxidative stress plays an important role in the progression of complications associated with diabetes and that there is the potential to reduce the complications of diabetes via supplementation with antioxidant therapeutics (Gopaul et al., 2001; Kiss \& Szabo, 2005; Rains \& Jain, 2011; West, 2000; Ren et al., 2013). High levels of glucose contribute to an increase in ROS that up-regulates 8oxoguanine DNA glycosylase (OGG1) and decreases superoxide dismutase (SOD) (Bolajoko et al., 2008). A decrease in serum levels of SOD reduces the efficiency of neutralizing free radicals, which leads to an induction of mtDNA damage. The result of the mtDNA damage is an increase in the byproduct $8 \mathrm{OHdG}$ (Bolajoko et al., 2008; De Iuliis et al., 2013).

In the mitochondria, the reverse electron transport chain produces harmful superoxide radical $\left(\mathrm{O}_{2}{ }^{-}\right)$and other ROS (Wen et al., 2013). The body responds to the production of $\mathrm{O}_{2}{ }^{-}$by up-regulating the antioxidant enzyme SOD in order to neutralize the oxidizing effects from the superoxide (Ceriello, 2003; Di Naso et al., 2011). Antioxidants such as riboflavin, n-acetylcysteine, and vitamin E may down-regulate the production of ROS and assist the body's antioxidant defensive system, which has therapeutic implications (Clarke et al., 2008; Cobianchi et al., 2008; Deneke, 2000; Lee et al., 2013; Landete, 2013). 
Endothelial dysfunction and insulin resistance may result from oxidative stress (Pereira et al., 2008; Petocco et al., 2010). Additionally, there is a positive relationship of insulin resistance with 8-epi-PGF2-alpha, an indicator of oxidative stress, among persons with and without diabetes (Gopaul et al., 2001). Gopaul et al. (2001) also examined individuals with diabetes who had endothelial dysfunction, assessed by a non-invasive digital pulse wave photoplethysmography. The finding suggested an increase in arterial stiffness with the duration of diabetes. There was an increase in 8-epi-PGF2alpha in subjects with diabetes when compared to controls without diabetes. 8-epi-PGF2alpha positively correlated with fasting blood glucose, triglycerides, and insulin resistance. Gopaul et al. (2001) showed that, in T2D, development of endothelial dysfunction and insulin resistance are preceded by oxidative stress.

Oxidative stress is considered a common pathway for such health conditions as neurological degenerative disorders, diabetes, and various cancers. A number of studies have documented the role of oxidative stress in T2D and in MetS in both adults and children (Abate, Vatansev, \& Erkul, 2004; Baines, 1991; Block et al., 2002; Ren et al., 2013). Ren et al. (2013) observed that ROS may contribute to the T2D by damaging the normal function of islet $\beta$ cells via apoptosis of mitochondrial structure. Block et al. (2002) found that increased fruit consumption correlated with decreased lipid peroxidation and that the levels of the oxidative stress biomarker malondialdehyde (MDA) positively correlated with inflammation, as determined by C-reactive protein. They also found that oxidative stress biomarkers were inconsistent among races; i.e., African Americans had higher levels of thiobarbituric acid-reactive substances (TBARS), no difference in levels of MDA, and lower levels of Iso-P levels as compared to 
Caucasians. The level of oxidative stress appears to correlate with the degree of mitochondrial dysfunction in Asian Indians with T2D compared to healthy controls (Khan et al., 2011).

Khan et al. (2011) studied lymphocytes which were harvested by a density gradient centrifugation technique and were then used for DNA studies and immunophenotyping. The researchers used $\mathrm{mtDNA} / \mathrm{nDNA}$ as a biomarker for the pathophysiology of the disease. Oxidative DNA damage and cell death were determined via ELISA. In this way, Khan et al. (2011) examined the role of mitochondrial dysfunction in immune pathophysiology and were able to identify a strong association between lymphocytic nuclear DNA damage and T2D as well as an increase in levels of circulating pro-inflammatory cytokines in subjects with T2D as compared to controls. Khan et al. (2011) hypothesized that the inconsistency of oxidative stress biomarkers between ethnicities may be due to differences within an ethnic group. Researchers normally recruit and classify participants into one group based upon shared distinctive physical appearance with ancestral origin, such as African Americans, Afro-Caribbean, and Africans may be classified as Blacks or African Americans. However these ethnic groups may have large health disparities and different associated risk factors which may influence the serum levels of oxidative stress biomarkers (VanEenwyk, 2010).

Three factors that contribute to oxidative stress are an increase in oxidant generation, such as catechols, semiquinones, and reactive quinones; antioxidant protection degeneration; and oxidative damage repair dysfunction. Free radicals that contribute to oxidative stress status (OSS) include, but are not limited to, catechol, 2,3 
DHBA, lipid peroxides, reduced glutathione, glutathione peroxidase (GSH-Px), and SOD (Nelson et al., 2006). Oxidative stress factors may contribute to mtDNA damage inside the cell. The byproduct of this DNA damage is an endonuclease repair nucleotide called 8OHdG, which is facilitated by an endonuclease repair enzyme (Nelson et al., 2006).

\section{Oxidative Stress and Obesity}

Obesity is the accumulation of excessive fat that have been correlated with increased mortality and health impairment (WHO, 2012). Abdominal fat is a major risk factor for diseases which are related to obesity and BMI, total body fat and waist circumference have been shown to be positively correlated with oxidative stress. It is clear that there is a positive relationship of oxidative stress with obesity, regardless of the etiology of obesity (Savini et al., 2013).

There is evidence of an increased chance of developing health related diseases with increasing obesity and BMI, and these findings are higher among some ethnic groups (Pan et al., 2004; Shai et al., 2006). Since BMI is correlated with oxidative stress levels and Vimalananda et al. (2011) reported that Haitians had lower mean BMI than African Americans, determining the relationship between oxidative stress levels in these two ethnic groups is warranted.

\section{Oxidative Stress and Dietary Antioxidants}

It has been proposed that the root cause and complications of T2D is associated with oxidative stress and that dietary intakes of antioxidants nutrients have been shown to have beneficial effect on the body's natural defense mechanisms by inhibiting ROS (Han 
et al., 2007) and preventing mitochondrial dysfunction. Published studies have shown that accumulated oxidative stress biomarkers and free radicals damages lipid membranes, DNA and influences insulin resistance and $\beta$-cell dysfunction (Morris, et al., 2002; Ceriello et al., 2004; Wright Jr. et al., 2006) and there is growing body of evidence to support the theory that oxidative stress may be reduced by dietary antioxidant intakes (Frei, 2004; Siedlak et al., 2009; Mullner et al., 2013 ).

In the review by Frei, a number of studies have shown that dietary antioxidants such as vitamin $\mathrm{C}, \mathrm{E}, \beta$-carotene provide protection against ROS in various biological systems. He reported that several case-controlled studies have shown an increase in the DNA oxidation marker, $8 \mathrm{OHdG}$, in subjects with certain types of cancers, cigarette smokers, and persons with diabetes and suggested that dietary antioxidants may be a viable therapeutic option. His suggestion was supported by a number of observational studies that reported an inverse relationship between dietary antioxidant intake and oxidative DNA damage.

Another dietary antioxidant that has been well studied and has been shown to be inversely correlated with oxidative stress is vitamin D. It has been reported that vitamin D deficiency have been correlated with an increased risk of cardiovascular disease and have been reported to be associated with obesity (Codoner-Franch et al., 2012; Earthman, et al., 2012; Alemzadeh et al., 2008; Pacifico et al., 2011). Codoner-Franch et al. (2012). The researchers studied the relationship between relationship of vitamin D and oxidative stress biomarkers in Caucasians. Overall, these researchers found a significant relationship of insufficient vitamin D levels and obesity, a risk factor for T2D. 
Similarly, Gradinaru et al. (2012) studied vitamin D status and oxidative stress in T2D and reported an inverse relationship of vitamin D status with oxidative stress biomarkers.

Siedlak et al. (2009) studied the effect of a diet rich in alpha-lipoic acid in a mouse model expressing amyloid- $\beta$ protein precursors. The oxidative stress biomarkers used in this study was heme-oxygenase -1 and 4-hydroxynonenal. The researchers reported a significant decrease in the level of these oxidative stress biomarkers in the animals fed the diet of alpha-lipoic acid compared to wild-type mice which served as controls.

Mullner et al. (2013) studied the effect of vegetables and PUFA-rich plant oils on DNA strand breaks in T2D subjects. Diabetes and non-diabetes participants were assigned to either a intervention or control group. Participants from the intervention group were provided vegetable rich and PUFA-rich oils. Blood samples were collected at baseline, and at 4, 8, and 16 weeks and oxidative stress assessment was conducted to determine DNA damage in mononuclear cells. The study showed that participants with diabetes had statistically significant reduced levels of DNA strand breaks and it appears that the healthy oils provided some protection to the DNA in the participants with diabetes.

Other research provided evidence of an association between diet and oxidative stress and the possible role of dietary antioxidants in the reduction of complications associated with T2D. Additionally, some foods may have powerful antioxidant properties which have been reported to have health benefits such as the Mediterranean diet (Savini et al., 2013). The effect of this diet on health conditions is related to the 
dietary benefits from fruits, vegetables, whole-grains, nuts, fish, moderate wine consumption and olive oil. A study by Ortega-Azorin et al. (2012) provided evidence that dietary patterns were more beneficial than specific foods and that adherence to one such dietary pattern, the Mediterranean diet, provided the health benefits of a high quality diet.

The dietary intake of antioxidant foods or supplements may reduce oxidative stress and, subsequently, lessen mtDNA damage (Weissenberger et al., 2010). Generally it is believed that the identification of dietary factors that play a key role in the protection of the mitochondria and the alleviation of symptoms associated with diabetes is crucial to the development of preventive measures. Due to the variability in ethnic dietary choices and food preparation, it is important to determine whether there are ethnic differences in oxidative stress biomarkers and mtDNA damage. There are few published studies on the relationship of antioxidant nutrient intake and mtDNA damage among different ethnic groups. This study identified the differences in dietary intakes of antioxidants for African Americans and Haitian Americans and also investigated the relationships between the dietary antioxidants and oxidative stress biomarkers.

\section{Oxidative Stress and Biochemical Mechanism}

There is convincing clinical and experimental evidence of the biochemical mechanism of oxidative stress. Experimental evidence establishes that there is a significant reduction in glutathione levels and erythrocyte CuZn-SOD activity in individuals with diabetes, with or without cardiovascular disease (CVD) (Chen, Osio, \& Anderson, 1999; Chatuphonprasert et al., 2013). The underlying mechanism of oxidative 
stress is a reduction of oxygen $\left(\mathrm{O}_{2}\right)$ that can have reversible or irreversible effect on cells, organs, or tissues. This biochemical effect results from intermediate compounds that are produced from the reduction of $\mathrm{O}_{2}$, which produces $\mathrm{O}_{2}{ }^{-}$, hydrogen peroxide, and hydroxyl anions.

There is strong evidence that oxidative stress is increased by several physiological conditions such as hyperglycemia, exposure to environmental pollutants, and the generation of ROS by DNA during its normal biochemical functions (Poljsak \& Fink, 2014). Oxidative Stress may also be generated from different sources in the body such the oxidation of polyunsaturated fatty acid (PUFA; West, 2000; Bae et al., 2011) and calcified regions of stenotic aortic valves and atherosclerotic arteries (Miller et al, 2008).

In the mitochondrial membrane, ROS is generated during the production of nicatinamide adenine dinucleotide phosphate (NADPH) and catalyzed by the enzyme NADPH oxidase (Bae, 2011). There are two biochemical pathways for the production of NADPH. The first pathway is the hexose monophosphate shunt, where the insulininduced enzyme glucose-6-phosphate-dehydrogenase (G-6PD) is required to oxidize glucose-6-phosphate (G-6P) to produce 6-phosphogluconate. The second pathway is driven by another insulin-dependent enzyme, 6-phosphogluconate dehydrogenase (6PGD), to oxidize 6-phosphogluconate, which produces more NADPH. The enzyme isocitrate dehydrogenase (ICD) is critical to the oxidative decarboxylation of isocitrate to alpha-ketoglutarate, utilizing either $\mathrm{NAD}^{+}$or $\mathrm{NADP}^{+}$as cofactors. In a rat model, superoxide dismutase (SOD) inactivates the NADP-dependent isocitrate dehydrogenase (ICD), resulting in a statistically significant reduction in ICD activity (Batini-Haberle \& 
Benov, 2008). Since $\mathrm{NAD}^{+}$and $\mathrm{NADH}^{+}$are both key components of cellular respiration and energy metabolism, then a reduction in ICD activity would profoundly affect apoptosis and increase oxidative stress levels.

Batini-Haberle \& Benov (2008) studied the reduction in ICD activity levels and found that it was due to the neutralizing and reducing effects of SOD on the production of NADPH. NADPH, a reducing agent, is involved in immunological reactions in immune cells and in respiratory burst reactions where there is a production of ROS. A similar mechanism is observed in immune response to the presence of bacteria or fungi in the blood stream (Omori et al., 2008). In persons with diabetes, it is observed that neutrophils which participate in the respiratory burst require priming by NADPH oxidase (Omori et al., 2008). Abnormal insulin production will impair the hexose monophosphate shunt and reduces the rate of NADPH production. This reduction in NADPH influences the oxidative defense systems, e.g., the glutathione peroxidase and catalase enzymatic system (Bono, 1987). This is because NADPH plays a crucial role in the activities of enzymes such as catalase and SOD, which are anti-oxidative defense systems whose function is to reduce ROS. The effect of the impairment is the elevation of the levels of serum ROS, which results in oxidative cell damage (Bono, 1987).

Miller et al. (2008) studied the biochemical mechanism that may contribute to the stenotic aortic valves and atherosclerotic arteries and he found that a major contributor is the activity of uncoupled nitrous oxide species (NOS). In addition, uncoupled nitrous oxide contributes to the production of superoxide and ROS and may assist in the disruption of cell membranes, proteins, lipids, and cellular constituents. The 
mitochondrion is a cellular component that is responsible for a vast majority of ROS production (Bae, 2011).

\section{Diabetes and Manganese Superoxide Dismutase (MnSOD)}

The major defense from free radical damage in the mitochondria is provided by the manganese superoxide dismutase (MnSOD), which is an enzyme unique to the inner mitochondrial space (Curtis et al., 2007). Manganese superoxide dismutase is regarded as the most powerful enzyme in the defense against active oxygen species, producing hydrogen peroxide and oxygen (Curtis et al., 2007). The mitochondria are the source of superoxide, which has been shown to be a major contributor to the progression of diabetes complications in persons with diabetes (Kowluru et al., 2006).

There is evidence that MnSOD may provide protection to diabetic cardiomyopathy in a diabetic mouse model by reducing ROS and improving mitochondrial function (Shen et al., 2006). The researchers identified that ROS participate in diabetes-induced heart muscle apoptosis, and they reported that this pathology was preventable with adequate antioxidants.

Manganese superoxide dismutase (MnSOD) is an enzyme that is encoded by a single-copy gene. Its expression is controlled by the GC-rich promoter region that contains numerous specificity protein 1 (SP-1) and activating protein 2 (AP-2) binding sites (Hitchler, Oberley, \& Domann, 2008). Hitchler et al. (2006) have shown that the MnSOD expression is regulated by epigenetic factors rather than just variations in DNA sequence. This enzymatic regulatory mechanism may provide an explanation of the 
reduction in MnSOD enzyme activity and that its production is influenced by both genetic and environmental factors (Hitchler et al., 2006).

Madsen-Bouterse, Zhong, Mohammad, Ho, and Kowluru (2010) conducted research on retinal endothelial cells and found evidence for the protection of mitochondrial DNA by the nuclear specific enzyme MnSOD. The researchers examined the DNA damage caused by hyperglycemia using a q-PCR method and identified the genes which were expressed using RT-PCR methodology. Madsen-Bouterse et al. (2010) found that there was an increase in mtDNA damage in retinal endothelial cells which were exposed to hyperglycemia and that MnSOD play a significant role in preventing mtDNA damage. A similar protective role of MnSOD on mtDNA damage was reported by Sadi, Eryilmaz, Tutuncuoglu, Cingir, and Guray (2011). In another study (Zhong \& Kowluru, 2011) that used rats, the results indicated that hyperglycemia reduced MnSOD activity, which, in turn, resulted in a $60 \%$ decrease in gene transcription. Overall, there are few studies that examine the relationship between MnSOD and mtDNA damage, and most were conducted using cell cultures or animal models. Because these experimental designs used animals, it is not known whether the results are generalizable to humans.

In an animal study, Kowluru et al. (2006) investigated the effects of diabetes complications in MnSOD-transfected rats. Wister rats were caused to be diabetic with the use of streptozotocin and were maintained as such through the 11-month duration of the study. The control group of transfected rats was fed a diet that was void of the antioxidant lipoic acid, while the experimental group had a diet that was supplemented with lipoic acid. Both groups were fed for 11 months, after which time they were 
sacrificed, and the retina was harvested and serum was collected and stored for analytical studies. The researchers used commercially available ELISA kits to determine MnSOD activity and $8 \mathrm{OHdG}$ levels; they also determined the development of retinopathy by pathological examination of the harvested retina. They observed an increase in the level of MnSOD and the progression of diabetic retinopathy in MnSOD-transfected rats when compared to the non-transfected rats.

In the same study Kowluru et al. (2006) also examined the effect of lipoic acid therapy on the MnSOD activity in the rats with diabetic retinopathy. They found a significant decrease in the enzymatic activity of MnSOD within the mitochondria of diabetic rats compared to rats without diabetes. In addition, there was similar cytosolic SOD activity between diabetic rats and non-diabetic rats. A statistically significant increase in the MnSOD level in the plasma of rats that consumed diets with lipoic acid was also found. They concluded that there was a decrease in oxidative stress in the lipoic acid-supplemented group, as determined by a decrease in $8 \mathrm{OHdG}$ level.

Garcia-Ramirez et al. (2008) have shown that subjects with diabetes, with or without CVD, had significantly reduced SOD activity when compared to a control group. The participants with diabetes were in the late stages of diabetes complications. Mitochondrial DNA was then determined via a real-time peripheral blood mononuclear cells (PBMC). MnSOD activity was determined from homogenized PBMC via an assay that measured inhibition of the reduction of cytochrome $\mathrm{C}$ by moving oxygen. Mitochondrial DNA damage and mitochondrial content were used as indicators of the 
degree of oxidative stress. MnSOD activity was used as a mitochondrial antioxidant defense index.

Mitochondrial DNA damage was significantly greater in the subjects with diabetes than without diabetes. MnSOD activity was significantly increased in the peripheral blood mononuclear cells (PBMC) of persons with T2D, as compared to the controls without diabetes. The researchers concluded that the increased MnSOD activity was due to an adaptive response to oxidative stress. Overall, the results showed that there was a reduction in mtDNA damage due to the degree of mtDNA oxidation (a result of oxidative stress) and that MnSOD was up-regulated as a response to the oxidative DNA damage.

The literature shows that there is an inverse relationship between serum MnSOD levels and T2D complications; i.e., the over production of serum levels of MnSOD levels were observed in subjects with diabetes complications as compared to subjects without diabetes complications. There is accumulating evidence that mitochondrial substrate sensitivity is increased in the skeletal muscle of subjects with T2D when compared to subjects without T2D. A decrease in mitochondrial substrate sensitivity correlates with reduced extracellular MnSOD levels (Larsen et al., 2011). In addition, it appears that mitochondria do not function efficiently in the skeletal muscle of subjects with T2D, and the size of the mitochondria, as measured by electron microscope, is smaller than that seen in a control group (Kelley, He, Menshikova, \& Ritov, 2002). 
There were no recent studies found in the literature that evaluated the relationship between the serum levels of MnSOD and either African American or Haitian American subjects with and without T2D.

\section{Diabetes and 8-hydroxy-2'-deguanosine (8OHdG)}

Diabetes contributes to numerous health complications such as neuropathies, blindness, and macular degeneration. The major mechanisms that cause the complications are the activation of protein kinase $\mathrm{C}(\mathrm{PKC})$, advanced glycation end products (AGE), and an increase in polyol and hexosamine pathway flux (Rolo \& Palmeira, 2006). The progression of diseases which are associated with T2D may be due to mutations in the mtDNA and mtDNA copy reduction. Rolo and Palmeira (2006) have shown an association between the mitochondrial nuclear-encoded glucose transporters, glucose-stimulated insulin secretion, and nuclear-encoded uncoupling proteins.

One of the effects of oxidative stress is the damage to the mitochondria. The damage is associated with an increase in mitochondrial reactive oxygen and the generation of nitrogen species, i.e. Nitrogen oxide. MnSOD plays a key role in the protection of the mtDNA damage from oxidative stress (Li \& Zhou, 2011). Lumini, Magalhaes, Oliveira, and Ascensao (2008) stated that the dysfunction of the mitochondria produces reduced uncoupling proteins (UCPs). UCPs are located in the inner membrane of mitochondria that function as transporters. UCP1 is predominantly found in brown adipose tissue and is involved in respiration, UCP2 is ubiquitous and is highly expressed in the lymphoid system, and UCP3 is solely expressed in skeletal muscle and heart. The UCP2 that is expressed in the pancreas has been linked to hyperinsulinemia (Fleury et al., 
1997). In addition, under-expressed UCP2 is associated with a reduction in glucoseinduced insulin secretion (Saleh, Wheeler, \& Chan, 2002). Lumini et al. (2008) indicated that exercise may reverse the mitochondrial defect, but the mechanism by which this occurs is not clearly understood. This finding was corroborated by Jun et al. (2009) in a study of male and female Koreans between the ages of 20 and 70 years. From the 1,500 subjects, the researchers collected data on dietary intake, physical activity, anthropometrics, and biochemical analysis, including single-nucleotide polymorphism genotype, using fasting blood specimen. Low physical activity was correlated with under-expression of UCP2, BMI, and waist circumference. The polymorphism in the UCP2 gene was related to T2D.

In hyperglycemic subjects, elevated levels of oxidative stress contribute to the progression of diabetes complications. Research has shown an association between diabetes complications and mitochondrial DNA damage (Madsen-Bouterse et al., 2010; Kowluru et al., 2006). The effect of oxidative stress on the mitochondria is evidenced by an increase in the conversion of deoxyguanine (dG) to $8 \mathrm{OHdG}$ in DNA (Suzuki et al., 1999; Xu et al., 2004). Suzuki et al. (1999) investigated mtDNA4977 deletion in muscle DNA and $8 \mathrm{OHdG}$ content in diabetes and found that there was an increase in deltamtDNA4977. The study showed that an increase in mtDNA4977 was proportional to the severity of the diabetes complications. The study also showed that increased $8 \mathrm{OHdG}$ was related to the severity of diabetes complications (Suzuki et al., 1999). The mechanism of DNA damage appears to be directly associated with oxidative stress and defects in the mitochondrial oxidative phosphorylation (Lee \& Pervaiz, 2011; Suzuki et al., 1999). 


\section{Diabetes and Diet}

According to the National Institute of Diabetes and Digestive and Kidney Diseases (NIDDKD), the improvement of the quality of the diet may reduce the risk of T2D by lowering blood glucose and cholesterol levels, lower BMI, and in some cases it is preventable by early detection of insulin resistance and subsequent high quality dietary intervention. In persons with $\mathrm{T} 2 \mathrm{D}$, the risk of $\mathrm{T} 2 \mathrm{D}$ may be reduced by including daily exercise and physical activity, abstaining from smoking and alcohol, and maintaining a healthy weight, and dietary management (Martin-Timon et al., 2014; ADA, 2013; Izandi

et al, 2013). Of these cofactors of T2D, dietary management is probably the most difficult therapeutic intervention for individuals with T2D (Evert at al., 2014).

Several studies have demonstrated that T2D may be prevented with dietary modifications and lifestyle changes (Bazzano, Serdula, \& Liu, 2005; Caro, Ward, \& O’Brien, 2002; O’Brien et al., 2000; Tuomilehto et al., 2011). According to Bazzano et al. (2002), the development of T2D may be influenced by a combination of environmental factors, such as low dietary fiber and high fat intakes, high glycemic index and high glycemic load of the diet, being overweight or obese, and physical inactivity. Tuomeliheto et al. (2011) observed that T2D may be prevented when several lifestyle targets were followed, such as loss of weight, decrease fat intake, increase dietary fiber intake, and increased physical activity. Participants who followed a healthy diet had favorable health outcomes.

A healthy diet is defined as being of high quality when it includes whole grains, healthy fats and proteins, unrefined foods, and fruits and vegetables (Akbaraly et al., 
2011; McCullough et al., 2002; Larsen et al., 2010). Harvard School of Public Health provided evidence that eating more whole grains, fruits, and vegetables will reduce the risk of T2D by 20 percent (ADA, 2014). In this study, the researchers determined the quality of diet with the use of the 110-point Alternate Healthy Eating Index 2010.

The inability to follow a recommended high quality diet may be influenced by ethnic culture, lifestyles, and beliefs (Anderson-Loftin et al., 2005). African Americans (Liburd, 2003) and Haitian Americans may find it challenging to follow a high quality diet because of cultural and ritualized nature of food choices and socio-economic status (Huffman et al, 2013). The adherence to a high quality diet has been shown to influence glycemic control in African American women with T2D (Skelly et al., 2009) and thereby the possible delay of the onset of complications (ADA, 2013).

The effect of diet and environmental factors on the progression of disorders associated with T2D has been well documented (Kallio et al., 2007; Tuomeliheto et al., 2011). In the Kallio et al. (2007) study, participants had a body mass index (BMI) $\left(\mathrm{Kg} / \mathrm{m}^{2}\right)$ of $26-40$, were between the ages of 40 and 70 , and satisfied at least three criteria for a diagnosis of MetS, using National Cholesterol Education Program (NCEP, 2011) guidelines. The researchers examined the effect of a carbohydrate-modified diet on gene expression in abdominal subcutaneous adipose tissue and on glucose and insulin metabolism (Kallio et al., 2007A diet comprised of rye-pasta influenced gene expression by down-regulating genes linked to insulin signaling, which resulted in a $21 \%$ decrease in the cell size of adipocytes (Kallio et al., 2007). A diet that consisted of oat-wheat-potato appears to activate the genes that are associated with inflammation and oxidative stress, 
without any observable change in adipocyte cell size (Kallio et al, 2007). The researchers established that the type of dietary carbohydrate played an important role in modulating gene expression.

\section{Serum Levels of MnSOD and Oxidative Stress}

The literature reports experimental and clinical findings of a link between MnSOD, oxidative stress and impaired mitochondrial function in diabetes. MnSOD is localized in the mitochondria and serves to protect the mtDNA from oxidative stress damages (Li \& Zhou, 2011). The damages to the mtDNA can impair the functions of cells (Garcia-Ramirez et al., 2008) and contribute to progressive disorders associated with diabetes. Although serum level of MnSOD is well documented in subjects with cancers (Lin et al., 2005; Nishida et al., 1993; Schadendor et al., 1995) and cardiovascular disease (Shen et al., 2006; Miriyala et al., 2011), the data for T2D is sparse and the clinical significance of serum MnSOD is yet to be determined. The data on serum MnSOD levels in T2D would provide information that may be used to guide and monitor dietary antioxidant intakes as a means to reduce oxidative stress (GarciaRamirez et al., 2008).

The enzyme MnSOD reduces oxidative stressors; however, it is well documented that the plasma levels of SOD in patients with T2D diabetes is markedly reduced (GarciaRamirez et al., 2008). Abnormally low levels of SOD may contribute to mtDNA damage (Garcia-Ramirez et al., 2008). A possible therapeutic approach to reduce or slow the mtDNA damage caused by oxidative stress is to improve the plasma levels of MnSOD, which can be accomplished through the use of hormones such as HCG or melatonin 
(Kozirog et al., 2010) as well as through antioxidant micronutrients such as copper, selenium, and manganese (Otsu, Ikeda, \& Fujii, 2004).

Kozirog et al. (2010) treated diabetes subjects with $5 \mathrm{mg}$ of melatonin. The subjects were instructed to take one capsule of melatonin before bedtime for a period of 60 days. Blood pressure (BP) and a fasting blood specimen were taken to establish baseline data, including serum lipid profiles and oxidative stress biochemical markers such as TBARS, SOD, and glutathione peroxidase (GSH-Px). After a 2-month intervention period, BP and blood sample were taken for the determination of the effect of the melatonin intervention. The researchers observed a significant improvement in blood pressure, lipid profiles, and glutathione.

The effect of mineral supplements on SOD enzymatic activity levels has shown positive influences, including the improvement of catalase enzymatic activity, another antioxidant enzyme (Kozirog et al., 2010; Beauchamp \& Fridovich, 1971). HepG2 cell lines are hepatocellular carcinoma-derived cells that are conventionally used to conduct in-vitro studies of the mechanism that occurs in liver cells. The researchers studied the effect of supplements, which were either replenished or depleted, of a mineral of interest. Supplements with or without $\mathrm{Cu}$ and $\mathrm{Zn}$, which were used to feed the cell lines, and SOD activity was determined (Beauchamp \& Fridovich, 1971; Otsu et al., 2004). Mineral depletion appeared to down-regulate both $\mathrm{Cu} / \mathrm{ZnSOD}$ and MnSOD to $70 \%-80 \%$ of baseline activity level. $\mathrm{Zn}$ was shown to be more critical than $\mathrm{Cu}$ in the up-regulation of MnSOD, which may be due to Zn's involvement in MnSOD induction (Otsu et al., 2004). 
Further research is needed to evaluate effect of antioxidants supplementation on plasma levels of MnSOD and on mtDNA damage.

\section{Serum Levels of 8OHdG and Oxidative Stress}

Oxidative stress has been implicated in a number of diseases, including cancers and Type 2 Diabetes. It is clear that $8 \mathrm{OHdG}$ is an oxidative stress biomarker found to be elevated in patients with diabetes and may contribute to diabetes complications (Pan et al., 2008; Al-Aubaidy et al., 2011). Clinical studies show that serum $8 \mathrm{OHdG}$ is measurable by ELISA method and proven to be a reliable biomarker for oxidative DNA damage (Basavarai, et al., 2013; Pagano, et al., 2014).

The acceptable specimen for the determination of $8 \mathrm{OHdG}$ levels are serum, cell lysate, peripheral blood mononuclear cells, and urine (Chen et al., 2008). Urine samples for $8 \mathrm{OHdG}$ testing require 24-hour urine collection, and it is demanding on the subject involved in the collection process (Khadem-Ansari et al., 2011). The predominant biomarker that is used to assess the degree of mtDNA damage is $8 \mathrm{OHdG}$ and the accumulation of $8 \mathrm{OHdG}$ in serum has been reported in patients with T2D (Jamil et al., 2014). Recently, a number of 8 OHdG ELISA test kits have been validated for serum specimens and the test kits have documented performance characteristics such as sensitivity, specificity, and inter- and intra-assay reproducibility. Akihiko, Odamaki, and Hishida (2003) have shown that the serum level of 8OHdG, using ELISA test kits, was significantly higher in subjects with diabetes, as compared to subjects without diabetes. 


\section{Oxidative Stress and Glycemic Control among Ethnic Groups}

Emerging literature shows that all Blacks should not be grouped together and identified as African Americans (Huffman et al., 2011; Huffman et al., 2013).

Feairheller, Diaz, Sturgeon, Williamson, and Brown (2011) examined total antioxidant capacity (TAC), protein carbonyls (PC), and TBARS among African Americans and Caucasians. They found that, even though there were no statistical differences between African Americans and Caucasians for age, BMI, or blood pressure (diastolic and systolic), there were statistically significantly higher levels of oxidative stress in African Americans. To examine the effect of geographical influences on oxidative stress, Deeq et al. (2008) conducted a cross-sectional study that included African Americans from Indianapolis, Indiana, and Yoruba from Nigeria. The researchers used 8-Isoprostane as the biomarker for oxidative stress. They found evidence of higher oxidative stress levels in Nigerians, which may be dietary and environmentally influenced.

Research has shown that diabetes, high blood pressure, and other cardiovascular disease (CVD) risk factors affect African Americans more than they do Caucasians (CDC, 2011; Liutkeviciene, Lesauskaite, Asmoniene, Zaliuniene, \& Jasinskas, 2010). One of the most important independent risk factors for the progression of complications associated with diabetes is hemoglobin A1C (O'Connor et al., 2011). Morbidity and mortality are highest in African Americans with peripheral artery disease (PAD). A meta-analysis (Kirk et al., 2013), examined glycemic control as measured by A1C and found that African Americans values were more elevated than non-Hispanic whites with diabetes. The authors reported that the observed disproportionate A1C levels between African Americans and non-Hispanic whites may be due to access to medical care, less 
optimal diabetes care, and medication affordability (Karter et al, 2002; Rhee et al., 2005; Kirk et al., 2005; Ofili, 2001). This may be related to the lack of agreement of the correlation between A1C and average glucose in certain subjects (Standards of medical care in diabetes, 2014). Glycation rates may be race dependent, consequently A1C levels may have ethnicity variability (Ziemer et al., 2010; Kumar et al, 2010). Glycation involves oxidative reactions that may adversely affect DNA function (Pun \& Murphy, 2012). Since glycation rates could be dependent on ethnicity, then oxidative stress levels could cause a higher rate of DNA damage in subjects with T2D. There is evidence of a strong inverse correlation between DNA damage, oxidative stress, and apoptosis with levels of A1C (Khan et al., 2011), providing a measure of the average blood glucose level over 2-3 month period. Subjects whose diabetes status is out-of-control are more likely to developed diabetes complications. It is well documented that glycemic control influences the extent of oxidative stress (Marling, Shubrook, Vernier, Wiley, \& Schwartz, 2011; Nahkjavani et al., 2010) and that A1C is a reliable biomarker and indicator of glycemic control.

\section{Ethnicity and Dietary Antioxidant Intake}

The literature on dietary antioxidants intake is varied and not conclusive. Suksomboon, Poolsup, and Sinprasert (2011) reviewed nine randomized clinical trials on vitamin E supplementation and glycemic control in subjects with T2D but found no significant changes in $\mathrm{A} 1 \mathrm{C}$ levels as a result of supplementation with vitamin $\mathrm{E}$. In a study by Camargo et al. (2006), subjects with T2D were administered pharmacological dose of vitamin E supplements over a 4 month period and it was observed that it did not impact A1C. Alternatively, in a review by Unnikrishnan et al. (2012), it was reported 
that high doses of Vitamin $\mathrm{C}$ and $\mathrm{E}$ have lowering effect on A1C. In their review, they reported that the mechanism for the lowering effect of $\mathrm{A} 1 \mathrm{C}$ is related to the reduction in the rate of hemoglobin glycation. Arab et al. (2011) compared dietary antioxidant intake between African Americans and Caucasians. They found that healthy African Americans were more likely to be overweight and that being overweight contributed to inflammation and oxidative stress status. In addition, they found that $32 \%$ of African Americans, as compared to $45.2 \%$ of Caucasians, took dietary supplements. Overall, they found a significant correlation between dietary antioxidant intake and plasma concentrations of carotenoids as determined by high-performance liquid chromatography (HPLC). African Americans had a significantly lower intake of antioxidants. The researchers believed that the difference may have been due to food preparation, dietary sources, genetic variants, or BMI (Arab et al., 2011). Huffman, Serge, and Himburg (2011) found intra-racial differences in caloric intake and BMI in African Americans and Haitian Americans.

Manganese (Mn) is an important antioxidant that scavenges free radicals and is secondary to biochemical functions, behaving as a backup free radical scavenger that is similar to MnSOD, especially in regard to oxidative stress (Reddi \& Culotta, 2011). Although there is a lack of data on the mechanism by which Mn participates in the cellular adaptation to oxidative stress (Reddi \& Culotta, 2011), research has shown that the antioxidant activity is regulated by nutrient-sensing pathways.

The data from published works shows that diabetes status influences manganese physiological status by various etiological factors such as viral infection, autoimmunity, genetics, and obesity (Walter et al., 1991). The mechanism which may influence the 
manganese status in diabetes may be related to dysfunction in mineral metabolism (Walter et al., 1991). It is well documented that Mn, an essential component of the enzyme MnSOD (Greger, 1998). Hope et al. (2006) reported that dietary Mn intakes were lower in non-tea drinkers compared with tea drinkers and that tea is a major source of dietary Mn. In their study, the levels of MnSOD were determined via RT-PCR from blood collected from volunteers who were assigned to either a tea-drinker and non-tea drinker group. This study showed that dietary Mn intake can improve the Mn status in the body and that there was an inverse relationship of Mn plasma levels and MnSOD of leucocytes.

The literature indicates an overwhelming evidence of the negative influence of oxidative stress and MnSOD in inflammation and cancer (Fu et al., 2011; Li et al., 2011; Suzuki et al., 2001). Because Mn and iron (Fe) play an important role in the biosynthesis of MnSOD (Hassan \& Schrum, 1994), data on the dietary intake of Mn may provide valuable information on possible biochemical requirements for the production and upregulation of MnSOD. There is some evidence that vitamins and minerals play an important role in slowing the progression of disease associated with T2D (Martini et al., 2010) and reducing oxidative stress levels. 


\section{CHAPTER III}

\section{METHODOLOGY}

\section{Study Design}

This study used a cross-sectional design to explore the relationship between two biomarkers that are closely linked to oxidative stress and the biomarkers' relationship to diet and disease state. The data and specimens that were used for this study were collected previously (Huffman et al., 2007). This study was conducted with Haitian Americans and African Americans with and without T2D. The investigator of this study fully participated in data collection. After the participants signed an informed consent form, they were assigned a unique identifier, and blood was collected and processed immediately and stored for analysis at a later time by this investigator. The unique identifier was the only link between the participants' demographic information and laboratory assessment. The participants' personal information, as linked with the unique identifier, was kept in a locked cabinet. This study was approved by the Institutional Review Board at Florida International University's Office of Research Integrity under IRB exemption number 073112-01 (Appendix E).

\section{Anthropometric Measurements}

Participants had their height, weight, and waist circumference recorded by a trained research assistant. Measurements for height and weight were obtained by using a SECA balance scale (Seca Corp., MD, US). Waist circumference was measured horizontally with a measuring tape. The participants completed a standardized sociodemographic dietary assessment questionnaire (FFQ) and a medical questionnaire that included medical history, prescribed medications, and the use of supplements. The 
control group participants (without T2D) underwent the same procedures as did the participants with T2D. This was a cross-sectional study that used data from male and female participants, aged 35 years or older, with and without T2D. Ethnicity (Haitian American and African American) and diabetes status (T2D or no diabetes) were selfreported but verified by blood test.

\section{Recruitment of Participants}

Participants were initially recruited by randomly generated mailing lists purchased from Knowledge Base Marketing, Inc., Richardson, TX, U.S. This company provided two mailing lists generated from multiple databases of African Americans, identified as having or not having T2D, from Miami-Dade and Broward Counties, Florida, U.S. Approximately 7,550 letters were mailed to African American participants with and without T2D. Approximately, 6.3\% $(n=477)$ of the letters were returned due to an invalid addresses. From the remaining delivered letters, $4 \%(n=256)$ responded (Figure 1). 
Figure 1 - Recruitment of African American Participants

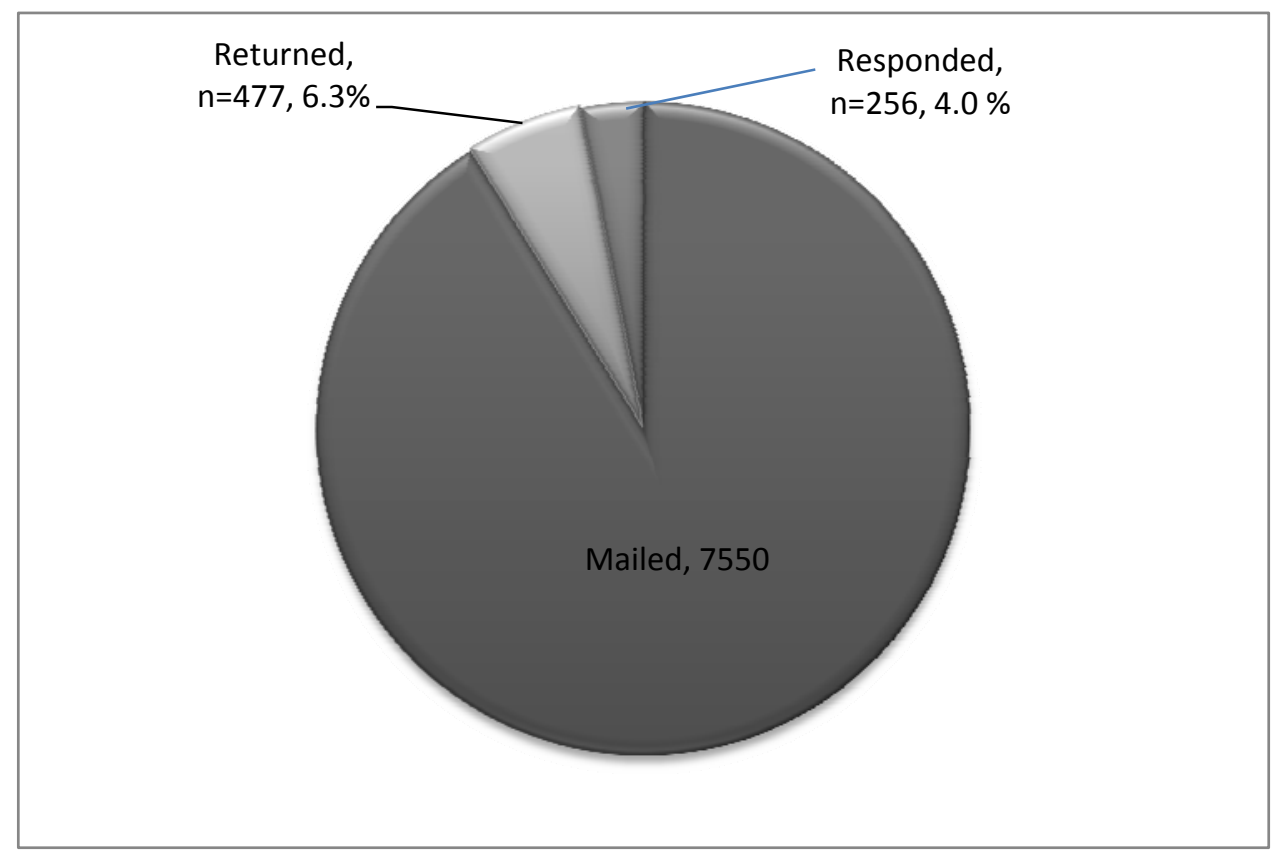

1. Local diabetes educators and community health practitioners in Miami-Dade and Broward Counties. Several local diabetes educators who were either former students or who were in close contact with the Department of Dietetics and Nutrition at Florida International University (FIU) were identified. Letters of invitation, which described the study, were mailed to the diabetes educators and health professionals in Miami-Dade and Broward counties and requested their cooperation in recruiting individuals.

2. FIU faculty, staff, and students. Invitational flyers were distributed to all university faculty, staff, and students who used the university-wide e-mail system; these flyers contained an explanation of the research protocol and requested their assistance in the study. 
3. Several residential and rental facilities were used to conduct interviews and complete questionnaires.

4. Advertisements. Print advertisements were placed in local Haitian newspapers and the principal gathering places of these groups, such as churches, supermarkets, and restaurants. Radio advertisements on local Creole stations also were aired.

When the target recruitment goal was reached for all ethnic groups, efforts to recruit participants were discontinued. Interested participants were initially interviewed on the phone, at which time the study's purpose was explained and the age, gender and ethnicity of the responders were determined. To ascertain T2D status, each participant who self-reported as having diabetes was asked for the age of diagnosis and initial treatment modalities. Participants who did not qualify for the study $(\mathrm{N}=28)$ consisted of those who were younger than 35 years old $(\mathrm{N}=12)$, another ethnicity $(\mathrm{N}=5)$, or who had other chronic diseases or illnesses $(\mathrm{N}=11)$. If a potential participant was determined to be eligible, then his or her participation was requested at the Human Nutrition Laboratory at FIU. Participants were instructed to refrain from smoking, consuming any food or beverages except water, and engaging in any unusual exercise for at least eight hours prior to their blood collection.

The study was approved by the Institutional Review Board at FIU. The purpose and the protocol of the study were explained to the participants, and their written consent, in either English or Creole, was obtained prior to the commencement of the study. Laboratory results showed that 12 participants (Haitian American $=8$, African American 
$=4$ ) who reported as not having diabetes were reclassified as having T2D, according to American Diabetes Association standards. These participants were given their laboratory results, referred to their physician. A total of 443 (234 Haitian American, 209 African American) participants were included in the final data analysis.

\section{Sample Size and Power Analysis}

In this study, multiple linear regressions were the primary statistical analysis method used. It was necessary to determine the sample size for an independent variable (e.g., total antioxidants) added to the equation explaining an additional $1.6 \%$ of the variability of the dependent variable (e.g., serum MnSOD levels) after controlling for eight covariates. Using a sample size calculator for multiple regression (GPower3, 2010, Faul et al, 2009) with eight covariates and a partial $\mathrm{R}^{2}$ of 0.18 for the added predictor, $80 \%$ power, and a $5 \%$ significance level, a sample size of 431 participants was necessary. The main study had enrolled 515 participants, and had complete data on 443 participants. This study was sufficiently powered for the statistical analysis.

\section{Compliance}

A fasting specimen is an important requirement to the assessment of the biomarkers that were evaluated in this study. To ascertain that the subjects were compliant with at least an 8-hour fast, they were asked to fill out a questionnaire that included an item regarding fasting, and the researcher asked the participant about his or her fasting compliance. In addition to a fasting glucose analysis (to verify fasting), the researcher determined the level of glycosylated hemoglobin A1C. Hemoglobin A1C was 
used for analysis of diabetes self-management and to help determine the presence of T2D.

\section{Nutritional Assessment}

Dietary intake of calories and nutrients were measured using the semi-quantitative food frequency questionnaire (FFQ; 97GP 2006 version copyrighted at Harvard University, Boston, MA, U.S.), which has been extensively validated and standardized in several multiethnic population-based studies (Willet et al., 1985). On the FFQ, participants self-report average consumption of specified amounts of various foods over the past year, with response categories that ranged from "never" to "six or more servings per day." In addition to food items, the FFQ included questions about type and duration of vitamin/mineral supplement use and specific details about fat, salt, and sugar used in cooking and as condiments. Each of the completed FFQs was reviewed for incomplete answers or blank responses before the interview was completed. Researchers completed the incomplete items by probing of the subjects before they left.

Daily servings for food groups were calculated by summing the frequency factors for all related food items. Macro- and micro-nutrient intakes were calculated by multiplying frequency of consumption by the nutrient value of the food item, as obtained from the Harvard University Food Composition Database (Willet et al., 1985). The calculated consumption of dietary antioxidants was used to determine the relationship between MnSOD and 8OHdG and antioxidants intakes.

\section{Blood Collection and Biochemical Assessment}

Participants were asked to fast for at least 8 hours before blood was collected by a certified phlebotomist. Blood was collected by venipuncture into serum separator tube 
(SST) and ethylenediaminetetraacetic acid (EDTA) tubes. Fasting Plasma Glucose levels and $\mathrm{A} 1 \mathrm{C}$ were measured from the blood which was collected in the EDTA tube by Laboratory Corporation of America, Miami, FL (LabCorp $\left.{ }^{\circledR}\right)$. Twenty milliliters of fasting venous blood was collected in serum separation tubes, centrifuged, and processed, and aliquots were stored in a $-70^{\circ}$ Celsius freezer by the researcher of this study. Biochemical studies were performed to determine total cholesterol, triglycerides, lowdensity lipoprotein, and high-density lipoprotein via a methodology from Cobas Mira, Roche Diagnostics (Bowling \& Katayev, 2010). Glucose levels were measured using the hexokinase enzymatic method, and a monoclonal antibody method (Bayer Corporation, Diagnostic Division, Tarrytown, NY, USA) was used to determine glycated hemoglobin (A1C). Participants were provided with a copy of their biochemical assessment, including a cardiovascular risk analysis which was calculated from the lipid profile.

Serum levels of MnSOD and 8OHdG were determined. ELISA was used as the method of detection of these biomarkers. Presently, there are numerous ELISA kits available that can detect the levels of $8 \mathrm{OHdG}$ in serum. There has been good correlation between plasma levels of $8 \mathrm{OHdG}$ and tissue $8 \mathrm{OHdG}$ by this method (Park et al., 2001). These correlations support the use of plasma levels of $8 \mathrm{OHdG}$ to predict the degree of mtDNA damage.

The gold standard for the identification of $8 \mathrm{OHdG}$ in tissue, blood, and urine is high-performance liquid chromatography tandem mass spectrometry (HPLC-ms), which is as effective as the more readily available high-performance liquid chromatographyelectrochemical (HPLC-EC) detection methodology (Harri et al., 2007). These methods require expensive equipment, analytical software, and highly skilled operators. The 
availability of monoclonal antibodies to $8 \mathrm{OHdG}$, however, provided a framework for the development of a method of detection (ELISA) that is cheaper, requires less costly equipment and reagents, and does not require highly trained experts to perform and analyze specimens. The ELISA kit platform is reliable, reproducible, and validated for the detection of $8 \mathrm{OHdG}$ in urine, cell lysates, and serum. In several studies, ELISA has been shown to be as effective as HPLC (Breton et al., 2003; Yoshida et al., 2003). Several manufacturers have developed highly sensitive 8 OHdG ELISA kits that require a pretreatment of serum before performing the analysis.

In this study serum MnSOD was detected via the ELISA method. The literature search for the rational in determining MnSOD in serum in T2D is missing, however the evidence is convincing that serum levels of MnSOD is a useful tool and potential clinical biomarker to predict disease associated with viruses (Tamai et al., 2011), and cancers (Schadendor et al., 1995; Nishida et al., 1993). The reagents were available on the open market and they were purchased from Cayman Chemicals (Ann Arbor, MI). The assay also requires a plate reader with a $450-\mathrm{nm}$ reading capacity. All supplies and equipment were available to the investigator in the Human Nutrition Laboratory at FIU.

\section{Determination of serum $80 \mathrm{HdG}$}

Several studies report an association of serum $8 \mathrm{OHdG}$ levels in subjects afflicted with different chronic diseases. The literature provides evidence that elevated levels of serum $8 \mathrm{OHdG}$ is associated with poor prognosis in patients with ovarian cancer (Pylvas et al., 2011), T2D, kidney disease (Kato et al., 2003), and also with obesity (Al-Aubaidy \& Jelinek, 2011). The source of the circulating $8 \mathrm{OHdG}$ was not determined in neither of 
these studies nor our study. Kikuchi et al. (2002) reported that elevated level of 8OHdG was observed in serum but not in cerebrospinal fluid in patients with Parkinson's disease, which suggest that $8 \mathrm{OHdG}$ may have originated from peripheral tissues.

The reagents used in the measurement of serum $8 \mathrm{OHdG}$ were manufactured by Cayman Chemicals (Ann Arbor, MI; Catalog\#589320) and the analytical procedure was followed precisely according to the manufacturer's instructions. The micro titer plate found in this kit utilized an anti-mouse IgG antibody and an $8 \mathrm{OHdG}$ enzyme conjugate. The kits contained all reagents necessary to perform analysis except for a micro titer plate reader which was available in the Human Nutrition Laboratory at FIU.

The principle of this assay is based on the competition between oxidative damaged guanine species and an 8OHdG-acetylcholinesterase conjugate (tracer). Aliquots of standards, controls and specimen were pipetted according to micro titer plate layout and then the tracer was added. The micro titer plate was incubated for 18 hours at 4 degrees $\mathrm{C}$, after which they were rinsed with a wash buffer and then an Ellman's Reagent was added. The plates were incubated for 120 minutes at room temperature and then the absorbance was measured by a micro titer plate spectrophotometer. The estimate of the oxidative DNA damage was determined by comparing the absorbance of an unknown specimen to the standard curve determined by the assay. In this study, the intra- assay and inter-Assay $\mathrm{CV}$ for the $8 \mathrm{OHdG}$ assay was calculated to be $6.2 \%$ and $4.5 \%$, respectively, which is an acceptable range of variation. 


\section{Determination of serum MnSOD}

The scientific literature contains very few studies on the relationship of serum MnSOD and health related conditions in humans, however we found numerous reports on the association of MnSOD with diseases in animal models. In human models, Lin et al. (2005) studied the role of serum MnSOD in patients with gastric cancer and found a weak, but not significant, association. Tamai et al., 2011) studied the role of serum MnSOD and hepatocellular carcinoma (HCC) and reported a significantly higher level of MnSOD in subject with HCC compared with subjects without HCC. Additionally, they reported that their findings were clinically significant in that serum MnSOD may be used to predict prognosis in HCC. There were no recent studies publications that dealt with serum MnSOD with MnSOD in tissue. We found one study where Koshida et al. (1996) reported positive relationship with testicular tumors with serum MnSOD but not with tissue MnSOD. The source of circulating MnSOD is not clear (Schandendorf et al., 1995) and the limited reports suggest that serum MnSOD is a sensitive biomarker for malignant tumors (Koshida et al., 1996; Ishikawa et al., 1990).

The reagent kits used in this study were manufactured by Young In Frontier Co., Ltd (Seoul, Korea; Catalog\# LF-EK0104) and the analytical procedure was followed according to the instructions found in the manufacturer's package insert. The contents of the reagent kit included all reagents necessary for the analysis, which included a micro titer plate that had been pre-coated with a monoclonal antibody specific to human MnSOD. Prior to the analyses, the samples were thawed and brought to room temperature. Aliquot of the sample, standards, and controls were pipetted into the precoated micro titer plate and was then incubated at room temperature with constant 
agitation for 2 hours. The wells were then washed. A working antibody solution was added and then allowed to incubate for 1 hour at room temperature. After incubation, the wells were washed again and a working AV-HRP solution (conjugate) was added to each well. Wells were allowed to incubate for an additional 30 minutes at room temperature. The plate was washed and a substrate solution was added to each well and incubated for 10 minutes. A stop solution was added at the end of incubation period. The micro plate was then read on a $450 \mathrm{~nm}$ using a micro plate reader. In this study, the intra- assay and inter-Assay CV for the MnSOD assay was calculated to be 5.5\% and 3.1\%, respectively.

\section{Covariates}

The covariates in this study were age, gender, smoking status, education, BMI, energy intakes, ethnicity, and diabetes status. These variables were shown to be strongly associated with oxidative stress and ROS (Zhu et al., 2012; Whaley-Connell et al., 2012; Pryor, 1997; Moller et al., 1996). Oxidative stress and reactive oxygen species levels progressively increase with aging (Andriollo-Sanchez et al., 2005; Junqueira et al., 2004; Harman, 1956) and may be related to a decline in the body's primary antioxidant defense system. There is evidence of gender-related differences in oxidative stress levels and the literature report lower levels of oxidative stress in female genders than males, suggesting that the female gender have a reduced susceptibility for DNA damage than males (Hakim et al., 1012; Vina et al., 2011). Additionally, Hakim et al. reported greater levels of oxidative stress biomarkers in subjects who smoke compared to non-smokers. Oxidative stress increases with BMI and age in African Americans (Wonisch et al., 2012; Warolin et al., 2014) and oxidative stress levels have been found to be higher in African 
Americans than in Whites. (Morris et al. (2012). Oxidative stress has been proposed as the root cause in T2D and excessive levels of ROS have been in subjects with T2D (Phillips et al., 2004; Wright et al., 2006).

\section{Statistical Analysis}

Data were analyzed using SPSS, Version 20.0 (SPSS Inc., Chicago, IL, U.S.). Descriptive statistics were used, and the results were expressed either as means \pm standard deviations, or frequencies and percentages. The significance level was set as $p<$ .05 for all tests. The relationships between the variables were analyzed using analysis of covariance (ANCOVA), Pearson's correlations, or multiple linear regression. Since MnSOD was not normally distributed, the natural logarithm of MnSOD was used in all analyses. The ANCOVA was used to compare the levels of $8 \mathrm{OHdG}$ and MnSOD between ethnic groups. Pearson's correlations and multiple linear regressions were used to determine the associations between dietary antioxidant intake and MnSOD and $8 \mathrm{OHdG}$ by ethnicity and as well as their interaction. Full models included all potentially significant demographics (age, gender, smoking status, energy intake, and education) and the physical covariate (BMI). Final models included age, gender, and all covariates which had $p$-values $\leq .20$ for the Pearson correlations with the dependent variables and diabetes status. Multiple linear regression analysis was used to compare the continuous dependent variables, i.e., enzymes and mtDNA damage byproduct, with diabetes status and ethnicity. 


\section{CHAPTER IV}

\section{RESULTS}

This chapter is organized according to the research questions and into sections according to the aims of the study. The first section includes the general characteristics of the study participants by ethnicity and diabetes status. First, socio-demographics are presented and then oxidative stress markers, and finally glycemic control biomarkers. The second section contains correlations among socio-demographics and biomarkers. The tests of the hypotheses are presented in the last section.

\section{Section 1: General Characteristics of Participants}

This cross-section study compared African Americans and Haitian Americans by their ethnicity and diabetes status. There were complete data for 443 participants: 233 with T2D and 210 free of diabetes; 209 African Americans and 235 Haitian Americans.

Table 1 presents the socio-demographics by ethnicity. African American were significantly younger $(M=53.3$ vs. $M=55.6 ; p<.018)$, had a higher BMI $\left(\mathrm{kg} / \mathrm{m}^{2}\right)(M=$ 32.8 vs. $M=29.3 ; p<.001)$, higher percentage of smokers ( $34 \%$ vs. $6.4 \% ; p<.001)$, a higher calculated energy intake (kcal/day) $(M d=1925$ vs. $M d=1650 ; p<.001)$ and were more educated (more than high school, $57 \%$ vs. $33 \% ; p<.001$ ) as compared to Haitian Americans. 
Table 1

General Characteristics of Participants by Ethnicity

\begin{tabular}{lccc}
\hline & \multicolumn{2}{c}{ Ethnicity } & \\
\cline { 2 - 3 } Variables & African & Haitian & \\
& Americans & Americans & P-value \\
& $(\boldsymbol{n}=\mathbf{2 0 9})$ & $(\boldsymbol{n}=\mathbf{2 3 4 )}$ & \\
\hline Age (years) & $53.3 \pm 9.5$ & $55.6 \pm 10.7$ & .018 \\
Gender (male) \% & 50.2 & 47.0 & .497 \\
BMI (kg/m $\left.{ }^{2}\right)$ & $32.8 \pm 7.1$ & $29.3 \pm 4.8$ & $<.001$ \\
Smoke (yes) \% & 34.4 & 6.4 & $<.001$ \\
Energy Intake (kcal/day) & $1925(1400)$ & $1650(1109)$ & $<.001$ \\
Education (\%) & & & \\
$<$ Grade 8 & 1.9 & 31.6 & \\
$\quad$ Some high school & 13.4 & 14.5 & \\
High school grad/GED & 28.2 & 20.5 & \\
Some college/technical school & 38.3 & 17.1 & \\
College graduate (bachelor's degree) & 11.0 & 12.0 & \\
Graduate degree & 7.2 & 4.3 & \\
\hline
\end{tabular}

Data are median (interquartile range) or means \pm SD unless otherwise indicated. $\mathrm{BMI}=$ body mass index. 
Table 2 shows the comparison of the participants by diabetes status. Participants with T2D were significantly older than participants without diabetes $(M=56.3$ vs. $M=$ 52.7; $p<.001)$ and had higher BMI $\left(\mathrm{kg} / \mathrm{m}^{2}\right)(M=32.1$ vs. $M=29.7 ; p<.001)$.

Participants with T2D did not have lower calculated energy intake (kcal/day) ( $M d=1681$ vs. $M d=1834 ; p=.052)$ than those without T2D, although the difference approached significance. There were no differences in gender, percentage of smokers, or educational status for participants with and without T2D.

The participants were also compared by both ethnicity and diabetes status using two-way ANOVA or non-parametric ANOVA (Table 3). African Americans with T2D had significantly higher BMI $\left(\mathrm{kg} / \mathrm{m}^{2}\right)(M=34.7)$ than African Americans without T2D $(M=30.6)$ and Haitian Americans with and without T2D ( $M \mathrm{~s}=29.6,29.0$, respectively). There were no significant differences for BMI in Haitian Americans with T2D compared to without T2D. Haitian Americans with T2D had significantly lower energy intake (kcal/day) $(M=1430)$ than Haitian Americans without T2D $(M=1719)$, and both had significantly lower intakes than African Americans with and without T2D $(M d \mathrm{~s}=1857$, 2020, respectively). Finally, a greater percent of Haitian Americans with T2D had less than grade 8 educations than those without T2D. Thirty six percent of Haitian Americans with T2D had less than 8 years education compared with $26.5 \%$ of Haitian Americans without T2D and African Americans with and without T2D (3.6\%, 0.0\%, respectively). 
Table 2

General Characteristics of Participants by Diabetes Status

\begin{tabular}{|c|c|c|c|}
\hline \multirow[b]{2}{*}{ Variables } & \multicolumn{2}{|c|}{ Diabetes } & \multirow[b]{2}{*}{$P$-value } \\
\hline & $\begin{array}{c}\text { Yes } \\
(n=233)\end{array}$ & $\begin{array}{c}\text { No } \\
(n=210)\end{array}$ & \\
\hline Age (years) & $56.3 \pm 10.3$ & $52.7 \pm 9.8$ & $<.001$ \\
\hline Gender (male) \% & 49.5 & 47.6 & .692 \\
\hline $\mathrm{BMI}\left(\mathrm{kg} / \mathrm{m}^{2}\right)$ & $32.1 \pm 6.5$ & $29.7 \pm 5.7$ & $<.001$ \\
\hline Smoke (yes) \% & 18.5 & 20.6 & .591 \\
\hline Energy Intake (kcal/day) & $1681(1306)$ & $1834(1382)$ & .052 \\
\hline Education $(\%)$ & & & .072 \\
\hline$<$ Grade 8 & 14.2 & 20.6 & \\
\hline Some high school & 11.4 & 16.3 & \\
\hline High school grad/GED & 24.2 & 24.0 & \\
\hline Some college/technical school & 28.5 & 25.7 & \\
\hline College graduate (bachelor's degree) & 13.3 & 9.8 & \\
\hline Graduate degree & 8.1 & 3.4 & \\
\hline
\end{tabular}


Table 3

General Characteristics of Participants by Ethnicity and Diabetes Status

\begin{tabular}{|c|c|c|c|c|}
\hline \multirow[b]{2}{*}{ Variables } & \multicolumn{2}{|c|}{ African Americans } & \multicolumn{2}{|c|}{ Haitian Americans } \\
\hline & $\begin{array}{c}\text { Yes } \\
(n=112)\end{array}$ & $\begin{array}{c}\text { No } \\
(n=97)\end{array}$ & $\begin{array}{c}\text { Yes } \\
(n=121)\end{array}$ & $\begin{array}{c}\text { No } \\
(n=113)\end{array}$ \\
\hline Age (years) & $54.8 \pm 10.2^{\mathrm{b}}$ & $51.7 \pm 8.6^{\mathrm{a}}$ & $57.6 \pm 10.3^{\mathrm{b}}$ & $53.5 \pm 10.7^{\mathrm{a}}$ \\
\hline Gender (male) \% & 50.0 & 50.5 & 45.5 & 48.7 \\
\hline BMI $\left(\mathrm{kg} / \mathrm{m}^{2}\right)$ & $34.7 \pm 7.1^{\mathrm{b}}$ & $30.6 \pm 6.4^{\mathrm{a}}$ & $29.6 \pm 4.8^{\mathrm{a}}$ & $29.0 \pm 5.0^{\mathrm{a}}$ \\
\hline Smoke (yes) \% & $35.7^{\mathrm{b}}$ & $33.0^{\mathrm{b}}$ & $6.6^{\mathrm{a}}$ & $6.2^{\mathrm{a}}$ \\
\hline Energy Intake (kcal/day) & $1857(1457)^{\mathrm{c}}$ & $2020(1296)^{\mathrm{c}}$ & $1430(1150)^{\mathrm{a}}$ & $1719(1210)^{b}$ \\
\hline \multicolumn{5}{|l|}{ Education (\%) } \\
\hline$<$ Grade 8 & $3.6^{\mathrm{b}}$ & $0.0^{\mathrm{a}}$ & $36.4^{\mathrm{b}}$ & $26.5^{\mathrm{a}}$ \\
\hline Some high school & 14.3 & 12.4 & 18.2 & 10.6 \\
\hline High school grad/GED & 28.6 & 27.8 & 19.8 & 21.2 \\
\hline Some college/technical school & 38.4 & 38.1 & 14.0 & 20.4 \\
\hline College graduate (bachelor's degree) & 8.9 & 13.4 & 10.7 & 13.3 \\
\hline Graduate degree & 6.3 & 8.2 & 0.8 & 8.0 \\
\hline
\end{tabular}

Data are median (interquartile range) or means \pm SD unless otherwise indicated. Variables in the four groups with different superscripts are significantly different using Holm's sequential Bonferroni post hoc test, $p<.05$. BMI $=$ body mass index. 
The participants were also compared by both ethnicity and diabetes status using two-way ANOVA or non-parametric ANOVA (Table 3). African Americans with T2D had significantly higher BMI $\left(\mathrm{kg} / \mathrm{m}^{2}\right)(M=34.7)$ than African Americans without T2D $(M=30.6)$ and Haitian Americans with and without T2D $(M \mathrm{~s}=29.6,29.0$, respectively). Haitian Americans with T2D had significantly lower energy intake (kcal/day) ( $M d=$ 1638) than Haitian Americans without T2D ( $M d=1719)$, and both had significantly lower intakes than African Americans with and without T2D $(M d s=1857,2020$, respectively). Finally, there was a greater percent of participants with T2D who had less than grade eight educations. Thirty six percent of Haitian Americans with T2D had less than grade 8 education compared with $26.5 \%$ of Haitian Americans without T2D. Four percent of African Americans with T2D had less than grade 8 education compared to $0.0 \%$ without $\mathrm{T} 2 \mathrm{D}$.

\section{Biomarkers}

Table 4 shows glycemic control and oxidative stress biomarkers of participants by ethnicity. African Americans had lower A1C levels (\%) than Haitian Americans $(M=$ 6.7 vs. $M=7.1 ; p=.014)$. African Americans had higher MnSOD levels $(\mathrm{pg} / \mathrm{ml})(M=$ 2538 vs. $M=2016)$, and higher $8 \mathrm{OHdG}$ levels (pg/ml) $(M=1691$ vs. $M=1626 ; p=$ .003) than Haitian Americans. 
Table 4

Biomarkers of Glycemic Control and Oxidative Stress of Participants by Ethnicity

\begin{tabular}{|c|c|c|c|}
\hline \multirow[b]{2}{*}{ Variables } & \multicolumn{2}{|c|}{ Ethnicity } & \multirow[b]{2}{*}{$P$-value } \\
\hline & $\begin{array}{c}\text { African } \\
\text { Americans } \\
(n=209)\end{array}$ & $\begin{array}{c}\text { Haitian } \\
\text { Americans } \\
(n=234)\end{array}$ & \\
\hline Fasting plasma glucose $(\mathrm{mg} / \mathrm{dl})$ & $121.0 \pm 51.2$ & $129.1 \pm 56.7$ & .117 \\
\hline Hemoglobin A1C (\%) & $6.7 \pm 1.5$ & $7.1 \pm 2.1$ & .014 \\
\hline MnSOD (pg/ml) & $2538.0 \pm 1091.8$ & $2015.8 \pm 656.3$ & $<.001$ \\
\hline Ln-MnSOD & $7.7 \pm 0.5$ & $7.6 \pm 0.3$ & $<.001$ \\
\hline 8OHdG (pg/ml) & $1691.0 \pm 225.1$ & $1626.2 \pm 222.9$ & .003 \\
\hline
\end{tabular}


Biomarkers of glycemic control and oxidative stress of participants were compared by diabetes status as shown in Table 5. Participants with T2D had higher fasting plasma glucose (mg/dl) and A1C levels (\%), had lower MnSOD levels (pg/dl), and higher $8 \mathrm{OHdG}$ levels (pg/dl) than subjects without T2D.

The participants were also compared by both ethnicity and diabetes status as shown in Table 6. Haitian Americans with T2D had significantly higher fasting plasma glucose $(\mathrm{mg} / \mathrm{dl})(M=158)$ than African Americans with T2D $(M=143)$, and both had significantly higher fasting plasma glucose than African Americans and Haitian Americans without T2D ( $M \mathrm{~s}=96,99$, respectively). Similarly, Haitian Americans with T2D had significantly higher A1C levels (\%) $(M=8.4)$ than African Americans with T2D $(M=7.5)$, and both had significantly higher A1C levels than African Americans and Haitian Americans without T2D ( $M \mathrm{~s}=5.9,6.0$, respectively $)$.

African Americans without T2D had the highest MnSOD levels (pg/ml) $(M=$ 3541) of the four groups, Haitian Americans with T2D had the second highest MnSOD levels $(M=2174)$, Haitian Americans without T2D had the next highest MnSOD levels $(M=1846)$, and African Americans without T2D had the lowest MnSOD levels $(M=$ 1669). These differences were all significant.

The serum levels of $8 \mathrm{OHdG}(\mathrm{pg} / \mathrm{ml})$ in African Americans with T2D were significantly higher $(M=1796)$ than those of the other three groups. Haitian Americans with T2D had significantly higher levels of $8 \mathrm{OHdG}(M=1735)$ than African Americans without T2D and Haitian Americans without T2D $(M \mathrm{~s}=1570,1510$, respectively). 
Table 5

Biomarkers of Glycemic Control and Oxidative Stress of Participants by Diabetes Status

\begin{tabular}{|c|c|c|c|}
\hline \multirow[b]{2}{*}{ Variables } & \multicolumn{2}{|c|}{ Diabetes } & \multirow[b]{2}{*}{$P$-value } \\
\hline & $\begin{array}{c}\text { Yes } \\
(n=233)\end{array}$ & $\begin{array}{c}\text { No } \\
(n=210)\end{array}$ & \\
\hline Fasting plasma glucose (mg/dl) & $150.5 \pm 63.7$ & $97.4 \pm 15.3$ & $<.001$ \\
\hline Hemoglobin A1C (\%) & $7.9 \pm 2.1$ & $5.9 \pm 0.4$ & $<.001$ \\
\hline $\operatorname{MnSOD}(\mathrm{pg} / \mathrm{ml})$ & $1931.6 \pm 630.1$ & $2628.9 \pm 1054.8$ & $<.001$ \\
\hline Ln-MnSOD & $7.5 \pm 0.3$ & $7.8 \pm 0.4$ & $<.001$ \\
\hline 8OHdG (pg/ml) & $1764.2 \pm 188.6$ & $1537.6 \pm 203.5$ & $<.001$ \\
\hline
\end{tabular}

MnSOD= Manganese Superoxide Dismutase; $8 \mathrm{OHdG}=$ 8-hydroxy-2"-deoxyguanosine; Ln-MnSOD = Natural logarithm of Manganese Superoxide Dismutase. 
Table 6

Biomarkers of Participants by Ethnicity and Diabetes Status

\section{Ethnicity}

Diabetes

\section{$\underline{\text { Status }}$}

Variables

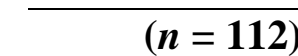

$(n=97)$

$(n=121)$

$(n=113)$

Fasting plasma glucose $(\mathrm{mg} / \mathrm{dl})$

$143.0 \pm 61.0^{b}$

$95.8 \pm 13.2^{\mathrm{a}}$

$157.6 \pm 65.5$

$98.7 \pm 16.9^{\mathrm{a}}$

Hemoglobin A1C (\%)

$7.5 \pm 1.8^{\mathrm{b}}$

$5.9 \pm 0.4^{\mathrm{a}}$

$8.4 \pm 2.4^{\mathrm{c}}$

$6.0 \pm 0.5^{\mathrm{a}}$

$\operatorname{MnSOD}(\mathrm{pg} / \mathrm{ml})$

$1669.3 \pm 521.3^{\mathrm{d}}$

$3541.1 \pm 609.4^{\mathrm{a}}$

$2174.4 \pm 626.7^{b}$

$1845.9 \pm 647.3^{\mathrm{c}}$

Ln-MnSOD

8OHdG (pg/ml)

$8.2 \pm 0.2^{\mathrm{d}}$

$7.6 \pm 0.3^{c}$

$7.5 \pm 0.3^{b}$

$7.4 \pm 0.3^{\mathrm{a}}$

$1795.9 \pm 194.7^{c}$

$1569.9 \pm 196.0^{\mathrm{a}}$

$1735.0 \pm 178.7^{b}$

$1509.8 \pm 206.5^{\mathrm{a}}$

Variables in four groups with different superscript are significantly different using Holm's sequential Bonferroni post hoc test, $p<.05 . \mathrm{MnSOD}=$ Manganese Superoxide Dismutase; $8 \mathrm{OHdG}=8$-hydroxy-2"-deoxyguanosine; Ln-MnSOD = Natural logarithm of Manganese Superoxide Dismutase. 


\section{Macro and Micronutrients}

Table 7 presents the macro and micronutrient intake of participants by ethnicity. Non-parametric tests were conducted on all variables, since all were non-normally distributed, so results were reported with median and interquartile range (IQR). African Americans had significantly higher median calculated energy intake (kcal/day) (1925 vs. $1650 ; p<.001)$, protein intake (g/day) (76.6 vs. $62.4 ; p<.001)$, fat intake (g/day) $(72.4$ vs. $45.3 ; p<.001)$, vitamin D intake (IU/day) (455.6 vs. $268.7 ; p<.001)$, vitamin $\mathrm{E}$ intake (IU/day) (11.0 vs. $7.9 ; p=.004)$, and zinc intake (mg/day) $(12.6$ vs. $9.0 ; p<.001)$ than Haitian Americans. Conversely, Haitian Americans had a significantly higher median intake of fiber (g/day) (24.1vs.17.0; $p<.001)$ and carotenoids (IU/day) (11864 vs. 5636; $p<.001)$ than African Americans.

Table 8 presents the macro and micronutrients intake of participants by diabetes status. Subjects with T2D had a significantly lower median carbohydrate intake (g/day) (225.4 vs. 257.6; $p=.012)$, vitamin E intake (IU/day) (8.1 vs. 10.7; $p=.030)$, and vitamin C intake (IU/day) (156.0 vs. 201.2; $p=.002)$ than subjects without T2D. 
Table 7

Macro and Micronutrients Intake of Participants by Ethnicity

\section{Ethnicity}

\begin{tabular}{lccc} 
& $\begin{array}{c}\text { African Americans } \\
\text { Variables }\end{array}$ & Haitian Americans & \\
& $(\mathbf{n}=\mathbf{2 0 9})$ & $\mathbf{( n = 2 3 4 )}$ & \\
\hline Energy Intake (kcal/day) & $1924.8(1400.0)$ & $1649.9(1109.0)$ & $<.001$ \\
Protein intake (g/day) & $76.6(54.7)$ & $62.4(46.4)$ & $<.001$ \\
Carbohydrate intake (g/day) & $249.0(192.8)$ & $229.9(165.0)$ & .107 \\
Fat intake (g/day) & $72.4(53.4)$ & $45.3(40.6)$ & $<.001$ \\
Fiber intake (g/day) & $17.0(15.8)$ & $24.1(19.6)$ & $<.001$ \\
Vitamin E (IU/day) & $11.0(17.6)$ & $7.9(10.5)$ & .004 \\
Vitamin D (IU/day) & $455.6(498.9)$ & $268.7(384.2)$ & $<.001$ \\
Vitamin C (mg/day) & $174.1(221.0)$ & $175.3(191.6)$ & .938 \\
Manganese (mg/day) & $3.4(3.1)$ & $4.5(3.2)$ & .009 \\
Carotenoids (IU/day) & $12.6(12.0)$ & $9.0(7.2)$ & $<.001$ \\
& & & \\
\hline
\end{tabular}

Data are expressed as median (interquartile range). 
Table 8

Macro and Micronutrients Intakes of Participants by Diabetes Status

\section{Diabetes}

\begin{tabular}{|c|c|c|c|}
\hline Variables & $\begin{array}{c}\text { Yes } \\
(n=233)\end{array}$ & $\begin{array}{c}\text { No } \\
(n=210)\end{array}$ & $P$-value \\
\hline Energy Intake (kcal/day) & $1680.7(1306.0)$ & $1834.1(1382.0)$ & .052 \\
\hline Protein intake (g/day) & $68.5(50.0)$ & $69.9(48.6)$ & .823 \\
\hline Carbohydrate intake (g/day) & $225.4(173.4)$ & $257.6(172.3)$ & .012 \\
\hline Fat intake (g/day) & $54.1(46.8)$ & $57.6(54.1)$ & .406 \\
\hline Fiber intake (g/day) & $20.3(17.6)$ & $21.3(19.2)$ & .294 \\
\hline Vitamin E (IU/day) & $8.1(11.5)$ & $10.7(16.5)$ & .030 \\
\hline Vitamin D (IU/day) & $325.8(431.5)$ & $355.9(509.1)$ & .052 \\
\hline Vitamin C (mg/day) & $156.0(181.2)$ & $201.2(241.7)$ & .002 \\
\hline Manganese (mg/day) & $3.7(3.1)$ & $3.9(3.1)$ & .334 \\
\hline Carotenoids (IU/day) & $7153.0(10132.5)$ & $8435.4(12374.0)$ & .214 \\
\hline Zinc (mg/day) & $9.8(10.0)$ & $10.7(10.2)$ & .376 \\
\hline
\end{tabular}

Data are expressed as median (interquartile range). 


\section{Energy intakes of participants by ethnicity and diabetes status}

The participants were compared on the macro and micronutrient intake by ethnicity and diabetes status using non-parametric ANOVA (Table 9). As seen in Table 3, Haitian Americans with T2D had significantly lower energy intake (kcal/day) ( $M d=$ 1430) than Haitian Americans without T2D (Md = 1719), and both had significantly lower intakes than African Americans with and without T2D $(M d s=1857,2020$, respectively).

Protein, Carbohydrate, and Fat Intakes by ethnicity and diabetes status

Haitian Americans with T2D had a significantly lower median carbohydrate intake (g/day) (206.3) than Haitian Americans without T2D (253) and African Americans with and without T2D $(236.6,259.8$, respectively).

\section{Vitamin and Mineral Intakes by ethnicity and diabetes status}

Haitian Americans with T2D had a significantly lower median vitamin E intake (IU/day) (7.3) than the other three groups. In addition, Haitian Americans without T2D (9.5) and African Americans with T2D (10.4) had significantly lower median vitamin E intakes than African Americans without T2D (12.3).

Haitian Americans with T2D had a significantly lower median vitamin D intake (IU/day) (236.4) than the other three groups. Haitian Americans without T2D had a significantly lower median vitamin D intake (280.5) than African Americans with and without T2D (371.8, 471.7, respectively). 
Haitian Americans with T2D had a significantly lower median vitamin C intake (mg/day) (138.4) than Haitian Americans without T2D (203.9) and African Americans with and without T2D (165.6 and 198.1, respectively).

Haitian Americans without T2D had a higher median manganese intake (mg/day) (4.4) than the other three groups. Median intakes for Haitian Americans with T2D was $4.1 \mathrm{mg} /$ day, for African American without T2D (3.4), and for African Americans with T2D (3.3). 
Table 9

Macro and Micronutrients Intake of Participants by Ethnicity and Diabetes Status

\begin{tabular}{|c|c|c|c|c|}
\hline \multirow[b]{2}{*}{ Variables } & \multicolumn{2}{|c|}{ African Americans } & \multicolumn{2}{|c|}{ Haitian Americans } \\
\hline & $\begin{array}{c}\text { Yes } \\
(n=112)\end{array}$ & $\begin{array}{c}\text { No } \\
(n=97)\end{array}$ & $\begin{array}{c}\text { Yes } \\
(n=121\end{array}$ & $\begin{array}{c}\text { No } \\
(n=113)\end{array}$ \\
\hline Energy Intake (kcal/day) & $1857(1457)^{\mathrm{c}}$ & $2020(1296)^{\mathrm{c}}$ & $1430(1150)^{\mathrm{a}}$ & $1719(1210)^{b}$ \\
\hline Protein intake (g/day) & $75.9(58.6)^{b}$ & $79.4(56.4)^{b}$ & $60.1(51.8)^{\mathrm{a}}$ & $63.5(42.9)^{\mathrm{a}}$ \\
\hline Carbohydrate intake (g/day) & $236.6(210.0)^{b}$ & $259.8(171.6)^{b}$ & $206.3(145.8)^{\mathrm{a}}$ & $253.4(174.5)^{\mathrm{b}}$ \\
\hline Fat intake (g/day) & $70.0(58.0)^{\mathrm{b}}$ & $73.5(49.5)^{\mathrm{b}}$ & $41.9(41.4)^{\mathrm{a}}$ & $46.4(41.2)^{\mathrm{a}}$ \\
\hline Fiber intake (g/day) & $16.6(13.6)^{\mathrm{a}}$ & $18.3(17.1)^{\mathrm{a}}$ & $22.4(18.8)^{\mathrm{b}}$ & $25.2(21.1)^{\mathrm{b}}$ \\
\hline Vitamin E (IU/day) & $10.4(15.7)^{b}$ & $12.3(19.4)^{\mathrm{c}}$ & $7.3(8.8)^{\mathrm{a}}$ & $9.5(11.4)^{b}$ \\
\hline Vitamin D (IU/day) & $371.8(472.7)^{\mathrm{c}}$ & $471.7(569.9)^{\mathrm{c}}$ & $236.4(380.3)^{\mathrm{a}}$ & $280.5(425.5)^{\mathrm{b}}$ \\
\hline Vitamin C (mg/day) & $165.6(208.3)^{b}$ & $198.1(260.3)^{b}$ & $138.4(170.0)^{\mathrm{a}}$ & $203.9(237.2)^{b}$ \\
\hline Manganese (mg/day) & $3.3(3.1)^{\mathrm{a}}$ & $3.4(3.4)^{\mathrm{a}}$ & $4.1(3.2)^{\mathrm{a}}$ & $4.4(2.9)^{\mathrm{b}}$ \\
\hline Carotenoids (IU/day) & $5618.8(7236.7)^{\mathrm{a}}$ & $5644.1(9472.6)^{\mathrm{a}}$ & $\begin{array}{c}11368.3 \\
(13612.3)^{b}\end{array}$ & $\begin{array}{c}12162.4 \\
(14915.2)^{b}\end{array}$ \\
\hline Zinc (mg/day) & $12.2(12.2)^{\mathrm{b}}$ & $13.0(11.9)^{\mathrm{b}}$ & $9.0(7.8)^{\mathrm{a}}$ & $9.0(6.8)^{\mathrm{a}}$ \\
\hline
\end{tabular}

Data are expressed as median (interquartile range). Variables in groups with different superscripts are significantly different using Holm's sequential Bonferroni post hoc test, $p<.05$. 


\section{Section 2: Correlations}

\section{Correlation of Oxidative Stress Biomarkers and Socio-demographic}

\section{Characteristics}

This section contains results of the correlation analysis between biomarkers and socio-demographics using Pearson's and point bi-serial correlations, depending on the type of socio-demographic variable. The associations between Ln-MnSOD and $80 \mathrm{OHG}$ levels and dietary antioxidant intakes were analyzed with Pearson's correlations. Additionally, Pearson's and point bi-serial correlations measured the relationship between glycemic control with socio-demographic variables and dietary antioxidant intakes for study participants with T2D. Overall, there was a significant negative correlation between Ln-MnSOD and 8OHdG, $r=-.17, p<.001$, so that lower levels of LnMnSOD associated with higher levels of $8 \mathrm{OHdG}$.

\section{Correlation of Oxidative Stress Biomarkers and Study Variables}

Table 10 presents the Pearson's correlation analysis of oxidative stress biomarkers with study variables. Ln-MnSOD was negatively correlated with BMI, $r=-.15, p<.05$, and 8OHdG was positively correlated with BMI, $r=-$ $.15, p<.05$, age, $r=.13, p<.01$, and being male, $r=.11, p<.05$. Thus, lower

levels of Ln-MnSOD were associated with greater BMI, while higher levels of $8 \mathrm{OHdG}$ were associated with greater BMI, being older and being male. 
Table 10

Pearson's Correlations of Oxidative Stress Biomarkers with Study Variables

$$
\text { Participants }(n=433)
$$

Variables

MnSOD Ln-MnSOD 8OHdG

\begin{tabular}{lccc}
\hline Age (years) & $-.10^{*}$ & -.09 & $.13^{* *}$ \\
Gender $($ male) & .07 & .06 & $.11^{*}$ \\
BMI $\left(\mathrm{kg} / \mathrm{m}^{2}\right)$ & $-.15^{* *}$ & $-.15^{* *}$ & $.15^{* *}$ \\
Smoke (yes) & $.10^{*}$ & .07 & .04 \\
Energy Intake(kcal/day) & .04 & .02 & -.05 \\
Education & .08 & .07 & .01 \\
Less than high school & $-.11 *$ & $-.10 *$ & -.03 \\
High school grad/GED & .07 & .07 & .04 \\
Some college/technical school & .07 & .06 & -.01 \\
Graduate school & -.02 & -.02 & .00 \\
\hline
\end{tabular}

$* p<.05, * * p<.01$

$\mathrm{BMI}=$ body mass index; MnSOD $=$ Manganese Superoxide Dismutase; $8 \mathrm{OHdG}=8$ hydroxy-2"-deoxyguanosine. Ln-MnSOD = Natural logarithm of Manganese Superoxide Dismutase. 
Table 11 presents Pearson's correlation analysis of oxidative stress biomarkers with dietary antioxidants intakes. Lower levels of Ln-MnSOD were associated with lower levels of zinc, $r=.10, p<.05$, and higher levels of carotenoids, $r=-.10, p<.05$. Higher levels of $8 \mathrm{OHdG}$ were associated with lower levels of Vitamin $\mathrm{D}, r=-.14, p<.01$, and carotenoids, $r=-.09, \mathrm{p}<.05$.

Table 12 presents Pearson's correlation analysis of glycemic control with socio-demographic variables and dietary antioxidant intakes for study participants with T2D. Diabetic participants with higher FPG had lower intakes of Vitamin $\mathrm{D}, r=-.14, p<.05$. Higher A1C levels in T2D participants were associated with being Haitian, $r=-.19, p<.01$, and having less education, $r=-$ $.14, p<.05$.

In addition, for Haitian Americans with T2D, higher FPG levels were associated with lower BMI, $\mathrm{r}=-.25, p<.01$, and lower Vitamin $\mathrm{C}$ intakes, $\mathrm{r}=-$ $.19, p<.05$. For African Americans with T2D, higher FPG levels were associated with higher Vitamin E intakes, $r=-.25, p<.01$. Higher A1C levels were associated with lower carotenoids intakes, $r=-.19, p<.05$, for this group. 
Table 11

Pearson's Correlations of Oxidative Stress Biomarkers with Study Variables

\begin{tabular}{lccc}
\hline & \multicolumn{3}{c}{ Participants $(\boldsymbol{n}=\mathbf{4 3 3})$} \\
Variables & MnSOD & LnMnSOD & 80HdG \\
\hline Energy Intake $(\mathrm{kcal} /$ day) & .04 & .02 & -.05 \\
Vitamin E / $1000 \mathrm{kcal} /$ day & -.00 & -.01 & .01 \\
Vitamin D / $1000 \mathrm{kcal} /$ day & .08 & .07 & -.02 \\
Vitamin C / $1000 \mathrm{kcal} /$ day & .06 & .07 & $-.14 * *$ \\
Manganese / $1000 \mathrm{kcal} /$ day & -.06 & -.03 & .00 \\
Carotenoids / $1000 \mathrm{kcal} /$ day & $-.11 *$ & $-.10^{*}$ & $-.09 *$ \\
Zinc / $1000 \mathrm{kcal} /$ day & $.10 *$ & $.10^{*}$ & .00 \\
\hline$* p<.05 * * p<.01$ & & & \\
\hline
\end{tabular}

$* p<.05, * * p<.01$

$\mathrm{BMI}=$ body mass index; $\mathrm{MnSOD}=$ Manganese Superoxide Dismutase $; 8 \mathrm{OHdG}=8$ hydroxy-2"-deoxyguanosine. Ln-MnSOD = Natural logarithm of Manganese Superoxide Dismutase. 
Table 12

Pearson's Correlations of Glycemic Control with Study Variables in Individuals with $T 2 D$

Glycemic Control

$$
(n=433)
$$

\begin{tabular}{|c|c|c|}
\hline Variables & FPG & $\mathrm{A} 1 \mathrm{C}$ \\
\hline Ethnicity (African American) & -.12 & $-.19^{* *}$ \\
\hline Age (years) & -.04 & -.10 \\
\hline Gender (male) & .07 & .06 \\
\hline BMI $\left(\mathrm{kg} / \mathrm{m}^{2}\right)$ & -.12 & -.07 \\
\hline Smoke (yes) & -.04 & .01 \\
\hline Energy Intake(kcal/day) & -.06 & -.09 \\
\hline Education & -.10 & $-.14^{*}$ \\
\hline Less than high school & .09 & .13 \\
\hline high school grad/GED & -.01 & -.04 \\
\hline some college/technical school & -.03 & -.04 \\
\hline graduate school & -.08 & -.08 \\
\hline Vitamin E / $1000 \mathrm{kcal}$ & .11 & -.01 \\
\hline Vitamin D / $1000 \mathrm{kcal}$ & $-.14^{*}$ & -.02 \\
\hline Vitamin C / $1000 \mathrm{kcal}$ & -.07 & -.05 \\
\hline Manganese / $1000 \mathrm{kcal}$ & .01 & .04 \\
\hline Carotenoids / 1000 kcal & .04 & .02 \\
\hline Zinc/1000 kcal & -.04 & -.05 \\
\hline
\end{tabular}

$* p<.05, * * p<.01$

$\mathrm{A} 1 \mathrm{C}=$ glycosylated hemoglobin; $\mathrm{FPG}=$ fasting plasma glucose; $\mathrm{BMI}=$ body mass index. 


\title{
Section 3: Hypotheses Testing
}

Hypothesis testing was conducted with Analysis of Covariance (ANCOVA), and multiple linear regression analysis. We compared the levels of MnSOD and $8 \mathrm{OHdG}$ by ethnicity and diabetes status using ANCOVAs. Post hoc test using Fisher's LSD procedure were carried out on the adjusted ethnic and diabetes status means for significant tests of interaction.

Relationships of MnSOD and $8 \mathrm{OHdG}$ with dietary antioxidants by ethnicity and diabetes status were analyzed by multiple linear regression analyses. The relationships between glycemic controls (A1C) and fasting plasma glucose levels (FPG) with dietary antioxidants by ethnicity and diabetes status were determined with multiple linear regression analyses. The covariates for all analyses were age, gender, smoking status, education, BMI, and energy intake.

\author{
Aim 1. To determine the differences in serum MnSOD and 8OHdG by \\ diabetes status and ethnicity.
}

Hypothesis 1a: Serum levels of MnSOD will be lower in participants with T2D as compared to those without T2D, independent of ethnicity

\section{ANCOVA on Manganese Superoxide Dismutase (MnSOD)}

In a two way ANCOVA on Ln-MnSOD by ethnicity (Haitian, African American) and diabetes status (yes/no), both main effects were significant, 
ethnicity, $F(1,433)=55.46, p<.001, \eta^{2}=.11$, diabetes status, $F(1,433)=$ $108.57, p<.001, \eta^{2}=.20$. However, the main effects were moderated by significant interaction of ethnicity by diabetes status, $F(1,433)=293.43, p<$ $.001, \eta^{2}=.40$. By convention, a "small" effect is $\eta^{2}=.01$, a "medium" effect is $\eta^{2}=.06$, and a "large" effect is $\eta^{2}=.16$. These effects were all very large. The adjusted mean Ln-MnSOD for African Americans without diabetes $(M=8.16)$ was significantly larger than for African Americans with diabetes $(M=7.40)$ and for Haitian Americans with and without diabetes $(M=7.63 ; M=7.46$, respectively).

Hypothesis one was not supported. Although African Americans with diabetes had lower MnSOD levels than African Americans without diabetes, this was not the case for Haitian Americans, so lower serum levels of MnSOD in T2D participants was not independent of ethnicity.

\section{Hypothesis 1b: Serum levels of $80 \mathrm{HdG}$ will be higher in participants with} T2D when compared to without T2D, independent of ethnicity.

\section{ANCOVA on mtDNA 8-hydroxy-2'-deoxyguanosine (8OHdG)}

In a two way ANCOVA on $8 \mathrm{OHdG}$ by ethnicity and diabetes status, both main effects were significant, ethnicity, $F(1,433)=6.44, p=.012, \eta^{2}=.02$, diabetes status $F(1,433)=126.38, p<.001, \eta^{2}=.23$. There was not a significant interaction effect, $F(1,433)=.05, p=.826, \eta^{2}<=.01$. 
In support of Hypothesis $1 \mathrm{~b}$, the adjusted $8 \mathrm{OHdG}$ mean $(M=1761.36)$

for individuals with diabetes was significantly higher than those without diabetes $(M=1544.11)$, independent of ethnicity. Additionally, the adjusted $8 \mathrm{OHdG}$ mean for African Americans $(M=1680.47)$ was significantly higher than for Haitian Americans $(M=1625.00)$.

Hypothesis 1c: There will be an inverse relationship between serum levels of MnSOD and 8OHdG in participants with T2D, independent of ethnicity.

\section{Multiple Linear Regression of MnSOD with 8OHdG}

The multiple regression analysis of $8 \mathrm{OHdG}$ on $\mathrm{MnSOD}$ with control variables of ethnicity, diabetes status, age, gender, smoking status, education, BMI, and energy intake was significant, $R^{2}=29.6 \%, F(10,433)=18.15, p<$ .001. However, MnSOD did not explain significant additional variability of $8 \mathrm{OHdG}, R^{2}$ change $=0.3 \%, F(1,432)=2.14, \beta=-.09, p=.145 . \quad$ In the final model, significant covariates were: having T2D, $\beta=.51, p<.001$, being male, $\beta$ $=.14, p=.002$, and being African American, $\beta=.22, p=.011$.

Hypothesis 1c was not supported in that the data did not show an inverse relationship between the serum levels of MnSOD and 8OHdG in African Americans and Haitian Americans with T2D.

\section{Aim 2: To determine the relationships of serum MnSOD and 8OHdG with various dietary antioxidants by diabetes status and ethnicity.}


Hypothesis 2a: Serum $80 \mathrm{HdG}$ levels will be negatively associated with dietary intake of antioxidants, independent of diabetes status and ethnicity.

\section{Multiple Linear Regression of 8OHdG on dietary intake of antioxidants}

Multiple linear regression analysis showed that vitamin C intake per 1000 kcal explained significant additional variability of $8 \mathrm{OHdG}, R^{2}$ change $=0.8 \%$, $F(1,432)=5.25, \beta=-.10, p=.022$. In this model, lower levels of $8 \mathrm{OHdG}$ were associated with higher vitamin $\mathrm{C}$ levels after controlling for age, gender, smoking status, education, BMI, energy intake, ethnicity, diabetes status and the interaction between ethnicity and diabetes status. Significant covariates were: having type 2 diabetes, $\beta=.48, p<.001$; being African American, $\beta=.13, p=$ .034 ; the interaction between having type 2 diabetes and African American, $\beta=-$ $.14, p<.001$; and being male, $\beta=.12, p<.005$.

Vitamin D intake per $1000 \mathrm{kcal}$ did not explain significant additional variability of $8 \mathrm{OHdG}, R^{2}$ change $=0.0 \%, F(1,432)=0.10, \beta=.01, p=.922$. Significant covariates were: having type 2 diabetes, $\beta=.49, p<.001$; being male, $\beta=.13, p=.002$; and being African American, $\beta=.13, p=.037$.

Vitamin E intake per $1000 \mathrm{kcal}$ did not explain significant additional variability of $8 \mathrm{OHdG}, R^{2}$ change $=0.0 \%, F(1,432)=0.80, \beta=.01, p=.927$. Significant covariates were: having type 2 diabetes, $\beta=.49, p<.001$; being male, $\beta=.13, p=.003$; and being African American, $\beta=.13, p=.035$. 
Carotenoids intake per $1000 \mathrm{kcal}$ did not explain significant variability of $8 \mathrm{OHdG}, R^{2}$ change $=0.2 \%, F(1,432)=.975, \beta=-.04, p=.324$. Significant covariates were: having type 2 diabetes, $\beta=.49, p<.001$; and being male, $\beta=$ $.13, p=.003$.

Hypothesis 2a was supported for vitamin C, but not for vitamin D, E, or carotenoids.

Hypothesis 2b: MnSOD levels will be negatively associated with dietary intake of antioxidants, independent of diabetes status and ethnicity.

\section{Multiple linear regression analysis on MnSOD on dietary intake of} antioxidants

Vitamin C intake per $1000 \mathrm{kcal}$ did not explain significant additional variability of $\ln -\mathrm{MnSOD}, R^{2}$ change $=0.2 \%, F(1,432)=1.90, p=.169$. Significant covariates were being African American, $\beta=.878, p<.001$, having diabetes, $\beta=.22, p<.001$, and interaction between ethnicity and diabetes status, $\beta=-1.01, p<.001$.

Vitamin D intake per $1000 \mathrm{kcal}$ did not explain significant additional variability of $\ln -\mathrm{MnSOD}, R^{2}$ change $=0.0 \%, F(1,432)=.294, p=.588$.

Significant covariates were being African American, $\beta=.872, p<.001$, having diabetes, $\beta=.215, p<.001$, and interaction between ethnicity and diabetes status $\beta=-1.007, p<.001$. 
Vitamin E intake per $1000 \mathrm{kcal}$ did not explain significant additional variability of $\ln -\mathrm{MnSOD}, R^{2}$ change $=0.1 \%, F(1,432)=.879, p=0.349$. Significant covariates were being African American, $\beta=.88, p<.001$, having diabetes, $\beta=.21, p<.001$, and the interaction between African American and diabetes status, $\beta=-1.01, p<.001$.

Carotenoids intake per $1000 \mathrm{kcal}$ did not explain significant additional variability of $\ln -\mathrm{MnSOD}, R^{2}$ change $=0.1 \%, F(1,432)=1.268, p=.261$.

Significant covariates were being African American, $\beta=.863, p<.001$, having diabetes, $\beta=.215, p<.001$, and interaction between ethnicity and diabetes status, $\beta=-1.009, p<.001$.

Hypothesis $2 \mathrm{~b}$ was not supported for any of the antioxidants, vitamin $\mathrm{C}$, D, E or carotenoids.

\section{Aim 3: To examine the relationships of glycemic control (A1C) and fasting plasma glucose level with dietary antioxidants in T2D by ethnicity.}

Control variables for the multiple regression analyses were: ethnicity, age, gender, education, energy intake, BMI, and smoking status. Only diabetic participants were included in these analyses.

Haitian Americans with T2D had significantly higher fasting plasma glucose $(\mathrm{mg} / \mathrm{dl})(M=158)$ than African Americans with T2D $(M=143)$, and similarly, Haitian Americans with T2D had significantly higher A1C levels (\%) $(M=8.4)$ than African Americans with T2D $(M=7.5)$, (Table 6). 


\section{Hypothesis 3a: There will be no relationship between serum A1C and any dietary antioxidants in participants with T2D independent of ethnicity.}

\section{Multiple Linear Regression of Hemoglobin A1C (A1C)}

Vitamin C intake per $1000 \mathrm{kcal}$ did not explain significant additional variability of A1C, $R^{2}$ change $=0.0 \%, F(1,432)=.27, \beta=.04, p=.601$. The significant covariates was being African American, $\beta=-.19, p=.023$.

The multiple regression analysis of A1C on vitamin D was not significant, $R^{2}=6.9 \%, F(8,224)=2.09, p=.995$. Vitamin D did not explain significant additional variability in the model, $R^{2}$ change $=0.0 \%, \beta=-.01, p=$ .905. The significant covariate was being African American, $\beta=-.20, p=.020$.

The multiple regression analysis of $\mathrm{A} 1 \mathrm{C}$ on vitamin $\mathrm{E}$, was not significant, $R^{2}=6.9 \%, F(8,224)=2.09, p=.943$. Vitamin $\mathrm{E}$ did not explain significant additional variability in the model, $R^{2}$ change $=0.0 \%, \beta=.01, p=$ .943. The significant covariate was being African American, $\beta=-.20, p=.020$.

The multiple regression analysis of A1C on carotenoids, was not significant, $R^{2}=6.9 \%, F(8,224)=2.09, p=.685$. Carotenoids did not explain significant additional variability in the model, $R^{2}$ change $=0.0 \%, \beta=.04, p=$ .604. The significant covariate was being African American, $\beta=-.12, p=.045$.

Hypothesis 3a was supported since $\mathrm{A} 1 \mathrm{C}$ was not related to any of the antioxidants, vitamin C, D, E or carotenoids, for T2D participants. 
Hypothesis $3 b$ : There will be no relationship between fasting plasma glucose level and any of the dietary antioxidant intakes in T2D independent of ethnicity.

\section{Multiple regression analysis of fasting plasma glucose (FPG)}

The multiple regression analysis of FPG on vitamin C per $1000 \mathrm{kcal}$ was not significant, $R^{2}=4.1 \%, F(8,224)=1.20, p=.302$. Vitamin $C$ intake did not explain significant additional variability of FPG, $R^{2}$ change $=0.1 \%, F(1,432)=$ $1.17, \beta=-.07, p=.280$. The significant covariate was being African American, $\beta=-.19, p=.023$.

The multiple regression analysis of FPG on vitamin D per $1000 \mathrm{kcal}$ was not significant, $R^{2}=5.3 \%, F(8,224)=1.57, p=.135$. Vitamin D intake per $1000 \mathrm{kcal}$ explained significant additional variability of FPG, $R^{2}$ change $=1.7 \%, F(1,432)$ $=4.05, \beta=-.13, p=.045$. The significant covariate was being African American, $\beta=-.20, p=.020$.

The multiple regression analysis of FPG on vitamin E intake per $1000 \mathrm{kcal}$ was not significant, $R^{2}=4.9 \%, F(8,224)=1.44, p=.183$. Vitamin $\mathrm{E}$ intake did not explain significant additional variability of FPG, $R^{2}$ change $=1.3 \%$, $F(1,432)=3.11, \beta=.11, p=.084$. The significant covariate was being African American, $\beta=-.19, p=.023$.

The multiple regression analysis of FPG on carotenoids intake per $1000 \mathrm{kcal}$ was not significant, $R^{2}=3.7 \%, F(8,224)=1.07, p=.388$. Carotenoids did not 
explained significant additional variability of FPG, $R^{2}$ change $=1.9 \%, F(1,432)$ $=2.09, \beta=-.14, p=.083$.

Hypothesis $3 b$ was supported since fasting plasma glucose was not significantly related to any of the antioxidants, vitamins C, D, E, or carotenoids for T2D participants. 
Table 13

Results of Hypothesis Testing

\section{HYPOTHESIS}

$\mathbf{H}_{1} \mathbf{a}$ : Serum levels of MnSOD will be lower

in participants with $\mathrm{T} 2 \mathrm{D}$ as compared to those without T2D, independent of ethnicity.

$\mathbf{H}_{\mathbf{1}} \mathbf{b}$ : Serum levels of $8 \mathrm{OHdG}$ will be higher in participants with $\mathrm{T} 2 \mathrm{D}$ when compared to those without T2D, independent of ethnicity.

$\mathbf{H}_{\mathbf{1}} \mathbf{c}$ : There will be an inverse relationship between serum levels of MnSOD and $8 \mathrm{OHdG}$ in participants with $\mathrm{T} 2 \mathrm{D}$, independent of ethnicity.

$\mathbf{H}_{2} \mathbf{a}$ : Serum $8 \mathrm{OHdG}$ levels will be negatively associated with dietary intake of antioxidants, independent of diabetes status and ethnicity.

$\mathbf{H}_{2} \mathbf{b}$ : Serum MnSOD levels will be negatively associated with dietary intake of antioxidants, independent of diabetes status and ethnicity.
RESULTS

Hypothesis ${ }_{1}$ a was not supported. Although African Americans with diabetes had lower MnSOD levels than African Americans without diabetes, this was not the case for Haitian Americans, so lower serum levels of MnSOD in T2D participants was not independent of ethnicity.

Hypothesis ${ }_{1} \mathbf{b}$ was supported since the adjusted serum levels of $8 \mathrm{OHdG}$ mean for individuals with diabetes was significantly higher than for those without diabetes, independent of ethnicity. Also, adjusted $8 \mathrm{OHdG}$ mean for African Americans was significantly higher than for Haitian Americans.

Hypothesis ${ }_{1} \mathrm{C}$ was not supported by the findings in this study.

Hypothesis ${ }_{2} \mathbf{a}$ was not supported for vitamin $\mathrm{C}$ since multiple linear regression analysis showed that vitamin C intake per $1000 \mathrm{kcal}$ explained significant additional variability of $8 \mathrm{OHdG}, R^{2}$ change $=$ $0.8 \%, \beta=-0.10, p=.022$

Hypothesis ${ }_{2} \mathbf{b}$ was not supported since multiple regression analysis showed that none of the antioxidants, vitamins C, D, E or 


\begin{tabular}{|c|c|}
\hline & $\begin{array}{l}\text { carotenoids, were significant in } \\
\text { explaining the variability of Ln- } \\
\text { MnSOD. }\end{array}$ \\
\hline $\begin{array}{l}\mathbf{H}_{3} \mathbf{a} \text { : There will be no relationship between } \\
\text { serum A1C and dietary antioxidants in } \\
\text { participants with T2D independent of ethnicity. }\end{array}$ & $\begin{array}{l}\text { Hypothesis }{ }_{3} \text { a was supported since } \\
\text { serum } \mathrm{A} 1 \mathrm{C} \text { was not related to any } \\
\text { of the antioxidants in the multiple } \\
\text { regression analyses on T2D } \\
\text { participants. }\end{array}$ \\
\hline $\begin{array}{l}\mathbf{H}_{3} \mathbf{b} \text { : There will be no relationship between } \\
\text { fasting serum glucose level and any of the } \\
\text { dietary antioxidant intakes in T2D independent } \\
\text { of ethnicity. }\end{array}$ & $\begin{array}{l}\text { Hypothesis } 3 \mathbf{b} \text { was supported } \\
\text { since fasting plasma glucose was } \\
\text { not related to any of the } \\
\text { antioxidants in the multiple } \\
\text { regression analyses on T2D } \\
\text { participants. }\end{array}$ \\
\hline
\end{tabular}




\section{CHAPTER V}

\section{DISCUSSION}

This chapter presents the discussion of the results. It is organized as follows: First, the descriptive statistics of the participants' general characteristics and socio-demographic status; Secondly the interpretation and qualitative analysis are discussed in the order which the aims and hypothesis were presented in this study. Finally, the study strengths and limitations, conclusions, and recommendations for future studies are provided.

Researchers and healthcare practitioners recognize that there are ethnic differences and disparities in many health disorders. It has been reported that blacks have a higher incidence of diabetes and diabetes related complications (Huffman et al., 2013) than whites, and there is an increasing awareness of ethnic group differences among subgroups normally grouped together as blacks. Two such subgroups are African Americans and Haitian Americans, both of whom were examined in this research study.

\section{General Characteristics of Participants}

African Americans are affected by diabetes disproportionately as compared to the general population. They are 1.8 times more likely to have diabetes and also more likely to develop diabetes complications such as kidney disease, blindness and cardiovascular disease when compared with whites (ADA, 2013). The prevalence of having diabetes in African Americans was determined to be 18.7 percent (ADA, 2013). Often time poor dietary patterns correlate with 
poor health, and the traditional diet of African Americans called "soul food" has been reported as being a poor diet, consisting of southern style foods which include pork chops and fried fatty foods (Anderson-Loftin et al., 2005).

The culture of Haitian Americans may explain the differences in study variables when compared with African Americans ("Background on Haiti", 2010). Haitian Americans resistance to healthcare screening may relate to their mistrust of healthcare providers. This under-utilization of health care resources may result in undiagnosed or untreated cardiovascular disease and T2D. According to a report by Huffman et al. (2013), although the diet of Haitian Americans is healthier than African Americans, it is not necessarily a healthy diet. The researchers reported that African American diet consisted of high fat content as compared with Haitian Americans whose diet consisted of fish, chicken, fruits and vegetables. African Americans scored lower than Haitian Americans using the Health Eating Index, indicating that Haitian Americans had a healthier diet than African Americans. The components of a high fat diet include hydrogenated oils, animal fats, free fatty acids, which are found in African Americans and may contribute to an increase risk of T2D and this type of dietary pattern may lead to increased oxidative stress (Watters, et al., 2007).

The information on the general characteristics of the respective diets for the study participants were obtained from a FFQ completed by the participants and from physiologic biometrics recorded by trained research assistants. In this study, African American participants were generally younger, had higher BMI, 
higher energy intakes, were more educated, and had a greater percentage of smokers than Haitian Americans (Table 1). There were similar numbers of male and female participants for both ethnicities. The data obtained from the FFQ show higher energy intakes observed in African Americans which explains the higher BMI compared with Haitian Americans.

The characteristics of participants by diabetes status are shown in Table 2. Participants with T2D had higher BMI $\left(32.1 \mathrm{~kg} / \mathrm{m}^{2} \pm 6.5\right)$ compared with participants without T2D $\left(29.7 \mathrm{~kg} / \mathrm{m}^{2} \pm 5.7\right)$. The average BMI of participants without T2D were within the range classified as overweight and those with T2D were classified as obese. Since the participants without T2D were classified as overweight, they also have an increased risk for diabetes (Sanada et al., 2012). These findings complement those reported by other researchers (Wee et al., 2008) who used data obtained from the 1999-2004 National Health and Nutrition Examination Survey (NHANES).

The participants with T2D had lower energy intake when compared to participants without T2D. The lower energy intake in participants with T2D may be explained by low calorie diets which are normally prescribed by healthcare practitioner as part of a treatment program. It is well documented that there is a strong positive association between energy intake with insulin resistance (Donin et al., 2013) and that weight loss is central to glycemic control improvement (Looker et al., 2001). Additionally, the low energy intake may be a result of under-reporting or due to false perception of food portion sizes and 
misrepresentation of actual intake (Samuel-Hodge et al. 2004). Olendzki et al. (2014) reported similar findings about under-reporting and they observed that the prevalence of under-reporting in a Caribbean Latino population studied was related to BMI, gender, and educational level. In this study, if the total energy intake calculated from the FFQ was $<500$ kcal per day or $>5000$ kcal per day, then the data was not included in the analysis. Similar cutoffs were reported by Hebert et al. (2002) as a common means to exclude reporting errors and extreme values.

\section{Biomarkers}

There are many assays developed to quantify oxidative stress, including the measure of oxidation of proteins, lipids, DNA, and antioxidant enzymes. The focus of this study is blood antioxidant enzyme manganese superoxide dismutase (MnSOD) and the byproduct of mtDNA damage known as 8-hydroxy-2'deguanosine (8OHdG). These variables were studied because of their localization and interaction in the mitochondria, and also because of their participation in the T2D associated progressive disorders (Kirk at al., 2006; Feairheller et al., 2011). The relationship between oxidative stress and diabetes status was examined because the literature review has shown that reactive oxygen species also influences the glycemic control (Kirk at al., 2006; Feairheller et al., 2011). In addition to elevated reactive oxygen species, the literature presented evidence that there is a direct correlation with elevated levels of oxidative stress biomarkers. 
Glycemic control can be determined with the blood biomarkers FPG and A1C (ADA, 2013). This study examined serum levels of oxidative stress biomarkers and glycemic control indicators and provided data on macro and micronutrients intakes obtained from food frequency questionnaire. The relationship of serum levels of manganese superoxide dismutase and mtDNA 8hydroxy-2'-deoxyguanosine were examined. In addition, the relationship when compared with dietary antioxidants intake in T2D in African Americans and Haitian Americans, two different ethnic groups, were determined.

An intensive literature search showed limited amount of data on the differences within minority groups. This study provided information of differences on serum levels of MnSOD and $80 \mathrm{OHdG}$ among African Americans and Haitian Americans. In addition, this report is the first cross sectional study that examined the relationship of oxidative stress biomarkers among African Americans and Haitians with and without T2D.

The aim of this study was to examine the serum levels of $8 \mathrm{OHdG}$, the surrogate biochemical marker for mtDNA damage, and MnSOD which is the body's primary antioxidant enzyme that protects the DNA in the mitochondria. We also investigated their relationship to dietary antioxidant intakes and glycemic control. Previous studies (Arab at al., 2011; Kirk at al., 2006; Feairheller et al., 2011) reported differences between African Americans and whites for glycemic control, oxidative stress biomarkers, and dietary antioxidants. Kirk et al. found ethnic disparities in glycemic control in African 
Americans and Non-Hispanic White adults with diabetes and reported that the cause of disparity may be related to the access to medical care and the amount of dietary antioxidants consumed. In this study, differences were found in glycemic control and dietary antioxidants intakes between African Americans and Haitian Americans. While access to medical care and attendance of doctor's visits was not a part of this project, these variables may have played a role. The findings of this study show significantly higher levels of $8 \mathrm{OHdG}$ and lower levels of MnSOD found in African Americans with T2D than in Haitian Americans with T2D, indicating higher oxidative stress among African Americans.

The mitochondria produce superoxide ions, the most abundant ROS produced, that may participate in the damage of cellular macromolecules. There is evidence that superoxide has an association with the development of diabetes complications and that MnSOD is the first line of defense in neutralizing superoxide in the mitochondria (Du et al., 2003; Brownlee, 2005). This study showed that the serum levels of MnSOD were higher in African Americans than Haitian Americans. Upon closer examination, the serum MnSOD levels of African Americans were lower for those with diabetes compared to without diabetes. These finding supported previous reports of decreased MnSOD activity in white blood cells of participants with diabetes compared to those without diabetes (Wegner, et al., 2014; Kazi et al., 2008). These findings may be interpreted that the mtDNA is not being protected efficiently due to the reduce MnSOD level and could lead to development diseases associated with T2D. Additionally, it was observed that dietary manganese intake level was lower in 
African Americans compared with Haitian Americans, and since manganese is a cofactor for the production of MnSOD, then may indicate a need for an improved quality in their diet. Currently there is no information available in the literature on serum levels of MnSOD in African American versus Haitian Americans.

The significant differences in serum levels of MnSOD and 8OHdG among African Americans and Haitian Americans provide evidence of ethnic difference within the black population. African Americans group had greater levels of both MnSOD and $8 \mathrm{OHdG}$ when compared with Haitian Americans. These observations also suggest that there appears to be ethnic differences in T2D, a major risk factor for CVD, therefore therapeutic interventions need to be managed according to ethnicity. To the best of our knowledge, this is the first time that these differences were determined.

The method that is used to quantify the serum levels of $8 \mathrm{OHdG}$ in this study was based on the ELISA principle, and has been validated and critically reviewed by Helliwell et al. (1996). The ELISA method is believed to be advantageous over analytical methods such as HPLC and gas chromatography/mass spectrometry. This is due to the elimination of artificial $8 \mathrm{OHdG}$ which may be introduced during the isolation of DNA, especially in phenol-based DNA purification procedures (Claycamp, 1992). The fact that we were able to identify significant association between $8 \mathrm{OHdG}$ and MnSOD suggest that cross-reactivity was not likely to interfere with the validity of the 
assay. In addition, the intra-assay coefficient of variation, $8.5 \%$, indicates that the ELISA assay had repeatability.

A two way ANOVA showed that ethnicity and diabetes status had a significant relationship with $8 \mathrm{OHdG}$. Higher levels of serum $8 \mathrm{OHdG}$ were found in T2D group compared to those participants without T2D. In addition, lower serum 8OHdG levels were found in Haitian Americans with T2D compared with African Americans with T2D. The role of MnSOD is to protect mtDNA from oxidative stress, and the data showed that MnSOD was higher while $8 \mathrm{OHdG}$ was lower in Haitian Americans than in African Americans. The strength of this observation was considered to be large since the effect size was large for both main effects. These findings indicate that there was more mtDNA damage in the T2D groups, of which African Americans may have a greater risk of T2D associated complications when compared with Haitian Americans with T2D.

The positive correlation of $8 \mathrm{OHdG}$ and $\mathrm{BMI}$ in the diabetic group suggests that obesity may have an additive effect with increased fasting plasma glucose in oxidative mtDNA damage. The covariates were age, gender, smoking status, education, BMI, and energy intake. Similar results were reported by AlAubaidy et al. (2011) in their clinical study on oxidative DNA damage and obesity in T2D mellitus. They also suggested that serum $8 \mathrm{OHdG}$ levels were already increasing in prediabetes. 
One of the risk factors for diabetes is smoking, which may contribute to elevated levels of ROS. Isik et al. 2007 showed that smoking may contribute to ROS through the weakening of the primary antioxidant defense system and production of free radicals. The literature provides conflicting evidence of the relationship of $8 \mathrm{OHdG}$ in smokers and non-smokers. In this study, we did not find any significant correlation of either $8 \mathrm{OHdG}$ or MnSOD with smoking, but this may be attributed to the low sample size of participants who were identified as smokers, thus the comparison may have lacked the power to detect a significant difference.

There were significant differences found with $8 \mathrm{OHdG}$ and gender. Gender, in addition to smoking and BMI, was also reported in the literature as significant predictor of increased 8OHdG levels (Loft, et al., 1992).

Although there was a weak relationship in the overall correlation between Ln-MnSOD and $8 \mathrm{OHdG}$, there is evidence that higher serum $8 \mathrm{OHdG}$ levels were associated with lower serum MnSOD levels. The regression analysis of $8 \mathrm{OHdG}$ on MnSOD was significant, with covariates of ethnicities, diabetes status, age, gender, education, energy intake, BMI, and smoking status. However, after controlling for all covariates, MnSOD did not explain the significance and additional variability of $8 \mathrm{OHdG}$. In the final model, significant covariates were being male, African American, and having with T2D.

We examined the relationship between dietary antioxidants intakes and found that serum $8 \mathrm{OHdG}$ levels negatively correlated with vitamin $\mathrm{C}$ intakes. 
That is, lower dietary intake of vitamin $\mathrm{C}$ was found to be associated with higher levels of 8 OHdG. Similar results were reported by Moller et al. (2002) in a dietary antioxidant intervention study. This observation may be due to the possible protection of the mtDNA from oxidative stress. Also, we observed a negative correlation between dietary carotenoids intakes with MnSOD and 8OHdG. There were no relationship observed between vitamin $\mathrm{E}$ and vitamin $\mathrm{D}$ with either MnSOD or 8OHdG.

In T2D, uncontrolled blood glucose levels may participate in disease pathophysiology which is associated with DNA damage. In this study, the findings were similar to the studies reported by Salem et al. (2012) in that subjects with T2D had greater DNA damage, higher levels of inflammation and oxidative stress, and were positively associated with higher levels of blood glucose levels. Since high blood glucose levels may interfere with cell replication and adversely influence the death rate of cells, there is a need to study ways in which to maintain DNA integrity and also to reduce the abnormal levels of ROS.

This study used A1C and FPG as indices glycemic control. The data showed that there were ethnic differences in A1C where African Americans had lower A1C than Haitian Americans. These findings were similar to Vimalananda et al. (2011) study that compared diabetes control among Haitians, African Americans, and Non-Hispanic Whites. Although Haitian Americans appear to consume less carbohydrate than the African Americans, the Haitian Americans 
had worse glycemic control. These findings may suggest that MnSOD may contribute to glycemic control, but proper medication use may be a major factor and this study was not designed to address this variable. Although findings of a negative relationship with glycemic control and serum MnSOD levels were not found in the scientific literature for Haitian Americans, a similar relationship was observed in Type 1 diabetes patients by Wegner et al. (2014). The report did not identify the ethnicity of the type 1 diabetes patients.

There was a marginal association of fasting plasma glucose with vitamin E, and vitamin D. Vitamin E intakes were not significant with FPG, but it explained some variance and it was marginally significant. In addition, dietary intake of vitamin D was found to be associated with lower fasting plasma glucose. Dietary intakes of vitamin D were not significantly associated with FPG, but it explained a small but significant variance in FPG. Saedisomeolia et al. (2013) had different findings in their cross-sectional study. They observed a positive relationship between serum vitamin D levels with glycemic control in Iranians, where $82 \%$ of the participants with $\mathrm{T} 2 \mathrm{D}$ and $75 \%$ of the participants without T2D were either vitamin D deficient or insufficient. The researchers interpreted these findings that vitamin D had beneficial effect on glycemic control.

\section{Strengths of the Study}

This study is the first to report on the serum levels of MnSOD and 8OHdG in Haitian Americans with and without T2D, and it also provided data 
on the relationship between these oxidative stress biomarkers with dietary and glycemic control indicators. This study provides evidence that there are ethnic difference in African American and Haitian American in dietary intakes, glycemic control indicators and oxidative stress levels components. This implies that educators and clinicians should be cognizant that treatment modalities should be ethnically based.

The instruments used in this study for data collection from the subjects were validated and standardized. The research personnel were trained to properly and accurately use the instruments and also correctly complete and score the questionnaires used to gather information from the participants.

The participants of this study were provided a copy of the results of their cardiovascular risk analysis, blood glucose levels, A1C, and lipid profile as determined from the blood collected and, in some cases, they were alerted to cardiovascular risk that they were not aware or would have identified if it was not for this study.

\section{Limitations of the Study}

A limitation of this study was that it was cross-sectional design and provided a snapshot relationship. In addition, although a validated nutrition assessment questionnaire was used to assess the dietary intake of antioxidants, it relies heavily on the subjects recall biases and estimate of portion size (SamuelHodge et al., 2004; Olendzki et al., 2014). The results of this study should be interpreted with caution and indeed, the lack of association between $8 \mathrm{OHdG}$ and 
dietary antioxidants could have a more favorable outcome if antioxidant levels were determined from serum or plasma. The study design was observational and the results may not be interpreted to have causality effect.

\section{Conclusion and Recommendations}

This study found inverse relationship between serum MnSOD and 8OHdG; suggesting that serum MnSOD and $8 \mathrm{OHdG}$ are useful biomarkers of oxidative stress in subjects with T2D. We found that there were decreased serum levels of MnSOD in participants with T2D when compared to participants without T2D, and that there were elevated levels of $8 \mathrm{OHdG}$ present in participants with T2D indicating higher oxidative stress in persons with T2D.

Additionally, we observed ethnic differences between African Americans and Haitian Americans with T2D, showing lower oxidative stress among diabetic Haitian Americans associated with higher intake of dietary antioxidants. The dietary antioxidants zinc and vitamin $\mathrm{C}$ were inversely correlated with $8 \mathrm{OHdG}$ suggesting that dietary intakes of antioxidant may provide health benefits by reducing mtDNA damage. 


\section{REFERENCES}

Background on Haiti \& Haitian Health Culture. (2010). Retrieved March 11, 2014, from http://www.cookross.com/docs/haiti.pdf

Standards of medical care in diabetes. (2014). Retrieved June 20, 2014, from http://care.diabetesjournals.org/content/37/Supplement 1/S14.full

Abate, M. E., Vatansev, H., \& Erkul, L. (2004). Oxidative stress in childhood obesity. Journal of Pediatric Endocrinology and Metabolism, 17, 10631068 .

Abraham, P., Ramamoorthy, H., \& Isaac, B. (2013). Depletion of the cellular antioxidant system contributes to tenofovir disoproxil fumarate - induced mitochondrial damage and increased oxido-nitrosative stress in the kidney. Journal of Biomedical Science, 20(1), 61-76.

Akbar, S., Bellary, S., Griffiths, H.R. (2011). Dietary antioxidants inteventions in T2D patients: a meta-analysis. The British Journal of Diabetes \& Vascular Disease, 11(2), 62-68.

Akbar, S., Bellary, S., Griffiths, H.R. (2003). Dietary Antioxidant Interventions in T2D Patients: A Meta-analysis. European Journal of Clinical Nutrition, 57, 999-1008.

Akbaraly, T. N., Ferrie, J. E., Berr, C., Brunner, E. J., Head, J., et al. (2011). Alternative Healthy Eating Index and mortality over 18 y of follow-up: results from the Whitehall II cohort. American Journal of Clinical Nutrition, 94(1), 247-253.

Akihiko, K., Odamaki, M., \& Hishida, A. (2003). Blood 8-hydroxy-2'deoxyguanosine is associated with erythropoietin resistance in haemodialysis patients. Nephrology Dialysis Transplantation, 18(5), 931-936.

Al-Aubaidy H.A. and Jelinek H.F. (2011). Oxidative DNA damage and obesity in T2D mellitus. European Journal of Endocrinology, 164,899-904.

Alemzadeh, R., Kichler, J., Babar, G., \& Calhoun, M. (2008). Hypovitaminosis $\mathrm{D}$ in obese children and adolescents: relationship with adiposity, insulin sensitivity, ethnicity, and season. Metabolism, 57(2), 183-191.

American Diabetes Association. (2013.). American Diabetes Association home page. Retrieved from http://diabetes.org

Anderson-Loftin, W., Barnett, S., Bunn, P., Sullivan, P., Hussey, J., Tavakoli, A. (2005). Soul food light: culturally competent diabetes education. Diabetes Education, 31(4), 555-563. 
Andriollo-Sanchez, M., Hininger-Favier, I., Meunier, N., Venneria, E., Oconnor, J. M., Maiani, G, Coudray, C., \& Roussel, A. M. (2005). Age-related oxidative stress and antioxidant parameters in middle-aged and older European subjects: the Zenith study. European Journal of Clinical Nutrition, 59 (suppl. 2), S58-S62.

Arab, L., Cambou, M. C., Craft, N., Wesseling-Perry, K., Jardack, P., \& Ang, A. (2011). Racial differences in correlations between reported dietary intakes of carotenoids and their concentration biomarkers. The American Journal of Clinical Nutrition, 93(5),1102-1108.

Bae, Y. S., Oh, H., Rhee, S. G., and Yoo, Y. D. (2011). Regulation of reactive oxygen species generation in cell signaling. Molecules and Cells, 32(6), 491-509.

Baines, J. W. (2001). Role of oxidative stress in development of complications in diabetes. Diabetes 40, 405-412.

Basavarai, K. H., Vasu, D. P., \& Rao, K. S. (2013). Studies on serum 8-hydroxy guanosine $(8-\mathrm{OHdG})$ as reliable biomarker for psoriasis. Journal of European Academy of Dermatology and Venereology, 27(5), 655-657.

Batini-Haberle, I., \& Benov, L. (2008). An SOD mimic protects NADP dependent isocitrate dehydrogenase against oxidative inactivation. Free Radical Research, 42(7), 843-850.

Bazzano, L. A., Serdula, M., \& Liu, S. (2005). Prevention of T2D by diet and lifestyle modification. Journal of the American College of Nutrition, 24(5), 310-319.

Beauchamp, C., \& Fridovich, I. (1971). Superoxide dismutase: improved assays and an assay applicable to acrylamide gels. Analytical Biochemistry, 44, 276-287.

Block, G., Dietrich, M., Norkus, E. P., Morrow, J. D., Hudes, M., CAfrican Americans n, B., \& Packer, L. (2002). Factors associated with oxidative stress in human populations. American Journal of Epidemiology, 156, 274-285.

Bolajoko, E., Mossanda, K., Adeniyi, F., Akinosun, O., Fasanmade, A., \& Moropane, M. (2008). Antioxidant and oxidative stress status in T2D and diabetic foot ulcer. South African Medical Journal, 98(8), 614-617.

Bono, A., Caimi, G., Catania, A., Sarno, A., Pandolfo, L. (1987). Red cell peroxide metabolism in diabetes mellitus. Hormone and Metabolic Research, 19, 264-266. 
Bowling, J., \& Katayev, A. (2010). An evaluation of the Roche Cobas c 111. LabMedicine, 41, 398-402.

Breton J., Sichel F., Bianchini F., \& Prevost V. (2003). Measurement of 8hydroxy-2'-deoxyguanosine by a commercially available ELISA test: Comparison with HPLC/electrochemical detection in calf thymus DNA and determination in human serum. Analytical Letters, 36, 123-134.

Brownlee M. (2005). The pathobiology of diabetic complications: a unifying mechanism. Diabetes, 54,1615-1625.

Calaf, G. M., Echiburú-Chau, C., Roy, D., Chai, Y., Wen, G., \& Balajee, A. S. (2011). Protective role of curcumin in oxidative stress of breast cells. Oncology Reports, 26(4), 1029-1035.

Caro, J. J., Ward, A. J., \& O'Brien, J. A. (2002). Lifetime costs of complications resulting from T2D in the U.S. Diabetes Care, 25, 476-481.

Centers for Disease Control and Prevention. (2011). Centers for Disease Control and Prevention home page. Retrieved from http://www.cdc.gov/diabetes/statistics/slides/maps_diabetes_trends.pdf

Ceriello, A. (2003). New insights on oxidative stress and diabetic complications may lead to a "causal" antioxidant therapy. Diabetes Care, 26(5), 15891596.

Ceriello, A. \& Motz, E. (2004). Is oxidative stress the pathogenic mechanism underlying insulin resistance, diabetes, and cardiovascular disease? The common soil hypothesis revisited. Artheriosclerosis, Thrombosis, and Vascular Biology, 5(4), 816-823.

Chen, L., Osio, Y. D., \& Anderson, J. (1999). Blood antioxidant defense system and dietary survey of elderly diabetic men. Archives of Gerontology and Geriatrics, 28(1), 65-83.

Chen, X., Ba, Y., Ma, L., Cai, X., Yin, Y., Wang, K., et al. (2008). Characterization of microRNAs in serum: a novel class of biomarkers for diagnosis of cancer and other diseases. Cell Research, 18, 997-1006.

Chatuphonprasert, W., Lao-Ong, T., \& Jarukamjorn, K. (2013). Improvement of superoxide dismutase and catalase in streptozotocin-nicotinamideinduced type 2-diabetes in mice by berberine and glibernclamide. Pharmaceutical Biology, 2013 Nov 5 [Epub ahead of print].

Clarke, M., Burnett, J., \& Croft, K. (2008). Vitamin E in human health and disease. Critical Reviews in Clinical Laboratory Sciences, 45(5), 417450 . 
Claycamp, H. G. (1993). Phenol sensitization of DNA to subsequent oxidative damage in 8-hydroxyguanine assays. Carcinogenesis, 13(7), 1289-1292.

Cobianchi, L., Fornoni, A., Ricordi, C., Inverardi, L., Pileggi, A., Molano, R., et al. (2008). Riboflavin Inhibits IL-6 and p38 Activation in Islet Cells. Cell Transplantation, 17(5), 559-566.

Cook, M. D., Heffernan, K. S., Ranadive, S., Woods, J. A., and Fernhall, B. (2013). Effect of resistance training on biomarkers of vascular function and oxidative stress in young African-American and Caucasian men. Journal of Human Hypertension, 27(6), 399-392.

Cooke, M. S., Henderson, P. T., \& Evans, M. D. (2009). sources of extracellular, oxidative-modified DNA lesions: Implications for their measurement in urine. Journal of Clinical Biochemistry and Nutrition, 45(3), 255-270.

Curtis, C., Landis, G. N., Folk, D., Wehr, N. B., Hoe, N., Waskar, M. et al. (2007). Transcriptional profiling of MnSOD-mediated lifespan extension of Drosophila reveals a species-general network of aging and metabolic genes. Genome Biology, 8(12), R262.

De Iuliis, G. N., Thomson, L. K., Mitchell, L. A., Finnie, J. M., Koppers, A. J., Hedges, A. (2009). DNA Damage in Human Spermatozoa is Highly Correlated with Efficiency of Chromatin Remodeling and the Formation of 8-Hydroxy-2'-Deoxyguanosine, a Marker of Oxidative Stress. Biology of Reproduction, 81(3), 517-524.

Daien, V., Carriere, I., Kawasaki, R., Cristol, J., Villain, M., Fesler, P. et al. (2013). Retinal Vascular Caliber is Associated with Cardiovascular biomarkers of Oxidative Stress and Inflammation: The POLA Study. PLoS, 8(7), e71089. doi:10.1371/journal.pone.0071089.

Dalle-Donne, I., Rossi, R., Colombo, R, Giustarini, D, and Milzani, A. (2006). Biomarkers of Oxidative Damage in Human Disease. Clinical Chemistry, 52(4), 601-623.

Demmer, R. T., Zuk, A. M., Rosenbaum, M., and Desvareaux, M. (2013). Prevalence of diagnosed and undiagnosed T2D mellitus among US adolescent: results from the continuous NHANES, 1999-2010. American Journal of Epidemiology, 178(7), 1106-1113.

Deneke, S. (2000). Thiol-based antioxidants. Current Topics in Cellular Regulations, 36, 151-180.

Di Naso, F. C., Simoes, D. A., Porawski, M., \& Marroni, N. A. (2011). Exogenous superoxide dismutase: action on liver oxidative stress in animals with streptozotocin-induced diabetes. Experimental Diabetes 
Research, vol. 2011, Article ID 754132, 6 pages, 2011. Doi:10.1155/2011/754132

Du Y., Miller C. M., Kern, T. S. (2003). Hyperglycemia increases mitochondrial superoxide in retina and retinal cells. Free Radical Biology and Medicine, 35, 1491-1499.

Earthman, C. P., Beckman, L. M., Masodkar, K., \& Sibley, S. D. (2012). The link between obesity and low circulating 25 -hydroxyvitamin D concentrations: considerations and implications. International Journal of Obesity, 36(1), 387-396.

Eastridge, D. K. (2009). An integrative review of interventions to reduce peripheral arterial disease risk factors in African Americans. Journal of Vascular Nursing, 27(2), 31-45.

Evert, A. B., Boucher, J. L., Cypress, M., Dunbar, S. A., Franz, M. J., et al. (2014). Nutrition Therapy Recommendations for the Management of Adults with Diabetes. Diabetes Care, 37(suppl.1), S120-S143.

Faghihi, T., Radfar, M., Barmal, M., Amini, P., Qorbani, M., \& Larijani, B. (2013). A Randomized, Placebo-Controlled Trial of Selenium Supplementation in Patients with T2D: Effects on Glucose Homeostasis, Oxidative Stress, and Lipid Profile. American Journal of Therapeutics, 2013 April 29 [Epub ahead of print].

Faul, F., Erdfelder, E., Buchner, A., \& Lang, A.-G. (2009). Statistical power analyses using $\mathrm{G}^{*}$ Power 3.1: Tests for correlation and regression analyses. Behavior Research Methods, 41, 1149-1160.

Feairheller, D. L., Diaz, K. M., Sturgeon, K. M., Williamson, S. T., \& Brown, M. D. (2011). Racial differences in the time-course oxidative stress responses to acute exercise. Journal of Exercise Physiology Online, 14 (1), 49-50.

Fleury, C., Neverova, S., Collins, S., Raimbault, S., Champigny, O., LeviMeyrueis, C., Bouillaud, F., Seldin, M., Surwitt, R., Ricquier, D., \& Warden, C. (1997). Uncoupling-protein-2: a novel gene linked to obesity and hyperinsulinemia. Nature Genetics, 15, 269-272.

Frei, B. (2004). Efficacy of Dietary Antioxidants to Prevent Oxidative Damage and Inhibit Chronic Disease. The American Society of Nutritional Sciences, 134(11), 31965-31985.

Fu, T. Y., Hou, Y. Y., Chu, S. T., Liu, C. F., Huang, C. H., Chen, H. C., Hsiao, M., Lu, P. J., Wang, J. S., \& Ger, L. P. (2011). Manganese superoxide dismutase and glutathione peroxidase as prognostic markers in patients 
with buccal mucosal squamous cell carcinomas. Head and Neck, 33(11), 1606-1615.

Garcia-Ramirez, M., Francisco, G., Garcia-Arumi, E., Hernandez, C., Martinez, R., Andreu, A., et al. (2008). Mitochondrial DNA oxidation and manganese superoxide dismutase activity in peripheral blood mononuclear cells from type 2 diabetic patients. Diabetes and Metabolism, 34(2), 117-124.

Giovannucci, E., Harlan, D. M., Archer, M. C., Bergenstal, R. M., Gapstur, S. M., Habel, L. A., et al. (2010). Diabetes and Cancer: A consensus report. Diabetes Care, 33(7), 1674-1685.

Gopaul, N., Manraj, M., Hebe, A., Kwai, S., Yan, S. L., Carrier, M., \& Anggard, E. (2001). Oxidative stress could precede endothelial dysfunction and insulin resistance in Indian Mauritians and impaired glucose metabolism. Diabetologia, 44(6), 706-723.

Gorduza, E. V., Indrei, L. L., \& Gorduza, V. M. (2008). Nutrigenomics in postgenomic era. Revista médico-chirurgicală a Societății de Medici ş̧ Naturaliş̧ti din Iaş,i, 112(1), 152-164.

Gradinaru, D., Borsa, C., Ionescu, C., Margina, D., Prada, G. I., \& Jansen, E. (2012). Vitamin D status and oxidative stress markers in the elderly with impaired fasting glucose and T2D mellitus. Aging and Clinical and Experimental Research, 24(6), 595-602.

Greger, J. L. (1998). Dietary standards for manganese: overlap between nutritional and toxicological studies. Journal of Nutrition, 128(2 suppl), 368S-371S.

Hakim, I. A., Harris, R., Garland, L., Cordova, C. A., Mikhael, D. M., \& SherryChow, H. H. (2012). Gender differences in systemic oxidative stress and antioxidant capacity in current and former heavy smokers. Cancer Epidemiology Biomarkers and Prevention, 21(12), 2193-2200.

Han, J., Paik, Y., Yu, J. H., and Kim, H. (2007). Antioxidant nutrientss inhibit LPS-induced IL-8 expression in human hepatic stellate cells. FASEB Journal, 21, 855.8

Harman, D. (1956). Aging: a theory based on free radical and radiation chemistry. Journal of Gerontology, 11, 298-300.

Harri, M., Kasai, H., Mori, T., Tornaeus, J., Savela, K., \& Peltonen, K. (2007). Analysis of 8-hydroxy-2'-deoxyguanosine in urine using high performance liquid chromatography-electrospray tandem mass spectrometry. Journal of Chromatography. B, Analytical Technologies in the Biomedical and Life Sciences, 853(1-2), 242.246. 
Hassan, H. M., \& Schrum, L. (1994). Roles of manganese and iron in the regulation of the biosynthesis of manganese-superoxide dismutase in Escherichia coli. FEMA Microbiology Reviews, 14(4), 315-323.

Helliwell, B. (1996). Oxidative stress, nutrition and health, experimental strategies for optimization of nutritional antioxidant intake in humans. Free Radical Res., 25, 57-74.

Higdon, J. V. and Frei, B. (2003). Obesity and Oxidative Stress. Arteriosclerosis, Thrombosis, and Vascular Biology, 23, 365-367.

Hitchler, M. J., Oberley, L. W., \& Domann, F. E. (2008). Epigenetic silencing of SOD2 by histone modifications in human breast cancer cells. Free Radical Biology and Medicine, 45(11), 1573-1580.

Hitchler, M. J., Wikainapakul, K., Yu, L., Powers, K., Attatippaholkun, W., \& Domann, F. E. (2006). Epigenetic regulation of manganese superoxide dismutase expression in human breast cancer cells. Epigenetics, 1(4), 163-171.

Huffman, F., Serge, T., \& Himburg, S. (2007). Diabetes indicators in Haitian adults in Miami-Dade County. FASEB Journal, 21, 828.4.

Huffman, F. G., De La Cera, M., Vaccaro, J. A., Zarini, G. G., Exebio, J., Gundupalli, D. \& Shaban, L. (2011). Healthy Eating Index and Alternate Healthy Eating Index among Haitian Americans and African Americans with and without T2D. Journal of Nutrition and Metabolism, vol. 2011, Article ID 398324, 8 pages, 2011. doi:10.1155/2011/398324

Huffman, F. G., Vaccaro, J., Ajabshir, S., Zarini, G. G., Exebio, J., \& Dixon, Z. (2013). Perceived stress and self-rated health of Haitian and African Americans with and without T2D. Journal of Research in Medical Sciences, 18, 198-204.

Ishikawa, T., Fujioka, H., Ishimura, T., Takenaka, A., \& Fujisawa, M. (2007). Increased testicular 8-hydroxy-2'-deguanosine in patients with varicocele. BJU International, 100(4), 863-866.

Ishikawa, T., Yaginuma, Y., Hayashi, H., Shimizu, T., Endo, Y., \& Taniguchi, N. (1990). Reactivity of a monoclonal antibody to manganese superoxide dismutase with human ovarian carcinoma. Cancer Research, 50(8), 2538-2542.

Isik, B., Ceylan, A., \& Isik, R. (2007). Oxidative stress in smokers and nonsmokers. Inhalation Toxicology, 19(9), 767-769. 
Izandi, N., Malek, M., Aminian, O., \& Saraei, M. (2013). Medical risk factors of diabetes mellitus among professional drivers. Journal of Diabetes and Metabolic Disorders, 12(1), 23-26.

Jagetia, G. C., \& Aggarwal B. B. (2007). "Spicing up" of the immune system by curcumin. Journal of Clinical Immunology, 27, 19-35.

Jamil, D., Al-Aubaidy, H., Al-Wasiti, E., \& Al Bayati, M. (2014). Evaluating Markers of Oxidative Stress in Managing Gestational Diabetes Mellitus: A Cross Sectional Study in Iraq. British Journal of Medicine \& Medical Research, 4(21), 3870-3877.

Jat, D., Parihar, P., Kothari, S. C., \& Parihar, M. S. (2013). Curcumin reduces oxidative damage by increasing reduced glutathione and preventing membrane permeability transition in isolated brain mitochondria. Cellular and Molecular Biology, 59 Suppl: OL1899-905.

Johnston, J. W., Pimple, I., Harding, K., \& Benson, E. E. (2010). Detection of 8hydroxy-2-deoxyguanosine as a marker of oxidative damage in DNA and germplasm exposed to cryogenic treatments. Cryo Letters, 31(1), 1-13.

Junqueira, V. B., Barros, S. B., Chan, S., Rodrigues, L., Giavarotti, L., Abud, R., \& Deucher, G. (2004). Aging and oxidative stress. Molecular Aspects of Medicine, 25(1-2), 5-26.

Jun, H. S., Kim, I. K., Lee, H. J., Kang, J. H., Kim, J. R., \& Shin, H. D. (2009). Effects of UCP2 and UCP3 variants on the manifestation of overweight in Korean Children. Obesity, 17(2), 355-362.

Kallio, P., Kolehmainen, M, L., Ksonen, D.E., Keka“la“inen, J., Salopuro, T., Sivenius, K., Pulkkinen, L., Mykkänen, H. M., Niskanen, L., et al. (2007). Dietary carbohydrate modification induces alterations in gene expression in abdominal subcutaneous adipose tissue in persons with the metabolic syndrome: The FUNGENUT Study 1-4. The American Journal of Clinical Nutrition, 85, 1417-1427.

Kaminski, M. M., Roth, D., Sass, S., Sauer, S. W., Krammer, P. H., \& Gulow, K. (2012). Manganese superoxide dismutase: A regulator of T cell activation-induced oxidative signaling and cell death. Biochimica et Biophysica Acta, 1823(5), 1041-1052.

Kannan K., \& Jain, S. K. (2000). Oxidative stress and apoptosis. Pathophysiology, 7(3), 153-163.

Karter, A. J., Ferrara, A., Liu, J. Y., Moffet, H. H., Ackerson, L. M., \& Selby J. V. (2002). Ethnic disparities in diabetic complications in an insured population. Journal of American Medical Association, 287, 2519-2527. 
Kato, A., Odamaki, M., \& Hishida, A. (2003). Blood 8-hydroxy2 'deoxyguanosine is associated with erythropoietin resistance in haemodialysis patients. Nephrology, Dialysis, and Transplantation, 18, 931-936.

Kazi, T. G., Afridi, H. I., Kazi, N., Jamali, M. K., Arain, M. B., Jalbani, N., \& Kandhro, G. A. (2008). Copper, chromium, manganese, iron, nickel, and zinc levels in biological samples of diabetes mellitus patients. Biological Trace Elements Research, 122(1), 1-18.

Kelley, D. E., He, J., Menshikova, E. V., \& Ritov, V. B. (2002). Dysfunction of mitochondria in human skeletal muscle in T2D. Diabetes, 51(10), 29442950 .

Khadem-Ansari, M., Shahsavari, Z., Rasmi, Y., \& Mahmoodlo, R. (2011). Elevated levels of urinary 8-hydroxy-2'-deoxyguanosine and 8isoprostane in esophageal squamous cell carcinoma. Journal of Carcinogenesis, 10, 14.

Khan, S., Raghuram, G. V., Bhargava, A., Pathak, N., Chandra, D. H., Jain, S. K., Mishra, P. K. (2011). Role and clinical significance of lymphocyte mitochondrial dysfunction in T2D mellitus. Translational Research, 8(6), 344-358.

Kikuchi, A., Takeda, A., Onodera, H., Kimpara, T., Sato, N., Nunomura, A., Castellani, R. J., Perry, G., Smith, M. A., \& Itoyama, Y. (2002). Systemic increase of oxidative nucleic acid damage in Parkinson's disease and multiple system atrophy. Neurobiological Disease, 9(2), 244-248.

Kim, G., \& Caprio, S. (2011). Diabetes and insulin resistance in pediatric obesity. Pediatric Clinics of North America, 58(6), 1355-1361.

Kirk J.K., D'Agostino R.B., Jr, Bell R.A., Passmore L.V., Bonds D.E., Karter A.J., Narayan K.M. (2006). Disparities in A1C levels between AfricanAmerican and non-Hispanic white adults with diabetes: a meta-analysis. Diabetes Care 29, 2130-2136.

Kiss, L., \& Szabo, C. (2005). The pathogenesis of diabetic complications: the role of DNA injury and poly (ADP-ribose) polymerase activation in peroxynitrite-mediated cytotoxicity. Memórias do Instituto Oswaldo Cruz, 100(Suppl. 1), 29-37.

Kowluru, R., Atasi, L., \& Ho, Y. (2006). Role of mitochondrial superoxide dismutase in the development of diabetic retinopathy. Investigative Ophthamology and Visual Science, 47(4), 1594-159. 
Kozirog, M., Poliwczak, A., Duchnowicz, P., Koter-Michalak, M., Sikora, J., \& Broncei, M. (2010). Melatonin treatment improves blood pressure, lipid profile, and parameters of oxidative stress in patients with metabolic syndrome. Journal of Pineal Research (Wiley Online Library). Retrieved from http://onlinelibrary.wiley.com/doi/10.1111/j.1600079X.2010.00835.x/full

Kumar, P. R., Bhansali, A., Ravikiran, M., Bhansali, S., Dutta, P., Thakur, J. S., Sachdeva, N., Bhadada, S. K., and Walia, R. (2010). Utility of glycated hemoglobin in diagnosing T2D mellitus: a community-based study. Journal of Clinical Endocrinology and Metabolism, 95(6), 2832-2835.

Landete, J. M. (2013). Dietary intake of natural antioxidants: vitamins and polyphenols. Critical Reviews in Food Science and Nutrition, 53(7), 706-721.

Larsen, S., Stride, N., Hey-Mogensen, M. Hansen, C. N., Anderson, J. L., Madsbad, S., et al. (2011). Increased mitochondrial substrate sensitivity in skeletal muscle of patients with T2D. Diabetologia, 54(6), 1427-1436.

Larsen, T. M., Stine-Mathilde, D., Van Baak, M., Jebb, S.A., Papadaki, A., et al. (2010). Diets with High or Low Protein Content and Glycemic Index for Weight-Loss Maintenance. New England Journal of Medicine, 363(1), 2102-2113.

Lee, E. S., Corfe, B. M., \& Powers, H. J. (2013). Riboflavin depletion of intestinal cells in vitro leads to impaired energy generation and enhanced oxidative stress. European Journal of Nutrition, 52(5), 1513-1521.

Lee, S. F., \& Pervaiz, S. (2011). Assessment of oxidative stress-induced DNA damage by immunoflourescent analysis of 8-OxodG. Methods in Cell Biology, 103, 99-113.

Lemacks, J., Wells, B. A., Ilich, J. Z., \& Ralson, P. A. (2013). Interventions for Improving Nutrition and Physical Activity Behaviors in Adult African American Populations: A Systematic Review, January 2000 Through December 2011. Prevention of Chronic Disease, 10:120256. DOI: http://dx.doi.org/10.5888/pcd10.120256.

Li, C., \& Zhou, H. M. (2011). The role of manganese superoxide dismutase in inflammation defense. Enzyme Research, V2011, article ID 387176, 6 pages.

Lin Y., Kikuchi, S., Obata, Y., \& Yagyu, K. A case-control study exploring the role of serum manganese superoxide dismutase (MnSOD) levels in gastric cancer. Journal of Epidemiology, 15(3), 90-95. 
Liburd, L. C. (2003). Food, Identity, and African American Women with T2D: An Anthropological Perspective. Diabetes Spectrum, 16(3), 160-165.

Liutkeviciene, R., Lesauskaite, V., Asmoniene, V., Zaliūniene, D., \& Jasinskas, V. (2010). Factors determining age-related macular degeneration: A current view. Medicina, 46(2), 89-94.

Lin, Y., Kikuchi, S., Obata, Y., \& Yagyu, K. (2005). A case-control study exploring the role of serum manganese superoxide dismutase (MnSOD) levels in gastric cancer. Journal of Epidemiology, 15(3), 90-95.

Loft, S., Vistisen, K., Ewertz, M, Tjonneland, A., Overvad, K., and Poulsen, H.E. (1992). Oxidative DNA damage estimated by 8 hydroxydeguanosine excretions in humans: influence of smoking, gender, and body mass index. Carcinogenesis, 13(12), 2241-2247.

Looker, H. C., Knowler, W. C., \& Hanson, R. L. (2001). Changes in BMI and Weight Before and After the Development of T2D. Diabetes Care, 24(11), 1917-1922.

Luke, A., Durazo-Arvizu, R., Rotimi, C., Prewitt, T. E., Forrester, T., Wilks, R., Ogunbiyi, O. J., Schoeller, D. A., McGee, D., and Cooper, R. S. (1997). Relationship between Body Mass Index and Body Fat in Black Population Samples from Nigeria, Jamaica, and the United States. American Journal of Epidemiology, 155(7), 620-628

Lumini, J., Magalhaes, J., Oliveira, P., \& Ascensao, A. (2008). Beneficial effects of exercise on muscle mitochondrial function in diabetes mellitus. Sports Medicine, 38(9), 7335-7350.

Madsen-Bouterse, S. A., Zhong, Q., Mohammad, G., Ho, Y. S., \& Kowluru, R. A. (2010). Oxidative damage of mitochondrial DNA in diabetes and its protection by manganese superoxide dismutase. Free Radical Research, 44(3), 313-321.

Manickam, B., Neagu, V., \& Barengolts, E. (2013). Relationship between glycated hemoglobin and circulating 25-hydroxyvitamin D concentration in African American and Caucasian American men. Endocrine Practice, 19(1), 73-80.

Marling, C. R., Shubrook, J. H., Vernier, S. J., Wiley M. T., \& Schwartz, F. L. (2011).Characterizing blood glucose variability using new metrics with continuous glucose monitoring data. Journal of Diabetes Science and Technology, 5(4), 871-878.

Martin-Timon, I., Sevillano-Collantes, S., Sergura-Galindo, A. \& del CanizoGomez, F. J. (2014). T2D and cardiovascular disease: Have all risk factors the same strength? World Journal of Diabetes, 5(4), 444-470. 
Martini, L., Catania, A., \& Ferreira, S. (2010). Role of vitamins and minerals in prevention and management of T2D mellitus. Nutrition Reviews, 68(6), 341-354.

McCullough, M. L., Feskanich, D., Stampfer, M. J., Giovannucci, E. L., Rimm, E. B., Hu, F. B., et al. (2002). Diet quality and major chronic disease risk in men and women: moving toward improved dietary guidance. American Journal of Clinical Nutrition, 76(6), 1261-1271.

Mayor, S. (2007). International Diabetes Federation consensus on prevention of T2D. International Journal of Clinical Practice, 61(10); 1773-1775.

Miller, J., Chu, Y., Brooks, R., Richenbacher, W., Pena-Silva, R., \& Heistad, D. (2008). Dysregulation of antioxidant mechanisms contributes to increased oxidative stress in calcific aortic valvular stenosis in humans. Journal of American College of Cardiology, 52(10), 843-850.

Miph, V., der Ploeg, H. V., Cheung, N., Dphil, R. H., \& Bauman, A. (2008). Sociodemographic correlates of the increasing trend in prevalence of gestational diabetes in a large population of women between 1995 and 2005. Diabetes Care, 31(12), 2288-2293.

Miriyala, S., Spasojevic, I., Tovmasyan, A., Salvemini, D., Vujaskovic, Z., St. Claire, D., \& Batinic-Heberle, I. (2012). Antioxidants and antioxidant treatment in disease. Biochemica and Biochemica Acta, 1822(5), 794814.

Moller, P., Wallin, H., \& Knudsen, L. E. (1996). Oxidative stress associated with exercise, psychological stress and life-style factors. ChemicoBiological Interactions, 102(1), 17-36.

Moller, P. \& Loft, S. (2002). Oxidative DNA damage in human white blood cells in dieatry antioxidant intervention studies. The American Journal of Clinical Nutrition, 76(2), 303-310.

Montonen, J., Järvinen, R., Knekt, P., \& Reunanen, A. (2004). Dietary antioxidant intake and risk of T2D. Diabetes Care, 27, 362-366.

Morris, M.C., Evans, D. A., Bienias, J. L., Tangney, C. C., Bennett, D. A., Aggarwal, N., Wilson, R. S., and Scherr, P. A. (2002). Dietary Intake of Antioxidant Nutrients and the Risk of Incident Alzheimer Disease in a Biracial Community Study. Journal of American Medical Association, 287(24), 3223-3261.

Morris, A. A., Zhao, L., Patel, R. S. , Jones, D. P., Ahmed, Y., Stoyanova, N. , Gibbons, G. H., Vaccarino, V., Din-Dzietham, R., \& Quyyumi, A. A. (2012). Differences in system oxidative stress based on race and the metabolic syndrome: the Morehouse and Emory Team up to Eliminate 
Health Disparities (META-Health) study. Metabolic Syndrome Related Disorders, 10(4), 252-259.

Mullner, E., Brath, H., Pleifer, S., Schiemayr, Baierl, A. et al. (2013). Vegetables and PUFA-rich plant oil reduce DNA strand breaks in individual with T2D. Molecular Nutrition and Food Research, 57(2), 328-338.

Nakhjavani, M., Morteza, A., Meysamie, A., Esteghamati, A., Khalilzadeh, O., et al. (2010). Serum heat shock protein 70 and oxidized LDL in patients with T2D: does sex matter? Cell Stress and Chaperones, 16(2), 195-201.

Nishidi, T., Sugiyama, T., Kataoka, A., Tashiro, M., Yakushiji, M., \& Isahikawa, M. (1993). Serum manganese superoxide dismutase (MnSOD) and histological virulence of ovarian cancer. Asia Oceania Journal of Obstetric and Gynecology, 19(4), 427-431.

National Cholesterol Education Program. (2011). National Institute of Health homepage. Retrieved from http://www.nhlbi.nih.gov/index.htm

Niki, E. (2013). Role of vitamin E as a lipid-soluble peroxyl radical scavenger: in vitro and in vivo evidence. Free Radical Biology and Medicine, 66, 312.

Nishida, T., Sugiyama, T., Kataoka, A., Tashior, M., Yakushiji, M., and Ishikawa, M. (1993). Serum manganese superoxide dismutase (MnSOD) and histological virulence of ovarian cancer. Asia Oceania Journal of Obstetrics and Gynecology, 19(4), 427-431.

O'Brien, J. A., Patrick, A. R., \& Caro, J. (2000). Estimates of direct medical costs for microvascular and macrovascular complications resulting from T2D mellitus in the United States in 2000. Clinical Therapeutics, 25, 1017-1038.

O'Connor, P. J., Bodkin, N. L., Fradkin, J., Glasgow, R. E., et al. (2011). Diabetes performance measures: Current status and future directions. Diabetes Care, 34(7), 1651-1659.

Ofili, E. (2001). Ethnic disparities in cardiovascular health. Ethnicity and Disease, 11(4), 838-840.

Olendzki, B. C., Ma, Y., Hebert, J. R., Pagoto, S. L., Merriam, P. A., Rosal, M. C., \& Ockene, I. S. (2008). Underreporting of energy intake and associated factors in a Latino population at risk of developing T2D. Journal of American Dietetic Association, 108(6), 1003-1008.

Omori, K., Ohira, T., Uchida, Y., Ayilavarapu, S., Batista, E., Yagi, M., et al. (2008). Priming of neutrophil oxidative burst in diabetes requires 
preassembly of the NADPH oxidase. Journal of Leukocyte Biology, 84(1), 292-301.

Osawa, T., \& Kato, Y. (2005). Protective role of antioxidative food factors in oxidative stress caused by hyperglycemia. Annals of the New York Academy of Science, 1043, 440-451.

Otsu, K., Ikeda, Y., \& Fujii, J. (2004). Accumulation of manganese superoxide dismutase under metal-depleted conditions: proposed role of zinc ions in cellular redox balance. Biochemical Journal, 377(1), 241-248.

Pacifico, L., Anania, C., Osborn, J. F., Ferraro, F., Bonci, E., Olivero, E., et al. (2011). Low 25(OH)D3 levels are associated with total adiposity, metabolic syndrome, and hypertension in Caucasian children and adolescents. European Journal of Endocrinology, 161(5), 603-611.

Pagano, G., Talamanca, A. A., Castello, G., Cordero, M. D., d'Ishia, M., et al. (2014). Oxidative Medicine and Cellular Longevity, vol. 2014, Article ID 541230, 27 pages, 2014. doi:10.1155/2014/541230

Palmeira, C., Rolo, A., Berthiaume, J., Bjork, J., \& Wallace, K. (2007). Hyperglycemia decreases mitochondrial function: the regulatory role of mitochondrial biogenesis. Toxicology and Applied Pharmacology, 225(2), 214-220.

Pan, H. Z., Zhang, H., Chang, D., Li, H., \& Sui, H. (2008). The change of oxidative stress products in diabetes mellitus and diabetic retinopathy. British Journal of Ophthamology, 92(4), 548-551.

Pan, W. H., Flegal, K. M., Chang, W. Y., Yeh, W. T., Yeh, C. J., and Lee, W.C. (2004). Body mass index and obesity-related metabolic disorders in Taiwanese and US whites and blacks: implications for definitions of overweight and obesity for Asians. American Journal of Clinical Nutrition, 79(1), 31-39.

Park, K.S., Kim, J.H., Kim, M.S., Kim, J.M., Kim, S.K., et al. (2001). Effects of Insulin and Antioxidant on Plasma 8-Hydroxyguanine and Tissue 8Hydroxydeoxyguanosine in Streptozotocin-Induced Diabetic Rats. Diabetes, 15(12), 2837-2841.

Patel, P. R., Bevan R. J., Mistry, N., \& Lunec, J. (2007). Evidence of oligonucleotides containing 8-hydroxy-2'-deoxyguanosine in human urine. Free Radical and Biological Medicine, 42(4), 552-558.

Pereira, E., Ferderbar, S., Bertolami, M., Faludi, A., Monte, O., Xavier, H., et al. (2008). Biomarkers of oxidative stress and endothelial dysfunction in glucose tolerance and diabetes mellitus. Clinical Biochemistry, 41(18), 1454-1460. 
Phillips, M., Cataneo, R. N., Cheema, T, \& Greenberg, J. (2004). Increased breath biomarkers of oxidative stress in diabetes mellitus. Clinica Chimica Acta, 344, 189-194.

Pitocco, D., Zaccardi, F., Di Stasio, E., Romitelli, F., Santini, S.A., Zuppi, C., \& Ghirlanda, G. (2010). Oxidative stress, nitric oxide, and diabetes. The Review of Diabetic Studies, 7(1), 15-25.

Poljsak, B. \& Fink, R. (2014). The protective role of antioxidants in the defence against ROS/RNS-mediated environmental pollution. Oxidative Medicine and Cellular Longevity, vol. 2014, Article ID 671539, 22 pages, 2014. doi:10.1155/2014/671539

Pun, P. B. L. \& Murphy, M. P. (2012). Pathological Significance of Mitochondrial Glycation," International Journal of Cell Biology, vol. 2012, Article ID 843505, 13 pages, 2012. doi:10.1155/2012/843505

Pryor, W.A. (1997). Cigarette smoking radicals and the role of free radicals in chemical carcinogenicity. Environmental Health Perspect, 105(1), 875882 .

Pylvas, M., Puistola, U., Laatio, L., Kauppila, S., \& Karihtala, P. (2011). Elevated serum 8-OHdG is associated with poor prognosis in epithelial ovarian cancer. Anticancer Research, 31(4), 1411-1415.

Racial and Ethnic Health Disparities in Miami-Dade County. (2008). Retrieved from http://www.dadehealth.org/downloads/Racial and Ethnic Health Disparities in Miami-Dade.pdf

Rains, J. L., \& Jain, S. K. (2011). Oxidative stress, insulin signaling, and diabetes. Free Radical Biology and Medicine, 50(5), 567-575.

Ramos, L. F., Shintani, A., Ikizler, T. A., and Himmelfarb, J. (2008). Oxidative Stress and Inflammation Are Associated with Adiposity in Moderate to Severe CKD. Journal of American Society of Nephrology, 19(30), 593599.

Reddi, A. G., \& Culotta, V. C. (2011). Regulation of manganese antioxidants by nutrient sensing pathways in saccharomyces cerevisiae. Genetics (epublication, ahead of print copy).

Ren, C. J., Zhang, Y., Cui, W. Z., \& Mu, Z. M. (2013). Progress in the role of oxidative stress in the pathogenesis of T2D. Acta Physiologica Sinica, 65(6), 664-673.

Rhee, M. K., Cook, C. B., Dunbar, V. G., Panayioto, R. M., Berkowitz, K. J., Boyd, B. G., George, C. D., Lyles, R. H., El-Kebbi, I. M., \& Phillips, L.S. (2005). Limited health care access impairs glycemic control in low 
income urban African Americans with T2D. Journal of Health Care for the Poor and Underserved, 16, 734-746.

Richard, P., Alexandre, P. K., Lara, A., Akamigbo, A. B. (2011). Racial and ethnic disparities in the quality of diabetes care in a nationally representative sample. Preventing Chronic Disease, 8(6), A142.

Rolo, A., \& Palmeira, C. (2006). Diabetes and mitochondrial function: Role of hyperglycemia and oxidative stress. Toxicology and Applied Pharmacology, 212(2), 167-178.

Rosen, A., Sharpe, I., Rosen, J., Doddard, M., \& Abad, M. (2007). The prevalence of T2D in the Miami-Haitian community. Ethnicity and Disease, 7, S3-S4.

Ruchko, M. K., Gorodnya, O. M., Zuleta, A., Pastukh, V. M., \& Gillespie, M. N. (2011). The DNA glycosylase Ogg1 defends against oxidant-induced mtDNA damage and apoptosis in pulmonary artery endothelial cells. Free Radical Biology and Medicine, 50(9), 1107-1113.

Sadi, G., Eryilmaz, N., Tütüncüoğlu, E., Cingir, S., \& Güray, T. (2011). Changes in expression profiles of antioxidant enzymes in diabetic rat kidneys. Diabetes/Metabolism Research and Reviews (epublication, ahead of print copy). doi:10.1002/dmrr.1302

Saedisomeolia, A., Taheri, E., Djalali, M., Qorbani, M., Rajab, A., \& Larijani, B. (2013). Vitamin D status and its association with antioxidant profiles in diabetic patients: A cross-sectional study in Iran. Indian Journal of Medical Sciences, 67(1), 29-37.

Saleh, M. C., Wheeler, M. B., \& Chan, C. B. (2002). Uncoupling protein-2: evidence for its function as a metabolic regulator. Diabetologia, 45, 174187.

Salem, S.I., El-Toukhy, S.E., El-Saeed, G.S, and El-Wassef, M. (2012) Correlation of DNA damage in T2D to glycemic control. Egyptian J of Hosp Med, 48, 472-482.

Samuel-Hodge, C. D., Fernandez, L. M., Henriquez-Roldan, C. F., Johnston, L. F., \& Keyserling, T. C. (2004). A Comparison of Self-Reported Energy Intake with Total Energy Expenditure Estimated by Accelerometer and Basal Metabolic Rate in African American Women with T2D. Diabetes Care, 27(3), 663-669.

Savini, I., Catani, M. V., Evangelista, D., Gasperi, V., and Avigliano, L. (2013). Obesity-Associated Oxidative Stress: Strategies Finalized to Improve Redox State. International Journal of Molecular Sciences, 14, 1049710538. 
Schadendor, D., Zuberbier, T., Diehl, S., Schadendorf, C., and Czametzki, B. M. (1995). Serum manganese superoxide dismutase is a new tumor marker for malignant melanoma. Melanoma Research, 5(5), 351-353.

Schramm, M., Wiegmann, K., Schramm, S., Gluschko, A., Herb, M., Utermohlen, O., Kronke, M. (2013). Riboflavin (vitamin B2) deficiency impairs NADPH oxidase 2 (Nox2) priming and defense against listeria monocytogenes. European Journal of Immunology (Wiley Online Library), retrieved from http://onlinelibrary.wiley.com/doi/10.1002/eji.201343940/full

Serrano, N .C., Díaz, L. A., Casas, J. P., Hingorani, A.D., Moreno de Lucca, D., \& Páez, M. C. (2010). Frequency of eNOS polymorphisms in the Colombian general population. BMC Genetics, 20, 11, 54.

Shai, I., Jiang, R., and Manson, J. E., Stampfer, M. J., Willett, W. C., Colditz, G. A., and Hu, F. B. (2006). Ethnicity, obesity, and risk of T2D in women: a 20 year follow-up study. Diabetes Care, 29(7), 1585-1590.

Shen, X., Zheng, S., Metreveli, N. S., and Epstein, P. N. (2006). Protection of Cardiac Mitochondria by Overexpression of MnSOD Reduces Diabetic Cardiomyopathy. Diabetes, 55(3), 798-805.

Siddiqi, Z., Tiro, J. A., \& Shuval, K. (2011). Understanding impediments and enablers to physical activity among African American adults: A systematic review of qualitative studies. Health Education Research, 26(6), 1010-1024.

Siedlak, S. L., Cassadeus, G., \& Perry, G. (2009). Chronic antioxidant therapy reduces oxidative stress in a mouse model with Alzheimer's disease. Free Radical Research, 43(2), 156-164.

Skelly, A. H., Carlson, J., Leeman, J., Soward, A., \& Burns, D. (2009). Controlled Trial of Nursing Interventions to Improve Health Outcomes of Older African American Women with T2D. Nurse Research, 58(6), 410418.

Soini, Y., Turpeenniemi-Hujanen, T., Kärjä, V., Karihtala, P. (2011). 8hydroxydeguanosine and nitrotyrosine are prognostic factors in urinary bladder carcinoma. International Journal of Clinical and Experimental Pathology, 4(3), 267-275.

Soper, D. S. (2011) A-priori sample size calculator for multiple regression [Online software]. Retrieved from http://www.danielsoper.com/statcalc3

Suksomboon, N., Poolsup, N., \& Sinprasert, S. (2011). Effects of vitamin E supplementation on glycemic control in T2D: Systematic review of 
randomized controlled trials. Journal of Clinical Pharmacy and Therapeutics, 36(1), 53-63.

Suzuki, S., Hinokio, Y., Toyota, T., Komatu, K., Ohtomo, M., Onoda, M., et al. (1999). Oxidative damage to mitochondrial DNA and its relationship to diabetic complications. Diabetes Research and Clinical Practice, 45(23), 161-168.

Suzuki, H., Usui, I., Kato, I., Oya, T., Kanatani, Y., Yamazaki, Y., Fujisaka, S., Senda, S., Ishi, Y., Urakaze, M., Mahmood, A., Takasawa, S., Okamoto, H., Kobayashi, M., Tobe, I., \& Sasahara, M. (2001). Deletion of plateletderived growth factor receptor- $\beta$ improves diabetic nephropathy in $\mathrm{Ca}^{2+} /$ calmodulin-dependent protein kinase II $\alpha$ (Thr286Asp) transgenic mice. Diabetologia, 54(11), 2953-2962.

Tamai, T., Uto, H., Takami, Y., Oda, K., Saishoji, A., Hashiquchi, M., Kumagai, K., et al. (2011). Serum manganese superoxide dismutase and thioredoxin are potential prognostic markers for hepatitis $\mathrm{C}$ virus-related hepatocellular carcinoma. World Journal of Gastroentrology, 17(44), 4890-4898.

Tan, X., Poulose, E. M., Raveendran, V. A., Zhu, B. T., Stechschulte, D. J., \& Dileepan, K. N. (2011). Regulation of the expression of cyclooxygenases and production of prostaglandin I and $\mathrm{E}$ in human coronary artery endothelial cells by curcumin. Journal of Physiology and Pharmacology, 62(1), 21-28.

Tuomilehto, J., Schwarz, P., \& Lindstrom, J. (2011). Long-Term Benefits From Lifestyle Interventions for T2D Prevention. Diabetes Care, 34(2), 210214.

United States Department of Commerce. (2009). United States Census Bureau. Retrieved from http://census.gov

Unnikrishnan, R., Anjana, R. M., and Mohan, V. (2012). Drugs affecting HbAlc levels. Indian Journal of Endocrinology and Metabolism, 16(4), 528-531.

Vanuzzo, D., Pilotto, L., Mirolo, R., \& Pirelli, S. (2008). Cardiovascular risk and cardiometabolic risk: An epidemiological evaluation. Giornale Italiano di Cardiologia, 9(4 Suppl. 1), 6S-S17.

Van Voorhis, W., \& Morgan, B. L. (2007). Understanding power and rules of thumb for determining sample sizes. Tutorials in Quantitative Methods for Psychology, 3(2), 43-50.

VanEewyk, J. (2010). Guidelines for Using Racial and Ethnic Groupings in Data Analyses. State Epidemiologist for Non-Infectious Conditions. 
Revision Date: April 30, 2010. Retrieved from:

http://www.doh.wa.gov/Portals/1/Documents/5500/RaceEthnGuidelines. pdf

Vimalananda, V.G., Rosenzweig, J.L., Cabral, H.J., David, M.M., and Lasser, K.E. (2011). Comparison of Diabetes Control Among Haitians, African Americans, and Non-Hispanic Whites in an Urban Safety-Net Hospital. Diabetes Care, 34(1), 58-60.

Vina, J., Gambini, J., Lopez-Gueso, R., Abdelaziz, K. M., Jove, M., \& Borras, C. (2011). Females live longer than males: a role of oxidative stress. Current Pharmaceutical Design, 17(36), 3959-3965.

Warolin, J., Coenen, K. R., Kantor, J. L., Whitaker, L. E., Wang, L., Acra, S. A., Roberts, L. J. $2^{\text {nd }}, \&$ Buchowski, M. S. The relationship of oxidative stress, adiposity, and metabolic risk factors in healthy Black and white American youth. Pediatric Obesity, 9(1), 43-52.

Walter Jr., R. M., Uriu-Hare, J. Y., Olin, K. L., Oster, M. H., Anawalt, B. D., Critchfield, J. W., and Keen, C. L. (1991). Copper, Zinc, Manganese, and Magnesium Status and Complications of Diabetes Mellitus. Diabetes Care, 14(11), 1050-1056.

Watters, J. L., Satia, J. A., \& Kupper, L. L. (2008). Correlates of antioxidant nutrients and oxidative DNA damage differ by race in a cross-sectional study of healthy African American and white adults. Nutrition Research, 28(9), 565-576.

Watters, J. L., Satia, J. A., Kupper, L. L., Swenberg, J. A., Schroeder, J. C., \& Switzer, B. R. (2007). Associations of Antioxidants Nutrients and oxidative DNA damage in healthy African American and White adults. Cancer, Epidemiology, Biomarkers and Prevention, 16, 1428-1436.

Wegner, M., Rawluszko-Wieczorek, A. A., Piorunska-Stolzmann, M., Zozulinksa-Zolkiewicz, d., Wierusz-Wysocka, B. \& Jagodzinski, P. (2014). Expression of mitochondrial superoxide dismutase in polymorphonuclear leukocytes from type 1 diabetes patients with and without microvascular complications. Polskie Archiwum Medycyny Wewnetrznej, 2014 Apr 15 [Epub ahead of print].

Weissenberger, J., Priester, M., Bernreuther, C., Rakel, S., Glatzel, M., Seifert, V., \& Kögel, D. (2010). Dietary curcumin attenuates glioma growth in a syngeneic mouse model by inhibition of the JAK1,2/STAT3 signaling pathway. Clinical Cancer Research, 16(23), 5781-5795.

Wen, X., Wu, J., Wang, F., Liu, B., Huang, C., \& Wei, Y. (2013). Deconvoluting the role of reactive oxygen species and autophagy in human disease. Free Radical Biology and Medicine, 65(1), 401-410. 
West, I. (2000). Radicals and oxidative stress in diabetes. Diabetic Medicine, 17, 171-180.

Whaley-Connell, A. \& Sowers, J.R. (2012). Oxidative stress in the cardiorenal metabolic syndrome. Current Hypertension Reports, 14(4), 360-365.

WHO. World Health Organization Fact Sheet for World Wide Prevalence of Obesity. Retrieved from www.who.int/mediacentre/factsheets/fs311/en/indexhtml (accessed on June 23rd, 2014).

Willet, W. C., Sampson, L., Stampfer, M. J., Rosner, B., Bain, C., Witschi, J., Hennekens, H., \& Speizer, F. E. (1985). Reproducibility and validity of a semi quantitative food frequency questionnaire. American Journal of Epidemiology, 122, 51-65.

Wonisch, W., Falk, A., Sundl, I., Winklhofer-Roob, B. M., \& Lindschinger, M. (2012). Oxidative stress increases continuously with BMI and age with unfavourable profiles in males. The Aging Male, 15(3), 159-185.

Wright, E. Jr., Scism-Bacon, J. L., \& Glass, L. C. (2006). Oxidative stress in T2D: the role of fasting and postprandial. International Journal of Clinical Practice, 60(3), 308-314.

Wu, L., Chiou, C., Chang, P., \& Wu, J. (2004). Urinary 8OHdG: A marker of oxidative stress to DNA and risk factor for cancer, atherosclerosis and diabetes. Clinica Chimica Acta, 339(1-2), 1-9.

Xu, G., Yao, Q., Weng, Q., Su, B., Zhang, X., \& Xiong, J. (2004). Study of urinary 8-hydroxydeoxyguanosine as a biomarker of oxidative DNA damage in diabetic nephropathy patients. Journal of Pharmaceutical and Biomedical Analysis, 36(1), 101-104.

Yoshida, M., Ogawa, Y., Kasai, H. (2003). Urinary 8-oxo-7, 8-dihydro- 2'deoxyguanosine values measured by an ELISA correlated well with measurements by high performance liquid chromatography with electrochemical detection. Cancer Epidemiology Biomarkers and Prevention, 11, 1076-1081.

Zhong, Q., \& Kowluru, R.A. (2011). Epigenetic changes in mitochondrial superoxide dismutase in the retina and the development of diabetic retinopathy. Diabetes, 60(4), 1304-1313.

Ziemer, D. C., Kolm, P., Weintraub, W. S., Vaccarino, V., Rhee, M. K., Twombly, J. G., Narayan, K. M., Koch, D. D., \& Phillips, L. S. (2010). Glucose-independent, black-white differences in hemoglobin A1c: a cross-sectional analysis of 2 studies. Annals of Internal Medicine, 152(12), 770-777. 
Zhu, H., Jia, Z., Misra, H., \& Li, Y. R. (2012). Oxidative stress and redox signaling mechanisms of alcoholic liver disease. Updated experimental and clinical evidence. Journal of Digestive Disease, 13(3), 133-142. 


\section{APPENDICES}

Appendix A: Recruitment Flyer (English version)

Appendix B: Recruitment Flyer (Creole version)

Appendix C: Florida International University IRB Approval

Appendix D: Form A- For Initial Submission for IRB Approval

Appendix E: IRB Exemption Memorandum

Appendix F: Harvard Food Frequency Questionnaire

Appendix G: Socio-demographic Questionnaire

Appendix H: Document to collect measured parameters

Appendix I Summary of study method 
APPENDIX A 


\title{
Cardiovascular Disease Risk Study \\ in Haitian \& African-American
}

You are invited to participate in a study conducted at Florida International

\author{
University \\ by Dr. Fatma G. Huffman
}

\section{Criteria to enroll:}

- You must be Haitian or African-American

- You must be 35 years old or older

- You must agree to give three tablespoons of blood to test glucose levels and other biochemical tests

- You must agree to give a urine sample

You will receive information on your diet, physical activity level, body mass index, blood pressure and laboratory blood analysis. The whole process generally takes 3 hours.

\section{You will receive \$ 75.00 upon completion of the study}

For information, please contact:

Dr. Fatma G. Huffman: 305-348-6427 or huffmanf@,fiu.edu 
APPENDIX B 


\section{Etid sou maladi Kadiovaskilè Lakay Ayisyen ak Afriken-Amériken}

Nou invité ou pou ou kapab patisipé nan yon étid Ké Dr. Fatma G. Huffman ap fè Nan Florida International Université

\section{Kondisyon pou kapab patisipé nan étid sa-a:}

- Ou sipozé Ayisyen ou byen Afriken-Amériken

- Ou sipozé genyen 35 ans ou plis

- Aksepté ké yo pran kèk gout san sou ou min-m pou yo kapab tchéké sik ou avèk lòt analiz nan san ou.

- Aksepté pou ou bay yon ti échantiyon pipi

Konsiltasyon a ap dire 3 zè de tan. Nan moman sa a,wap résévwa enfomasyon sou dayèt ou, enfomasyon sou aktivité fisik ou, enfomasyon sou tensyon ou, plis lòt résilta laboratwa.

Kòm rékompans wap résévwa $\$ 75$ pou patisipasyon ou

Pou plis enfomasyon sou étid la, ou kapab kontakté:

Dr. Fatma G. Huffman: 305-348-6427 or huffmanf@,fiu.edu Gustavo Zarini: 305-348-6427 or gzarini@hotmail.com Erskine Clerjeune: 786-355-4589 or eclerjeune@yahoo.com E. Nelson: 954-479-1150 or Enels002@fiu.edu 
APPENDIX C 


\section{MEMORANDUM}

Tw:

C.:

From:

Da1s:

Promesul Tifle:
Dr. l'acuta lJudtinum

Fìls

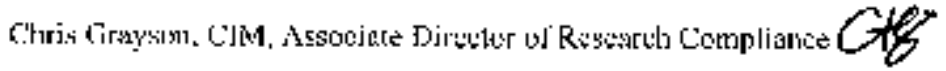

lil4i]li

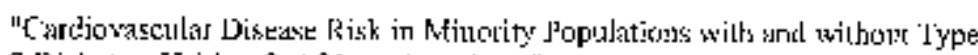
2 Disheles: Haitian \& Africar!-Amrnericun."

Approval \# 0ll210-60

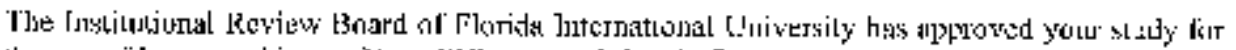

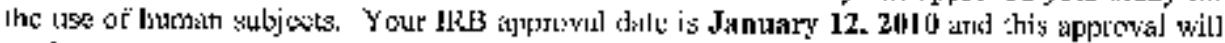

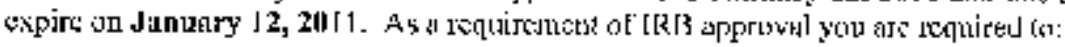

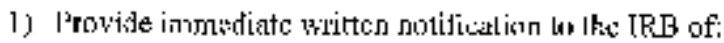

- Arry addilions to, ol changes in the proucedures involying human subjects,

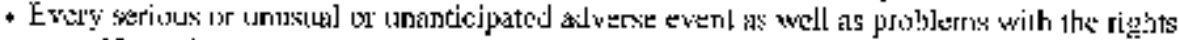

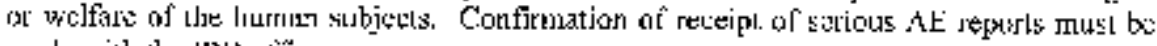

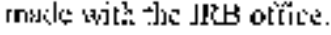

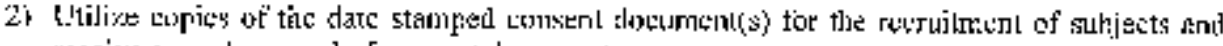

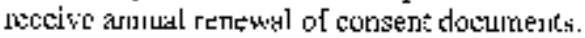

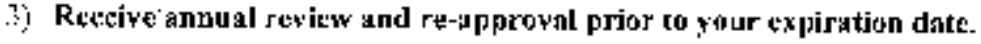

Spectal Conditions: inla

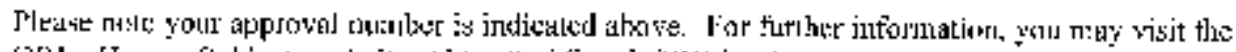

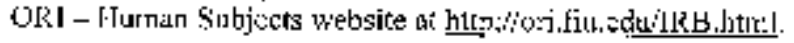


APPENDIX D 


\section{FIU \\ FLORIDA \\ Illi Appoval ti. \\ INTERNATIONAL \\ UNIVERSITY}

APPT,ICATION YOR APPROVAI. OF RESFAKCH LNVOLVIRG BUMAN S1TIJECTS

FORM A - FOR INITIAL SUBMISSION

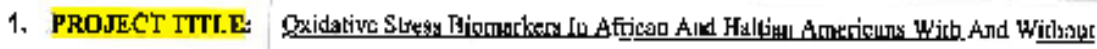

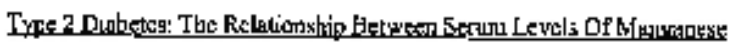

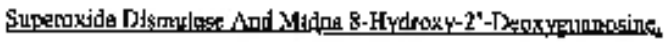

And Àntioxidanto

2. PRINCIPAL INVTSTIGATOR INFORMATTON

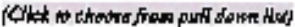

TIT VitTIE: MICHAEL A. MCLEAN

PT ?ivition: Grocuare Studomil

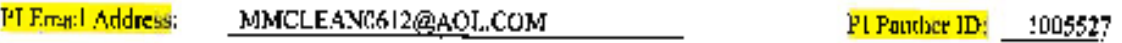

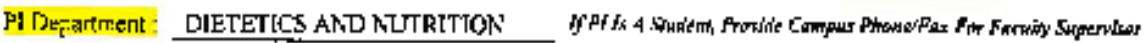

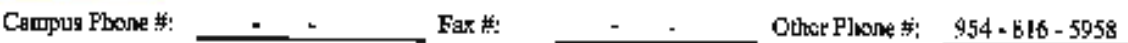

"TACUL'TY SUPERVISOR (If PI is a 8 tudenl or Non-FIL): FATMA G. TFUFFMAN

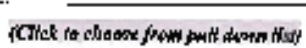

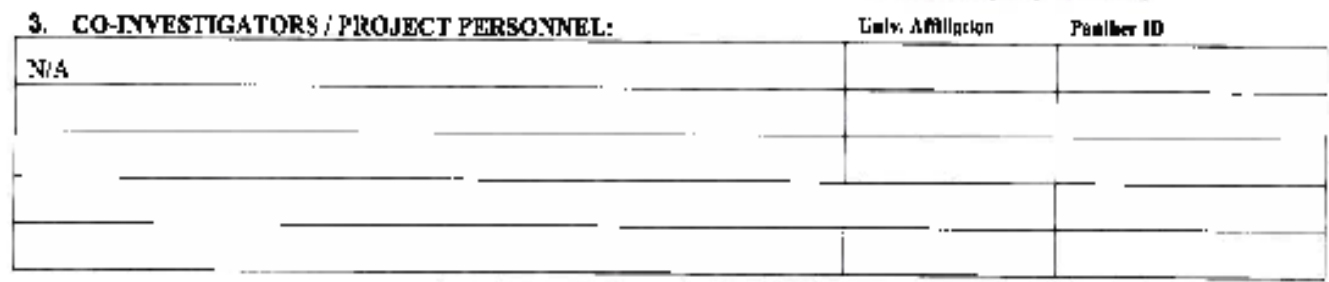

4. PROJECT OVERYTER

日. Fuxding Ageron; $\quad Y / A$

Finding Stanus: Nol Sotking Funding

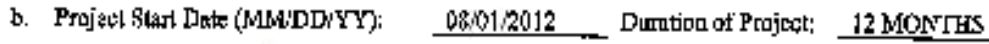

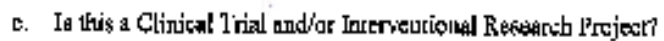

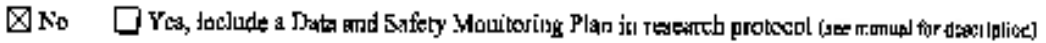

d. What ts the cisk clasaification of hig atudy?

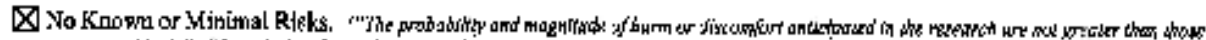

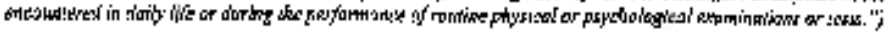

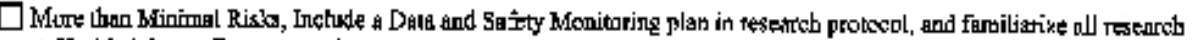

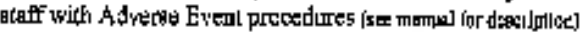

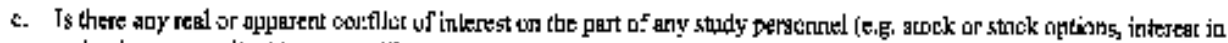
techoology, countltartt lo spousor)?

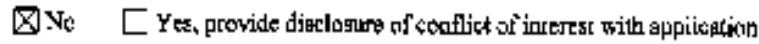

5. BRIEF DESCRIPT'ION OF SUBJECTS

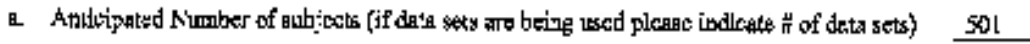

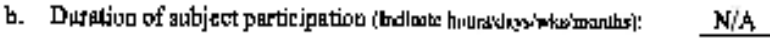

c. Is ithere sabjert compensation? (It yes yilsasc uparily): No

Revired 12/10

Page $l$ af 4 
APPENDIX E 


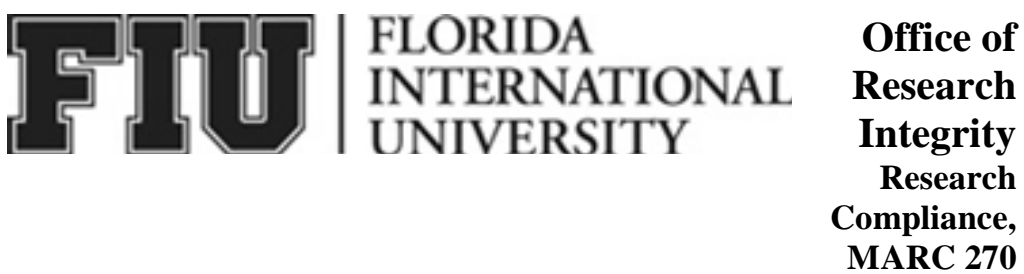

\section{MEMORANDUM}

To:

Michael McLean

CC: $\quad$ Dr. Fatma Huffman

File

From:

Jada Dixon, MJ, MPH, IRB Coordinator

Date: $\quad$ September 12, 2012

Proposal Title: $\quad$ "Oxidative Stress Biomarkers in African

and Haitian Americans with and without

Type 2 Diabetes: The Relationship between

Serum Levels of Manganese Superoxide

Dismutase and mtDNA

8-hydroxy-2'-deoxyguanosine, and Antioxidants"

IRB Exemption \# 073112-01

The Health Sciences Institutional Review Board of Florida International University has reviewed your study for the use of human subjects via the Exempt Review process. Your study was deemed Exempt by the Institutional Review Board on July 31, 2012.

As a requirement of IRB approval you are required to:

1) Submit a completion report (Form B-2) upon completion of your project in order for the file to be closed. 
APPENDIX F 


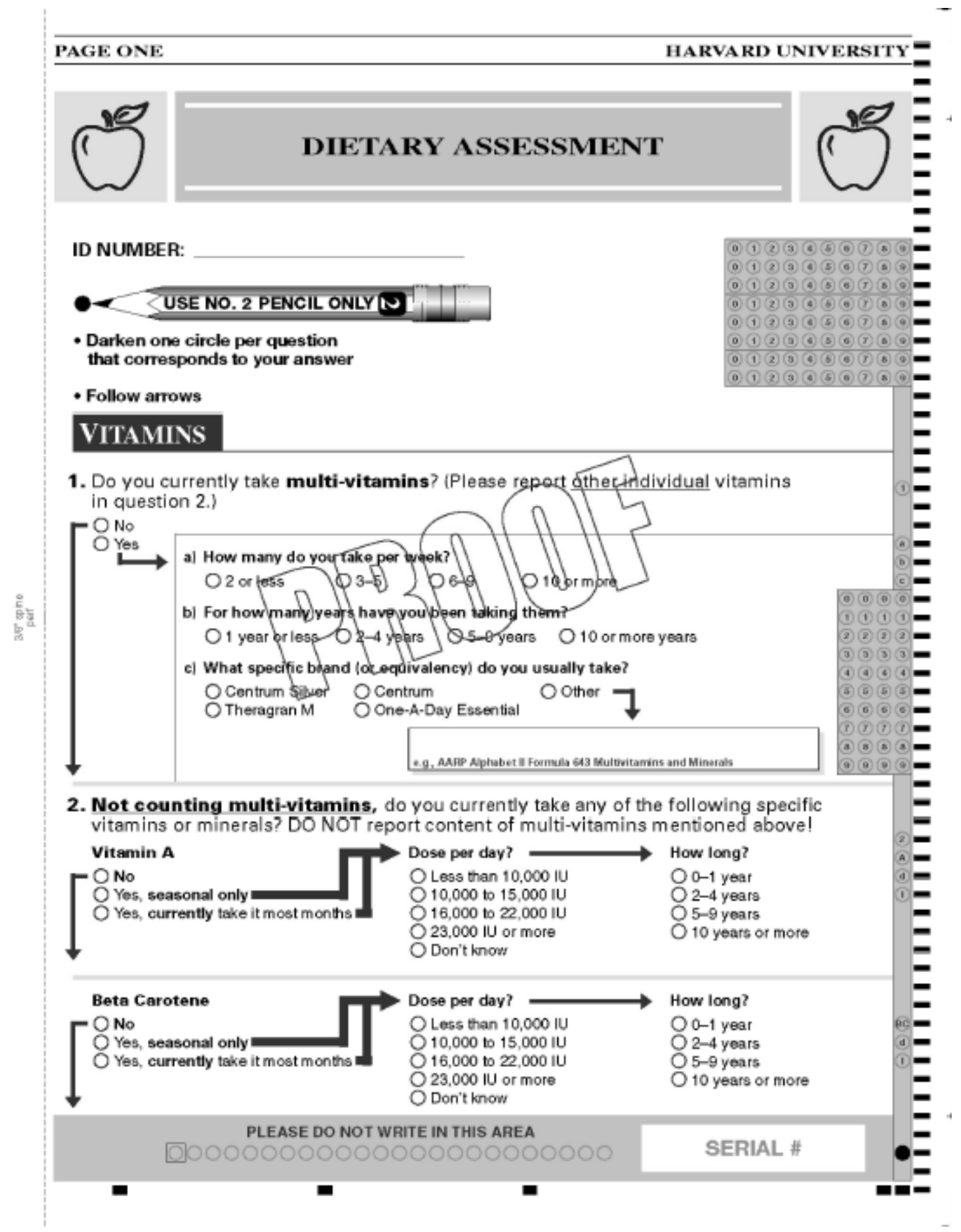




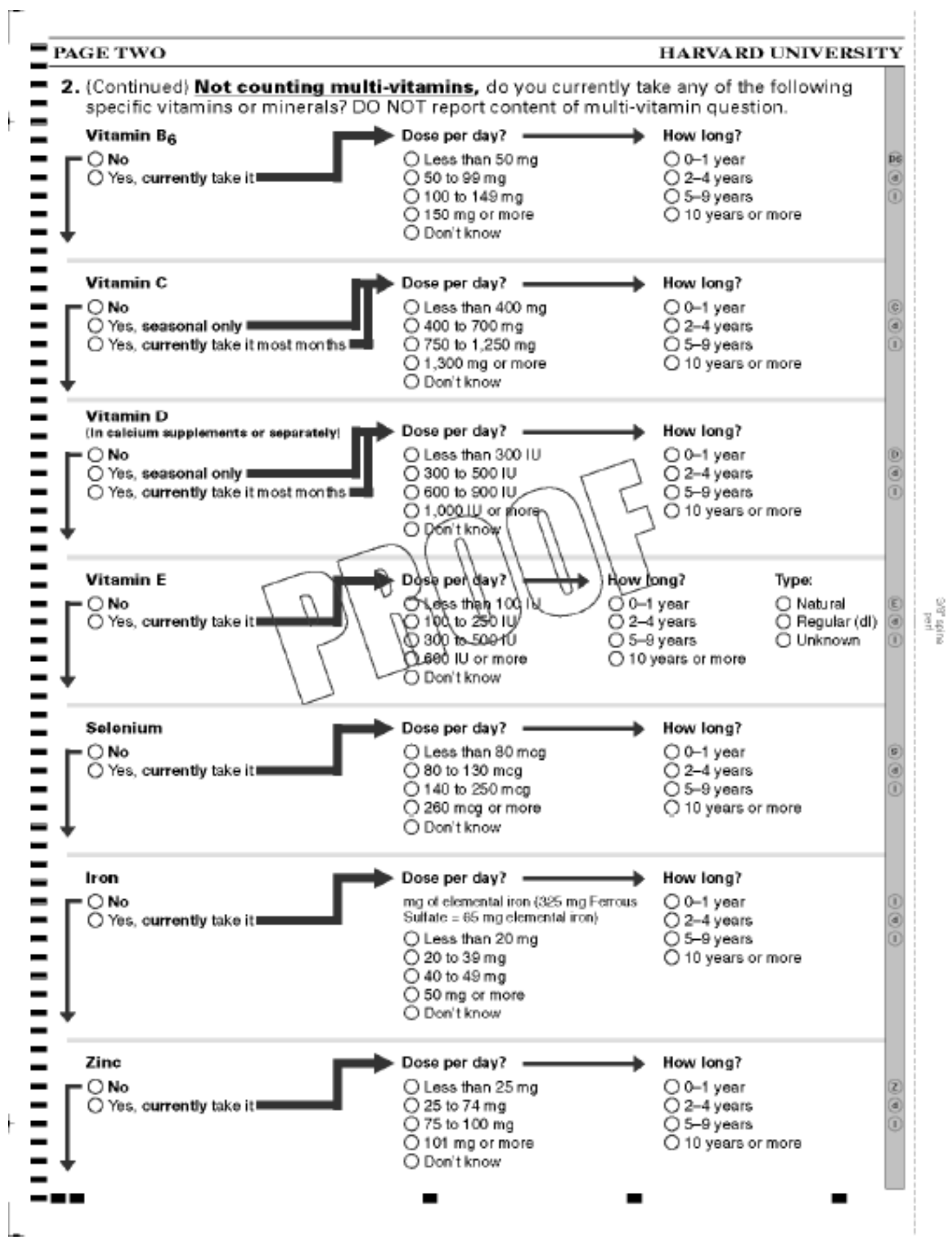




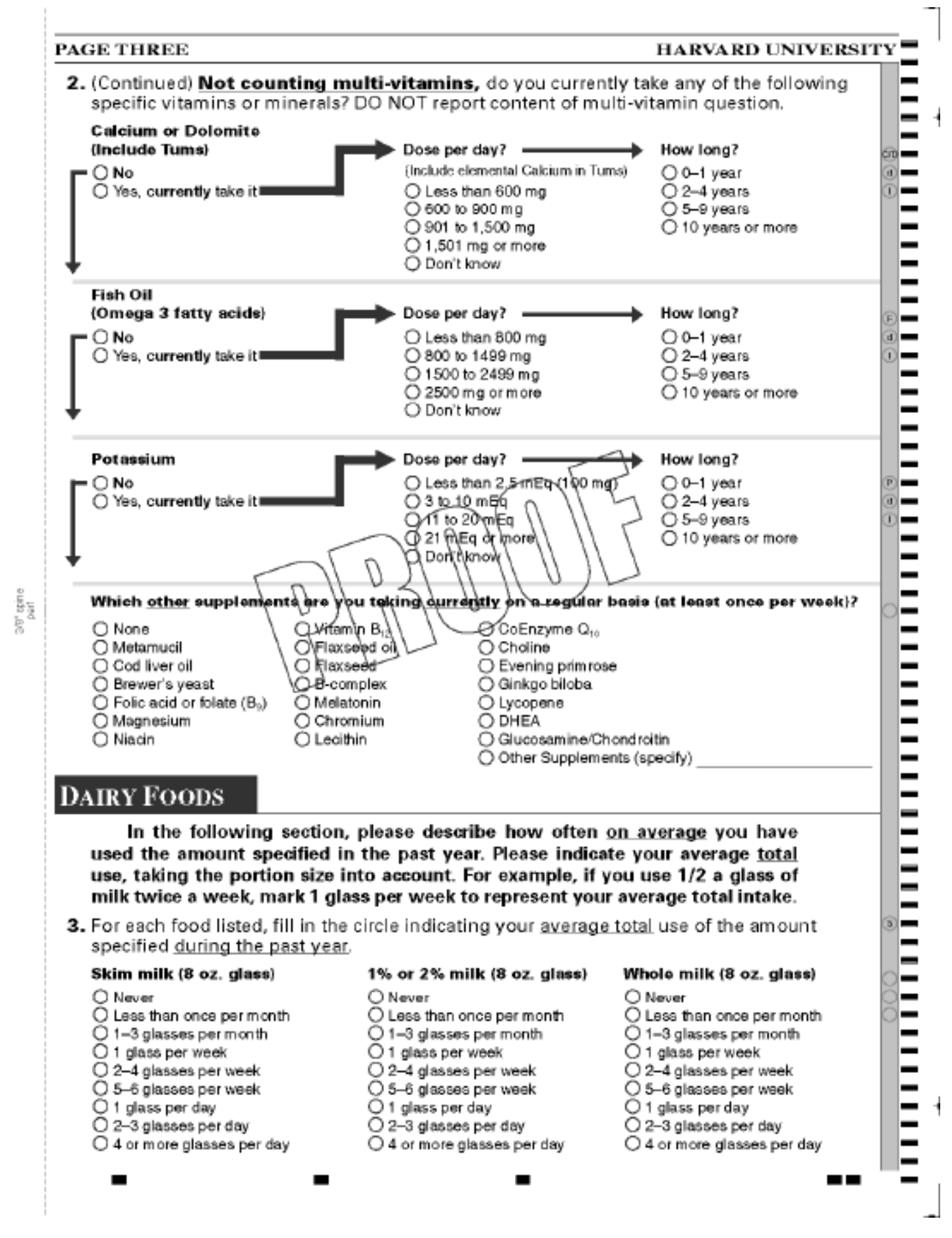




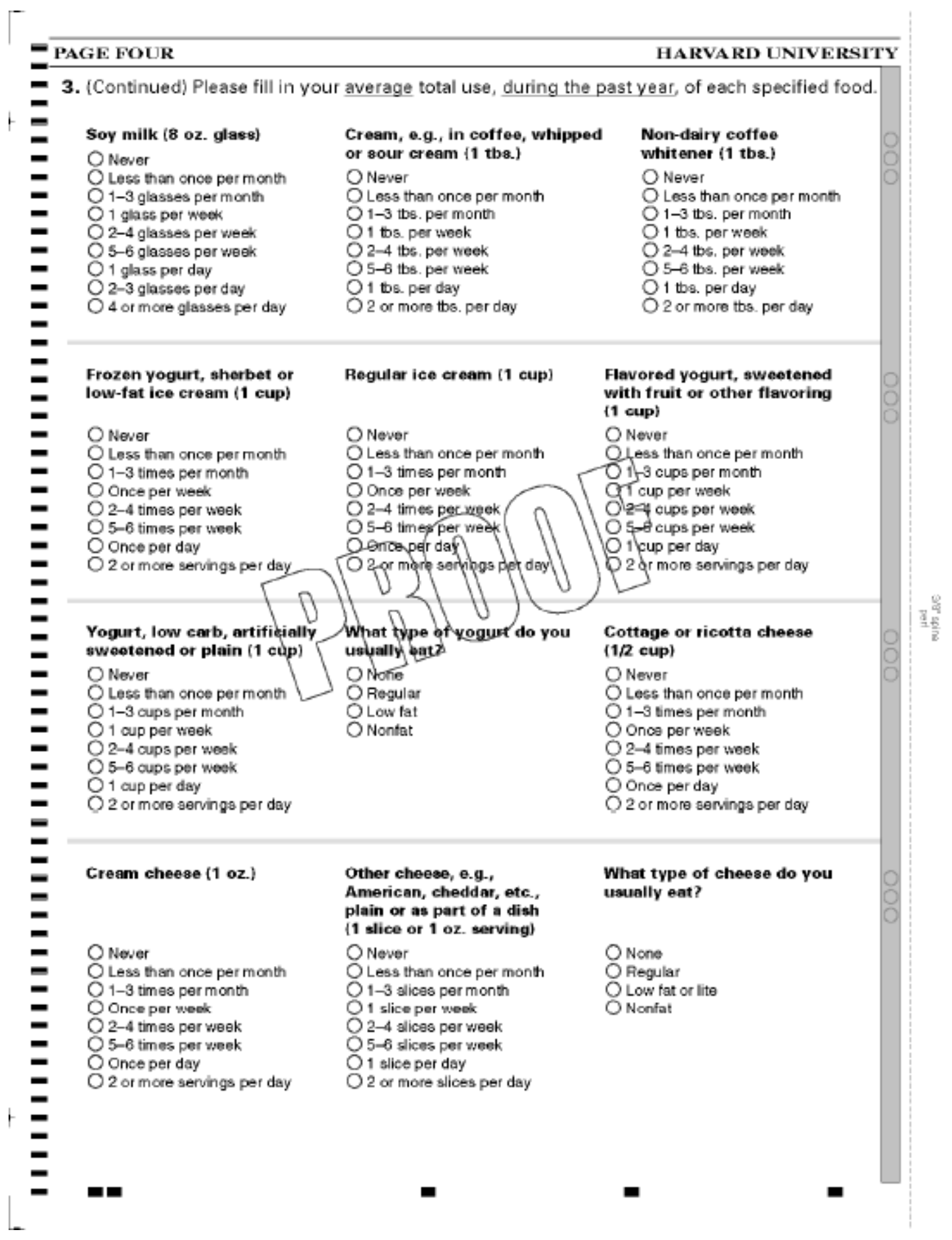


3. (Continued) Please fill in your average total use, during the past year, of each specified food.

Pure butter (amall pat or
tsp.), added to food or
bread; exclude use in
cooking
Never
Less than once per month
$1-3$ pats per month
1 pat per week
2-4 pats per week
5 -6 pats per week
1 pat per day
$2-3$ pate per dey
4 or more pats per day

"Sprendable butter"-
butter/oil blend (small pat or
tsp.), added to food or bread;
exclude use in cooking
Never
Less than once per month
1-3 pats per month
1 pat per week
2-4 pats per week
5 -6 pats per week
1 pat per day
2-3 pats per day
44 or more pats per day

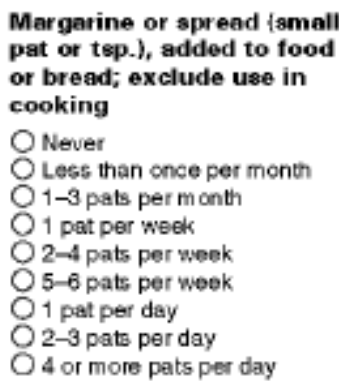

What form of margarine or spreadable butter do you usually use? (Exclude pure butter) $\begin{array}{cccc}\text { ONone Form? O Stick OSpray } & \text { Type? O Regular } & \text { ONontat } \\ \text { O Tub OSqueeze (liquid) } & \text { O Light spread } & \end{array}$

$$
\text { Tub OSqueeze (liquid) O Light spread }
$$

\section{FRUITS}

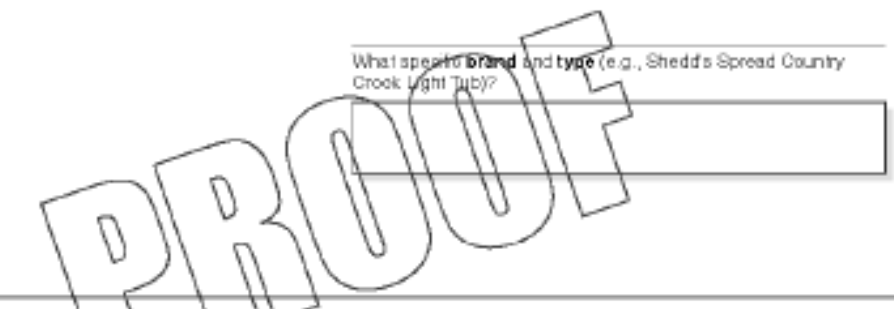

4. Please fill in your average total use, during the past year of each specified food.

Please try to average your keasonal use of foods over the entire year. For example, if a food such as cantaloupe is eaten 4 times a week during the 3 months that it is in season, then the average total use would be once per week over the year.

\begin{tabular}{|c|c|}
\hline $\begin{array}{l}\text { Raisins (1 oz or small pack) } \\
\text { or grapes }(1 / 2 \text { cup) }\end{array}$ & $\begin{array}{l}\text { Prunes or dried plums } \\
\text { (6 prunes or } 1 / 4 \text { cup) }\end{array}$ \\
\hline $\begin{array}{l}\text { Never } \\
\text { Less than once per month } \\
1-3 \text { tmee per month } \\
\text { Once per week } \\
2 \text {-4 times per week } \\
5-6 \text { times per week } \\
\text { Once per dey } \\
2 \text { or more servings per day }\end{array}$ & $\begin{array}{l}\text { ONever } \\
\text { Less than once per month } \\
\text { 1-3 times per month } \\
\text { Once per week } \\
2-4 \text { times per week } \\
5-6 \text { times per week } \\
\text { Once per day }\end{array}$ \\
\hline
\end{tabular}

Prune Juice (small glass)

Never

$O$ Less than once per month

O 1-3 glesees per month

O 1 glass per week

O 2-4 glasses per weok

O $5-6$ glasses per week

O 1 glase per day

$\mathrm{O} 2$ or more glasses per day

\section{Bananas (1)}

ONever

Lese than once per month

1-3 per month

O 1 per week

O 2-4 per week

O 5-6 per week

1 per day

$\mathrm{O} 2$ or more per day

Cantaloupe (1/4 molon)

Never

Less than once per month

1-3 times per month

Once per week

O 2-4 times per week

O 5-6 tim es per week

Once per day

2-3 imes per day

4 or more servings per day
Avocado (1/2 fruit or 1/2 cup)

Never

O Lees than once per month

1-3 times per month

Once per week

2-4 times per week

O 5 -6 times per weak

One per day

Two or more per day 


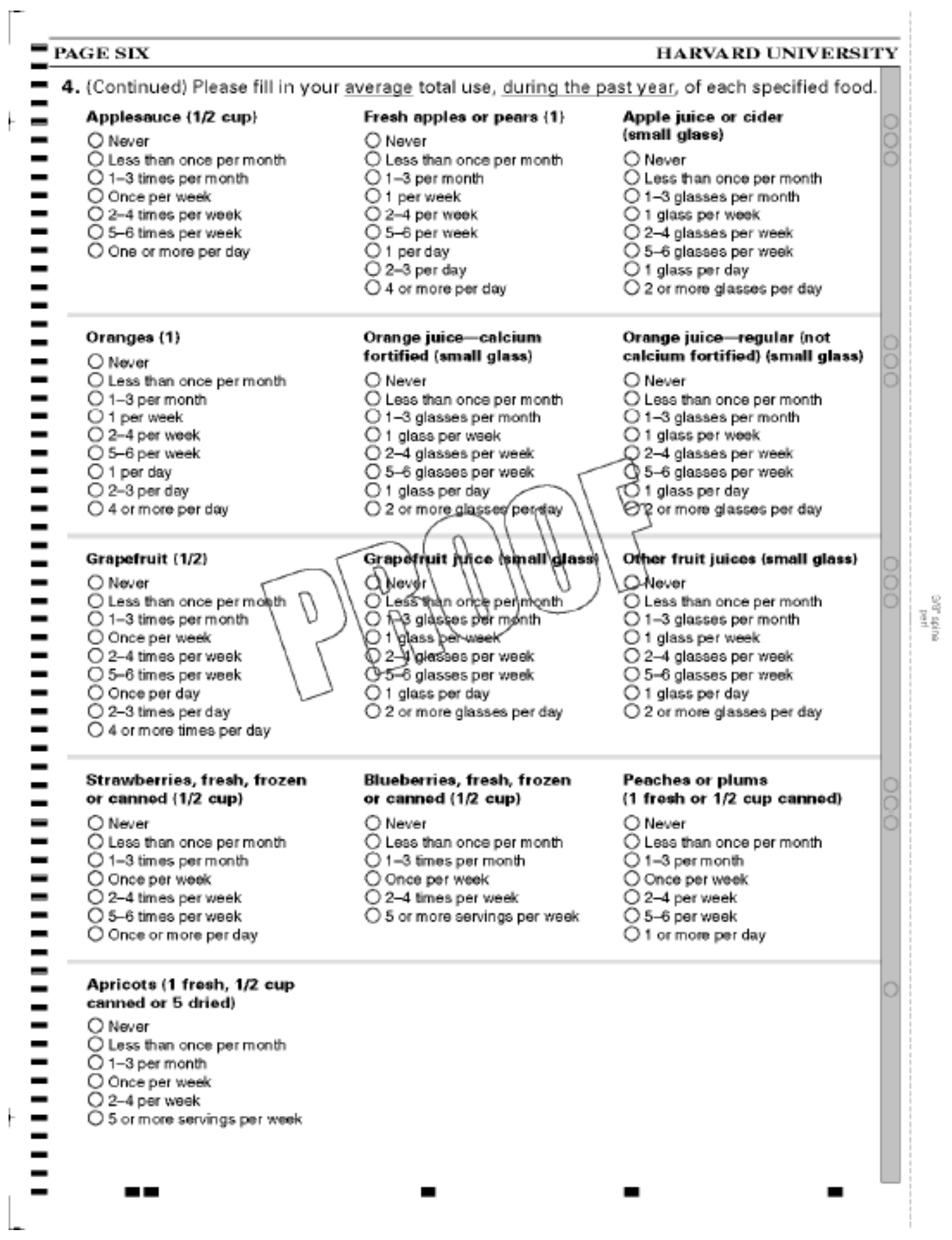


VEGETABLES

5. Please fill in your average total use, during the past year, of each specified food.

Tomatoes \{ 2 aices\}

O Never

Less than once per month

1-3 per month

O 1 per week

O 2-4 per week

5-6 per wook

O 1 or more per day
Tomato or V8 juice

(small glass)

O Never

$O$ Less than once per month

O 1-3 glasses per month

O 1 glass per week

O 2-4 glasses per week

O 5-6 glasses per week

O 1 glass per day

O 2 or more glasses per day
Tomato sauce (1/2 cup)

e.g. spaghetti sauce

ONever

O Less than once per month

1-3 times per month

Once per week

2-4 times per week

O 5 or more servings per week

Tofu, soy burgers, soybeans,

String beans

Salsa, picante or taco sauce (1/4 cup)

O Never

Less than once per menth

1-3 times per month

Once per week

O 2-4 times per week

O 5-6 times per week

Once per day

$\mathrm{O} 2$ or more servings per day

Brocestion 10

Broccoli (1/2 cup)

ONever

Less than once per month

O 1-3 times per month

Once per week

2-4 times per week

O $5-6$ times per week

O 1 or more servinge per day
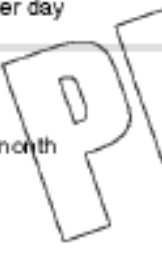

day

Brussels sprouts

(1/2 cup)

Never

O Lese than once per month

1-3 times per month

Once per week

O 2-4 times per week

O 5 -6 times per week

O 1 or more servings per day

\section{miso, or other soy protein (3-4 oz.) $\{1 / 2 \mathrm{cup})$}

O Never

Less than once per month

1-3 times per month

Once per week

2-4 times per weok

O Never

Less than once per month

1-3 times per month

Once per week

5-6 times per week Onof per day Ozormoreserming per

O 5 or more servings per week cabbate or dole alaw $11 / 2$ auph

\section{GNever ONewer}

O-tess thatnonee per month

1f-istimes per month

OOnce per week

2-4 times per week

O $5-6$ times per week

1 or more servinga per day

Less than once per month

1-3 times per month

Once per week

2-4 times per week

5-6 times per week

O 1 or more servinga per day

Carrots, ravy $(1 / 2$ carrot

or 2-4 sticks)

Never

O Lese than once per month

1-3 times per month

Onoe per week

O 2-4 times per week

O 5-6 times per week

Once per day

$\mathrm{O}_{2}$ of more servings per day

Carrots, cooked $\{1 / 2$ cup)

or carrot juice $(2-3 \mathrm{oz}$.

Never

$O$ Less than once per month

1-3 times per month

Once per weok

2-4 times per week

S-6 times per week

Once per day

O 2 or more servings per day

Corn (1 ear or 1/2 eup

frozen or canned)

ONever

Less than once per month

1-3 per month

O 1 per week

O 2-4 per week

5-6 per week

1 or more servings per day
Peas or lima beans (1/2 cup

Mixed vegetables, stir fry $(1 / 2$ cup), vegetable soup (1 cup)

ONever

Never

Lees than once per month

O 1-3 times per month

Once per week

2-4 times per week

5-6 times per week

1 of more servings per day
Less than onoe per month

O $1-3$ times per month

Once per week

1 or more servings per day
5-6 bimes per week
2-4 times per week घa 


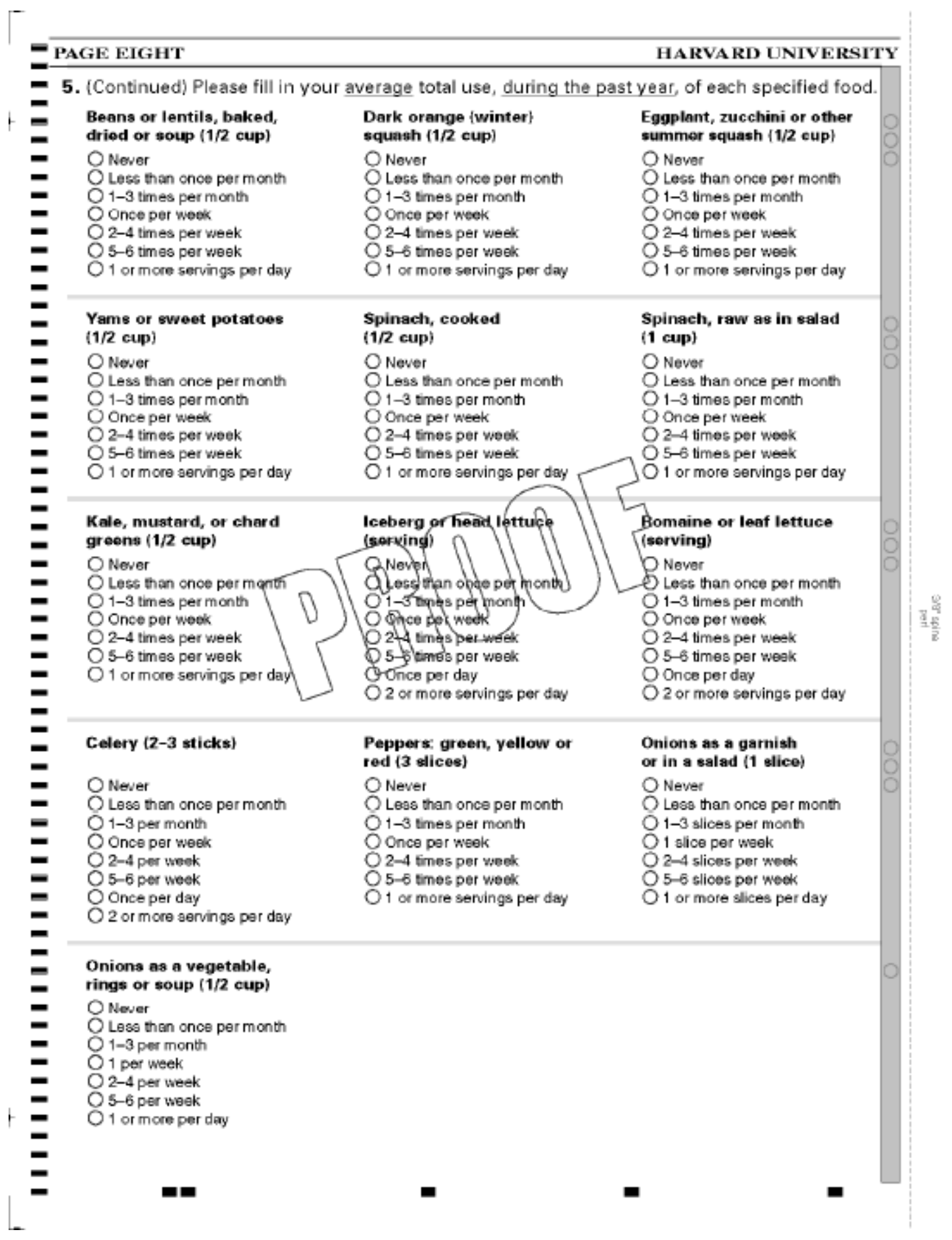




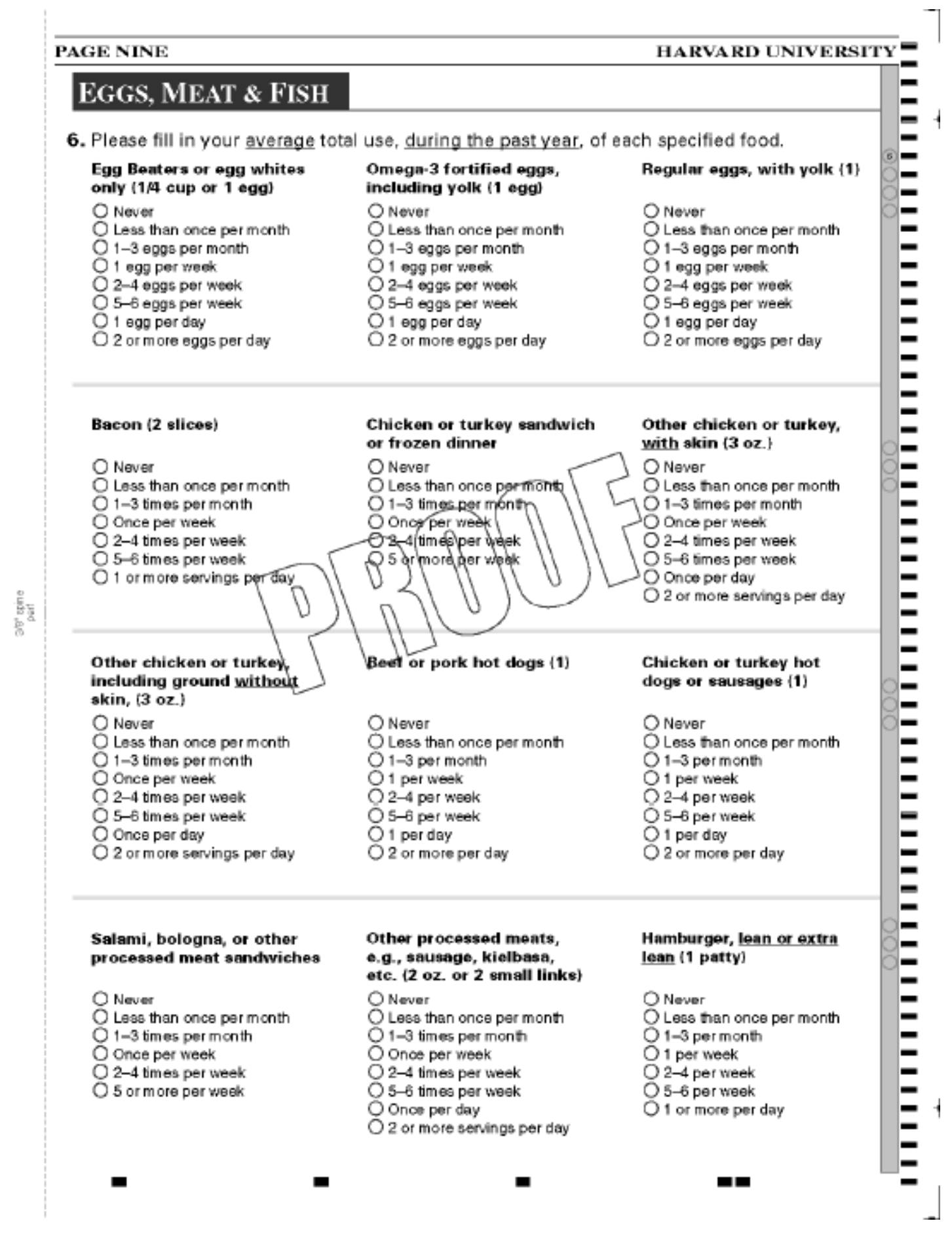




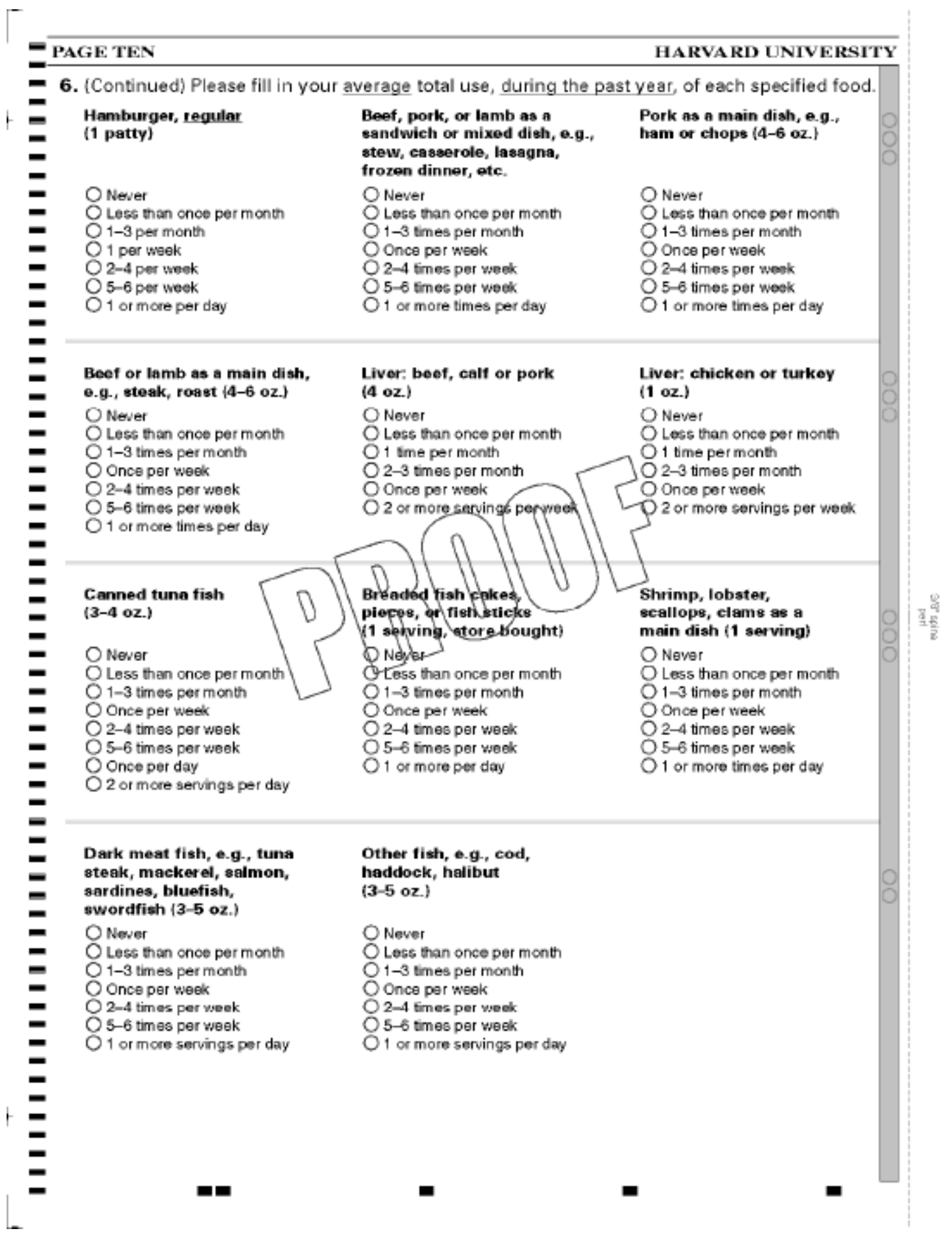




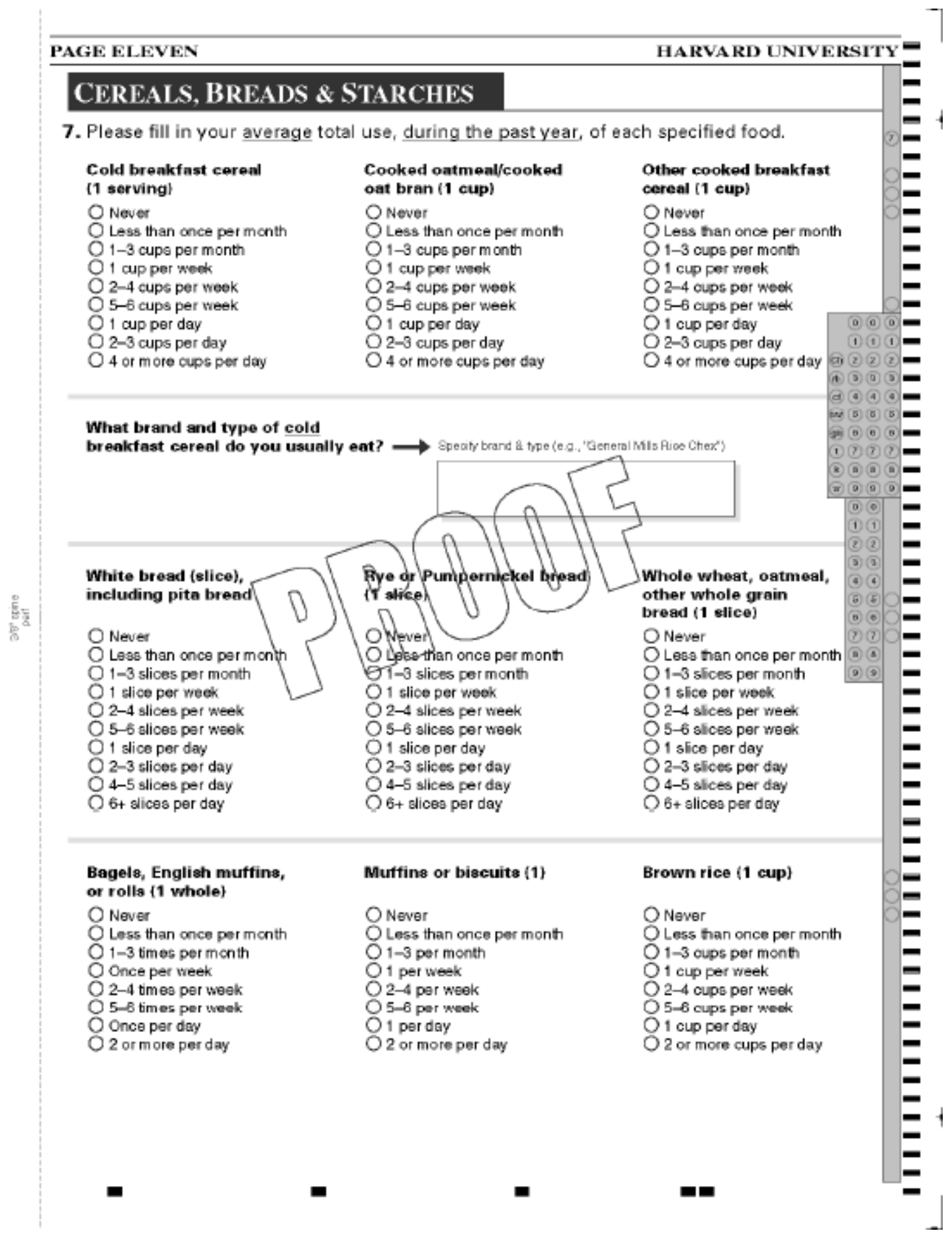




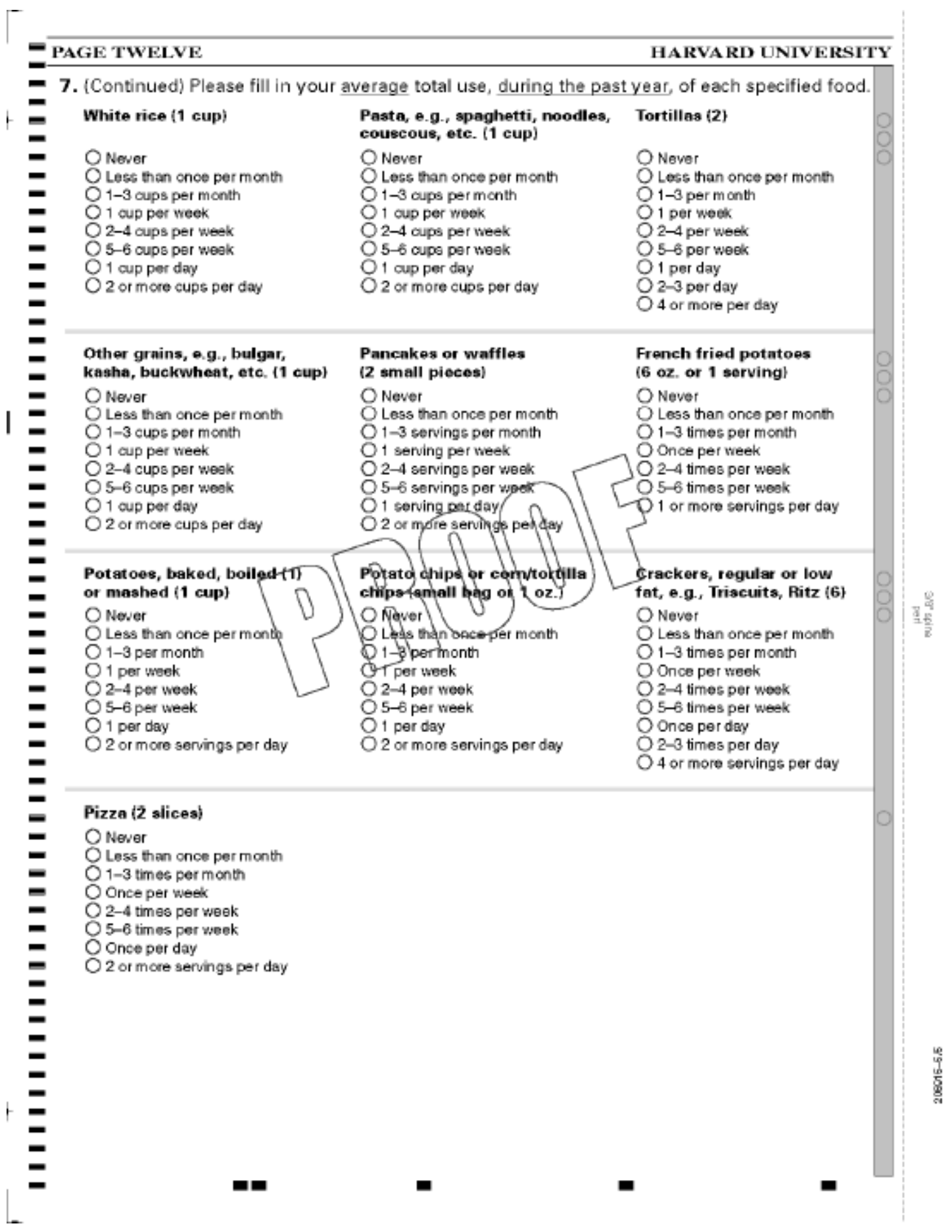




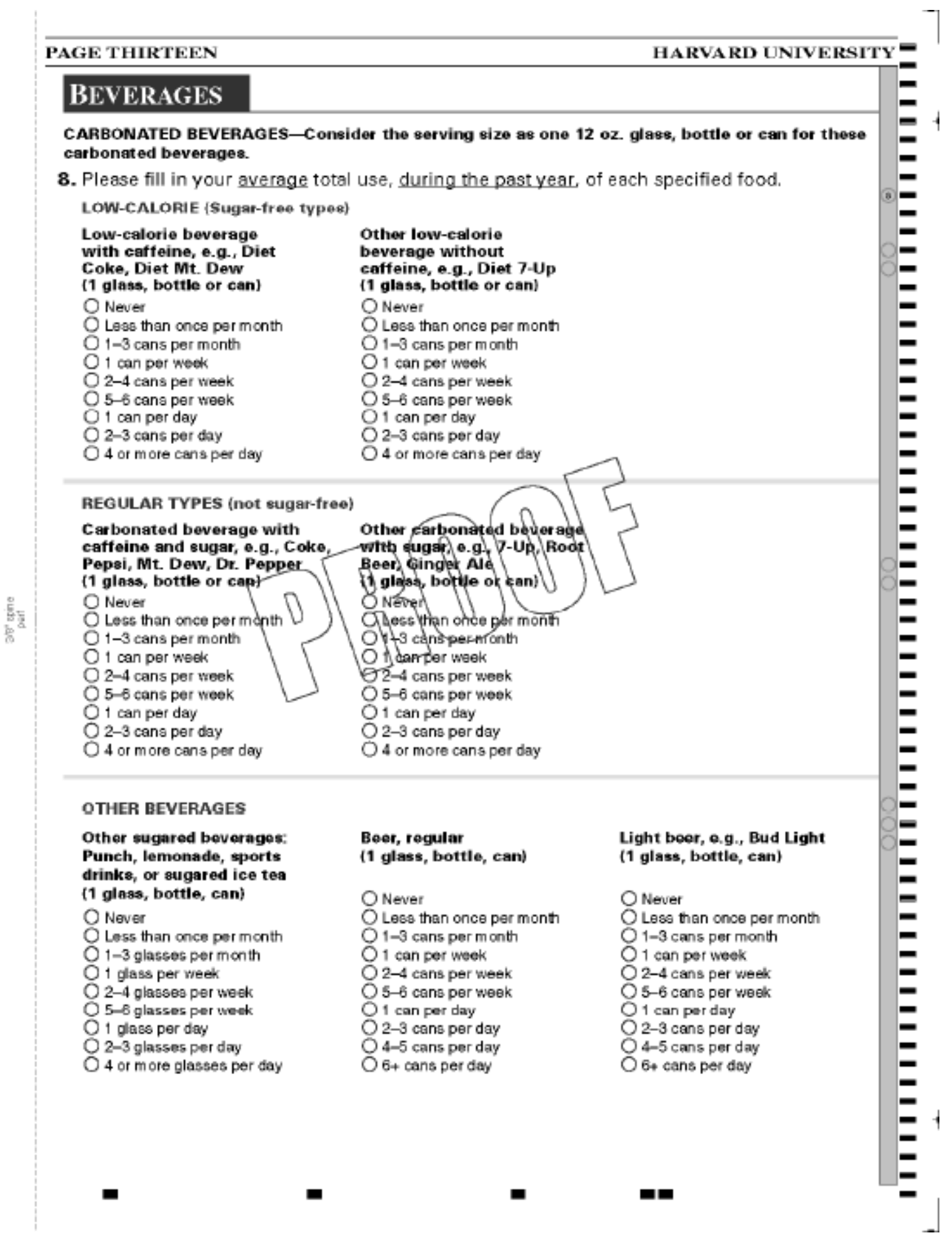




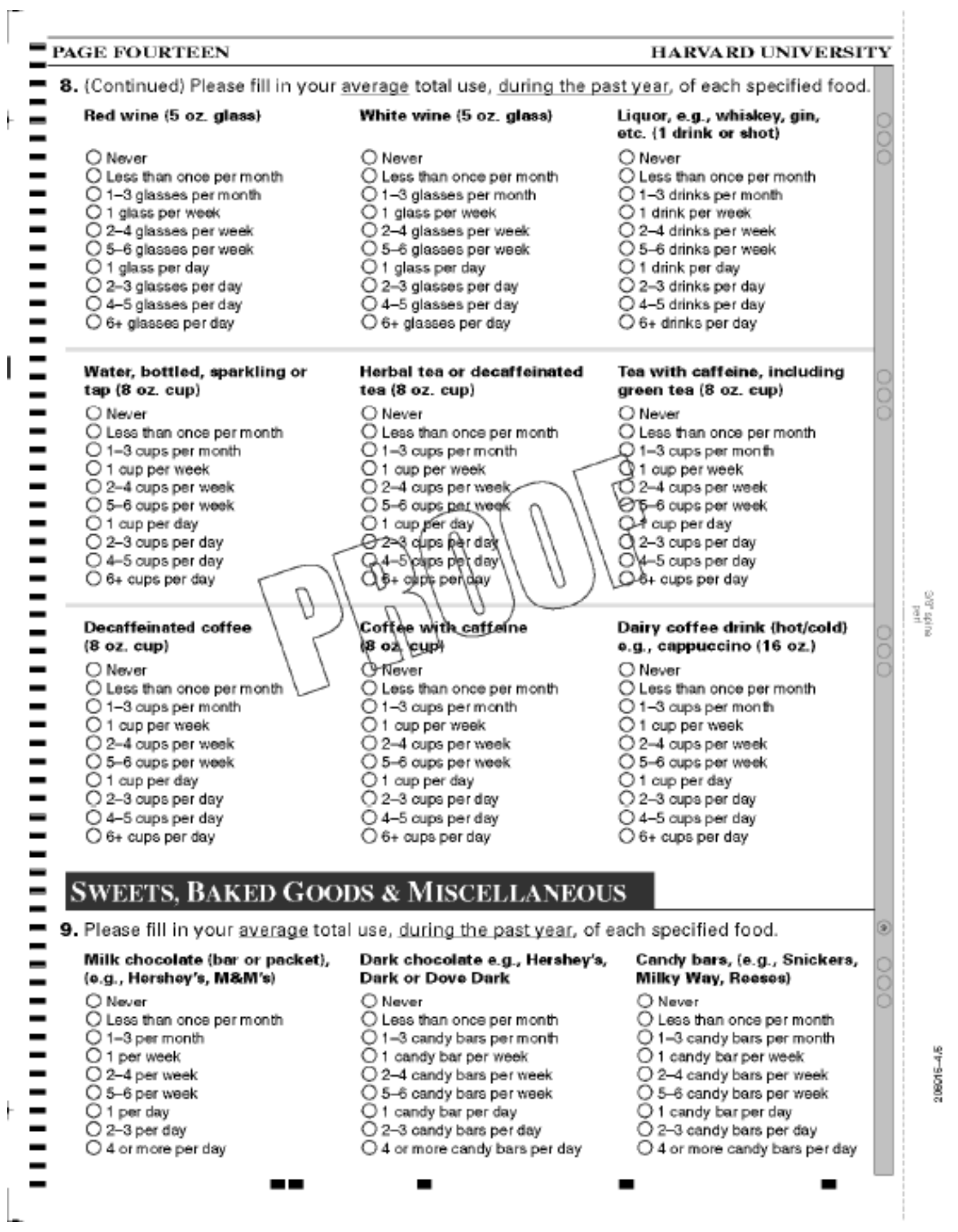




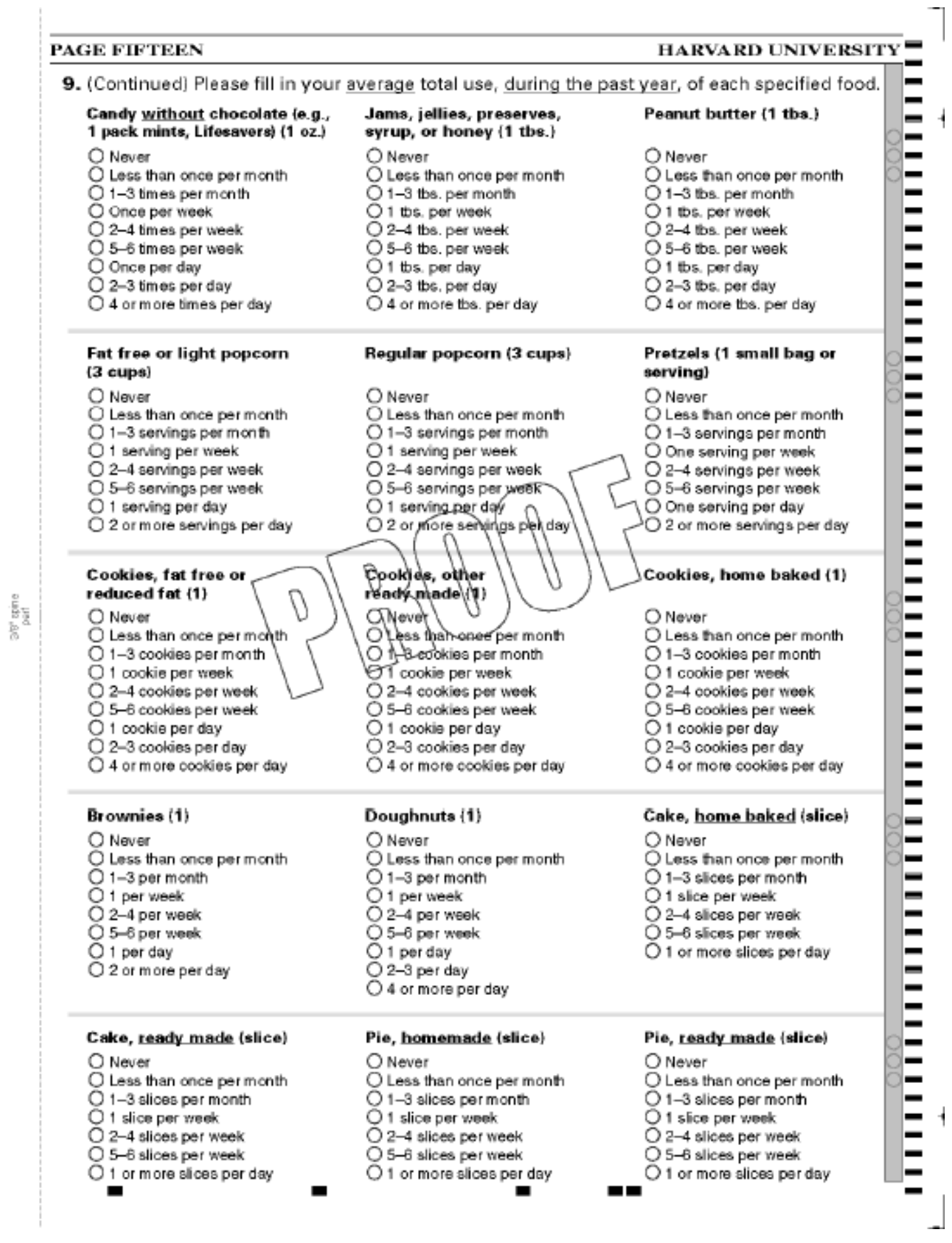




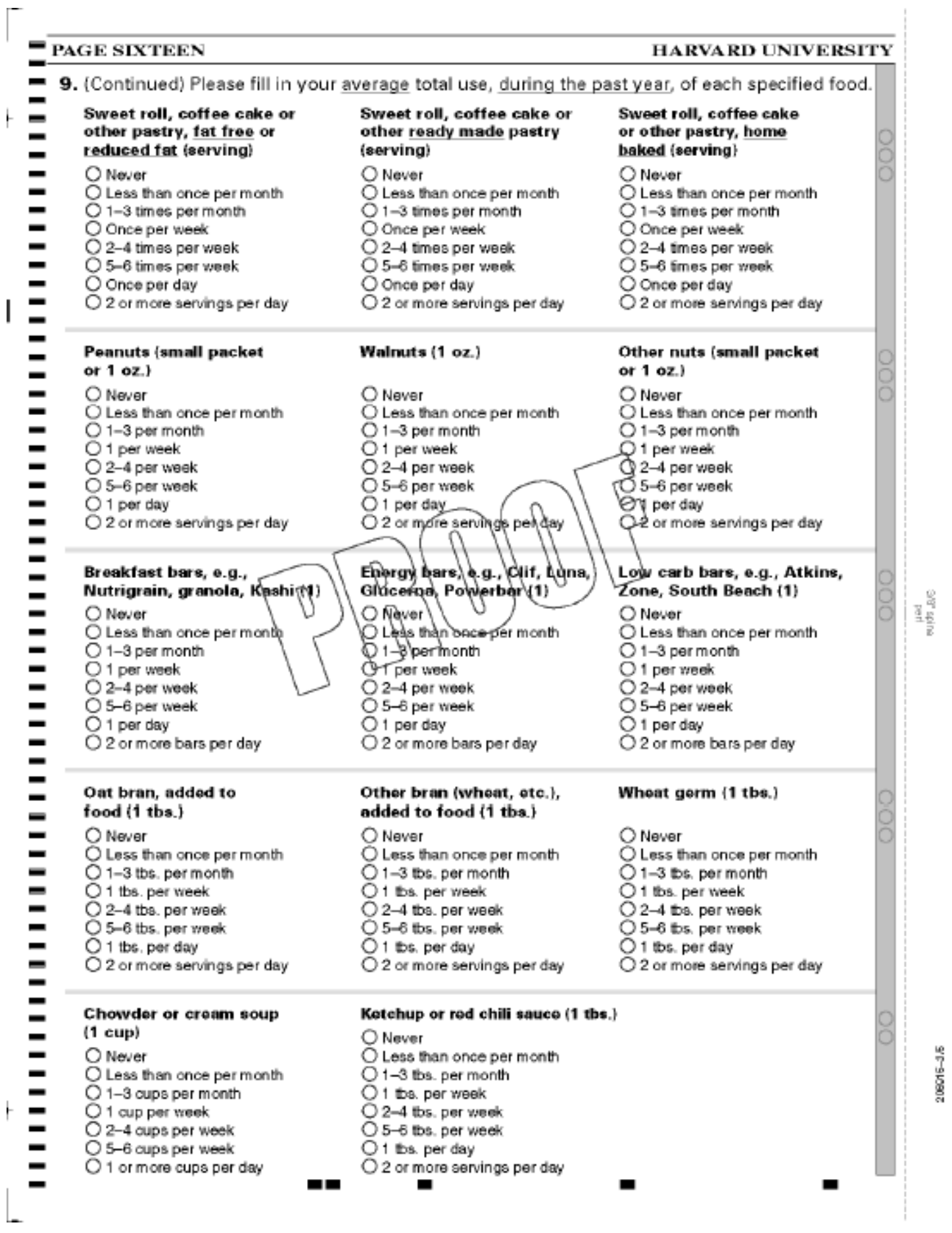




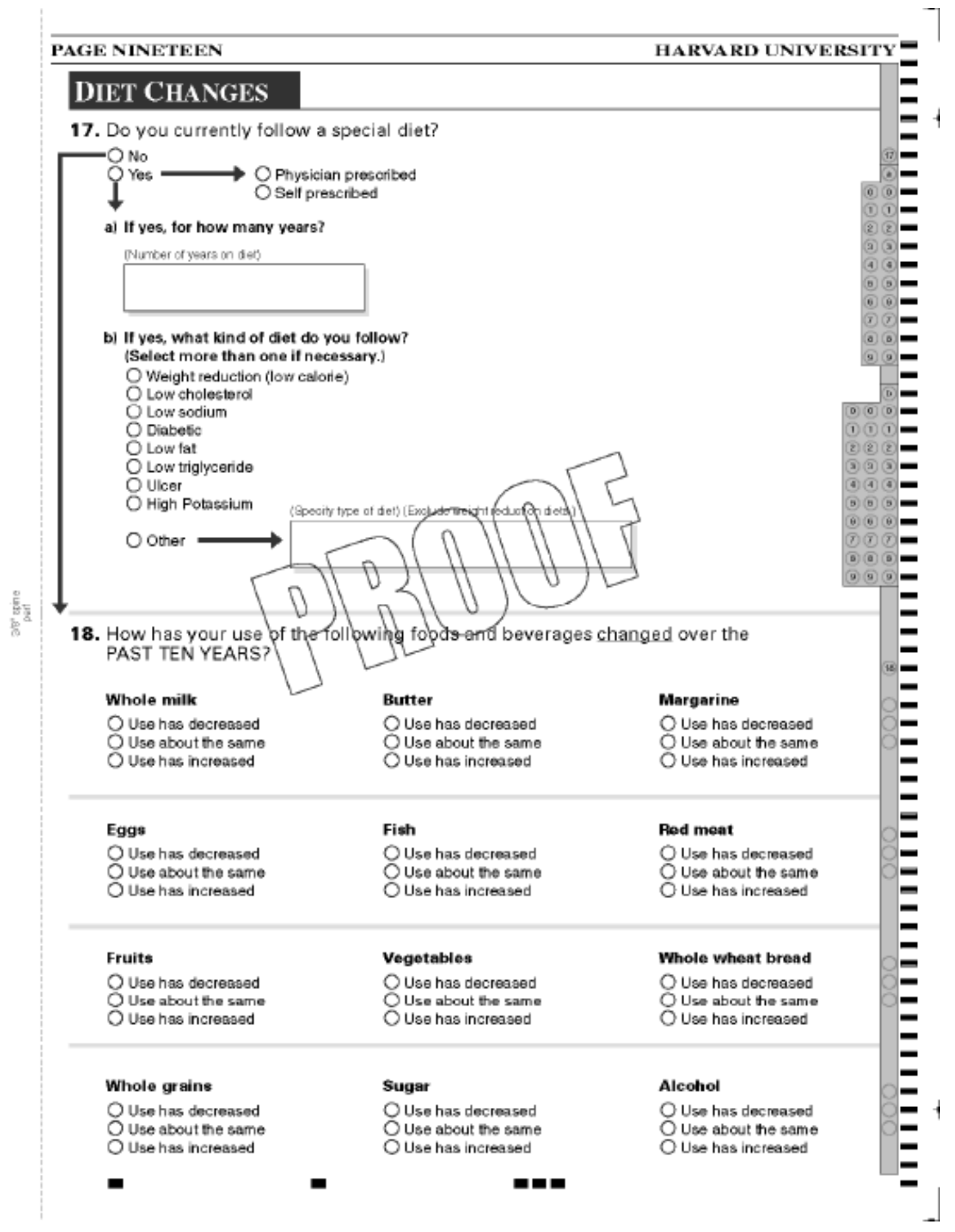




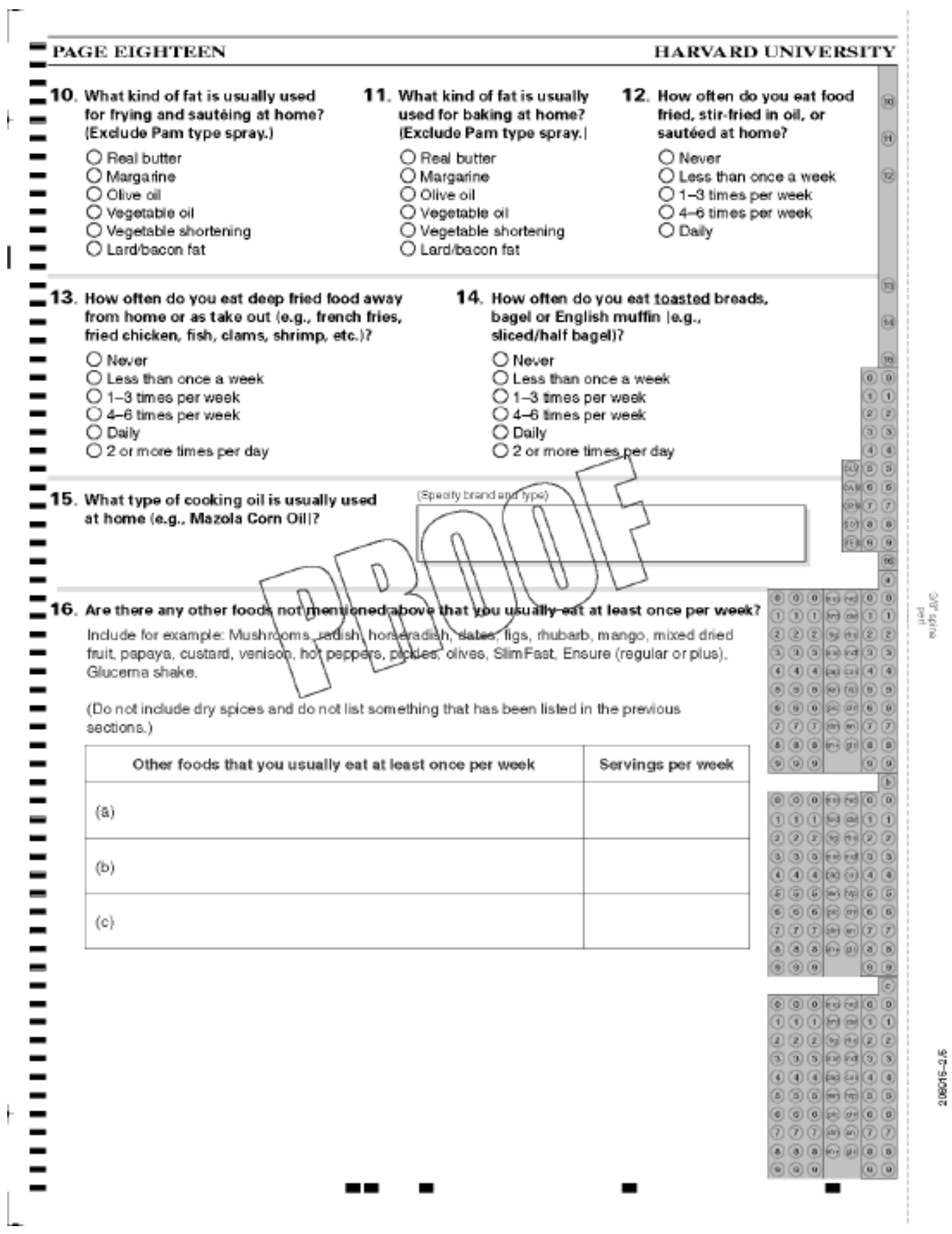




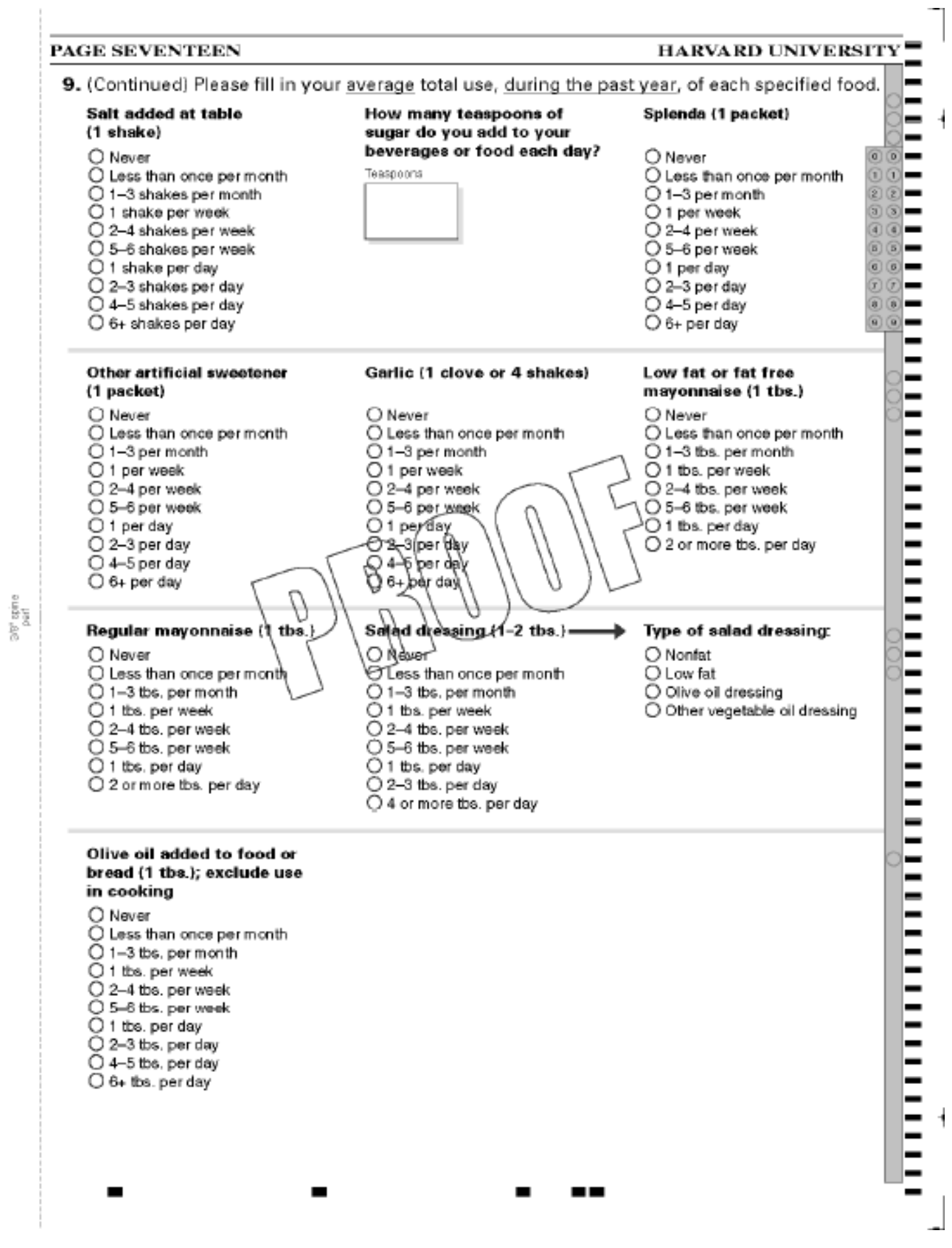




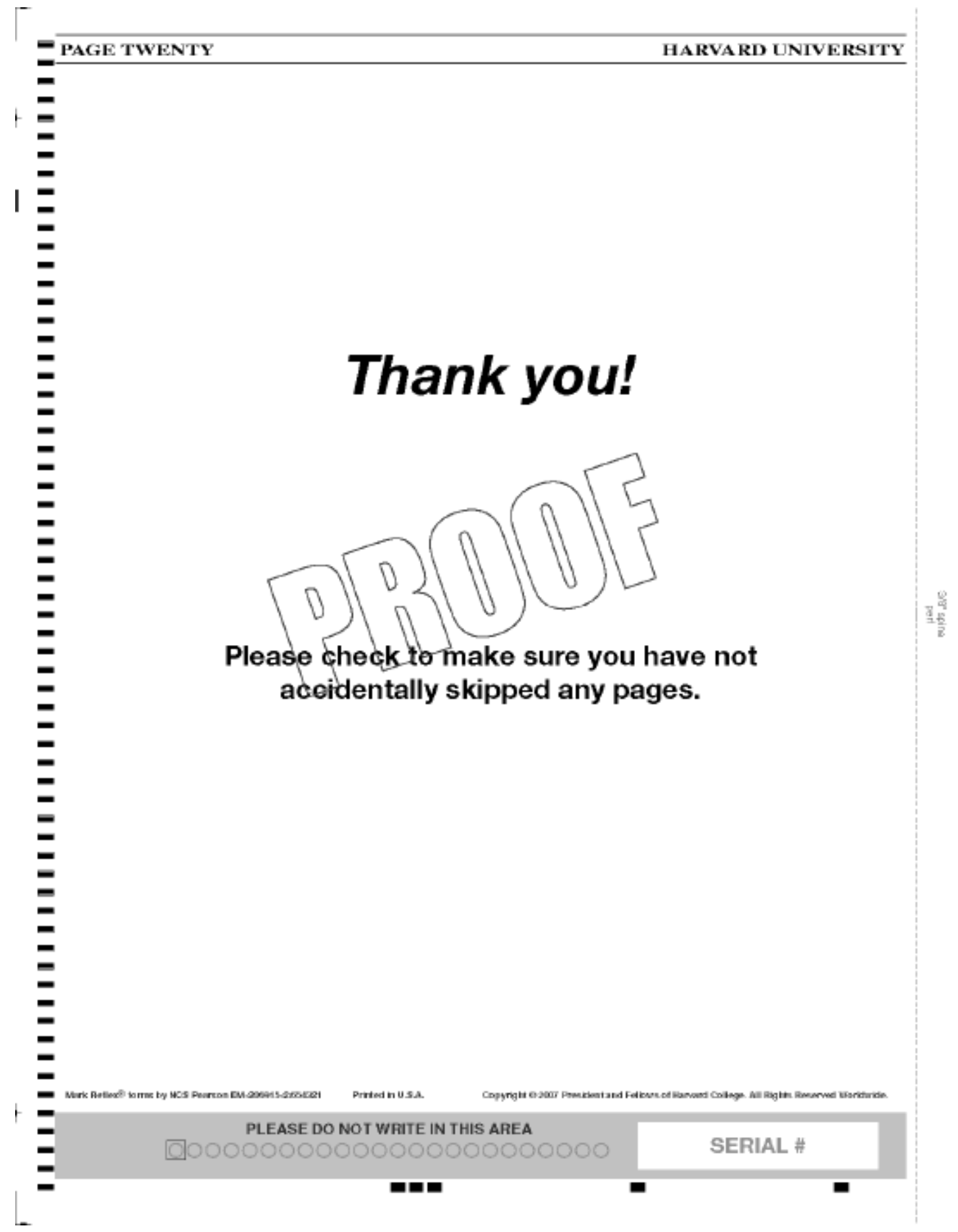


APPENDIX G 
ID \#:

Date

CVD RISK STUDY: HAITIAN \& AFRICAN AMERICAN 


\section{Section I - Demographics}

Please answer each of the following questions by filling in the blanks with the correct answers or by choosing the single best answer.

Note: For this survey, a Health Care Provider refers to a doctor, nurse practitioner, or physician assistant.

Q1. Age: years old

Q2. Birth date:

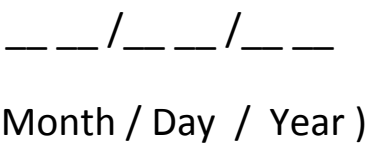

Q3. Sex: $\square_{1}$ Male $\square_{2}$ Female

Q4. Height: centimeters

Q5. Weight: kilograms

Q6. Waist Circumference: centimeters

Q7. What year were you first told you had diabetes? (Please enter the year)

Q8. What is your marital status? (check one box)

$\square$ Never married

$\square$ Married

$\square_{3} \quad$ Separated/Divorced

$\square$ Widowed 
Q9. Which country were you born in? (check one box)

$\square_{1} \quad$ Haiti

$\square_{2} \quad$ United States of America

$\square_{3} \quad$ Other

Q.10 How long have you been in the United States of America? (check one box)

$\square$ Less than one year

$\square 2 \quad$ One to three years

$\square_{3} \quad$ Four to six years

$\square 4 \quad$ Seven to ten years

$\square_{5} \quad$ Eleven to fifteen years

$\square 6 \quad$ More than fifteen years

Q11. How much schooling have you had? (Years of formal schooling completed) (check one box)

$\square_{1} \quad 8$ grades or less

$\square_{2}$ Some high school

$\square_{3} \quad$ High school graduate or GED

$\square$ 4 Some college or technical school

$\square_{5} \quad$ College graduate (bachelor's degree)

$\square$ 6 Graduate degree 
Q12. Which of the following best describes your current employment status?

(check one box)

$\square_{1} \quad$ Working full-time, 35 hours or more a week

$\square$ Working part-time, less than 35 hours a week

$\square$ Unemployed or laid off and looking for work

$\square 4$ Unemployed and not looking for work

$\square_{5}$ Homemaker

$\square_{6}$ In school

$\square_{7} \quad$ Retired

$\square$ Disabled, not able to work

9 Something else? (Please specify):

Q13. How would you describe the insurance plan(s) you have had in the past 12 months?

(check all that apply)

$\square$ An individual plan - the member pays for the plan premium

$\square 2$ A group plan through an employer, union, etc. - the employer pays all or part of the plan premium

3 U.S. Governmental Health Plan (e.g., Military, CHAMPUS, VA)

4 Medicaid

$\square_{5}$ Medicare

$\square$ I have not had an insurance plan in the past 12 months 
Q14. Which of the categories best describes your total annual combined household income from all sources? (check one box)

$\square$ Less than $\$ 5,000$

$\square 2 \$ 5,000$ to $\$ 9,999$

$\square_{3} \quad \$ 10,000$ to $\$ 19,999$

$\square_{4} \$ 20,000$ to $\$ 29,999$

$\square 5 \$ 30,000$ to $\$ 39,999$

$\square 6 \$ 40,000$ to $\$ 49,999$

$\square 7 \$ 50,000$ to $\$ 59,999$

$\square 8 \$ 60,000$ to $\$ 69,999$

$\square 9 \$ 60,000$ to $\$ 69,999$

$10 \$ 70,000$ and over

$\square$ 11 Don't know

Q15. How many person(s) age 18 years and over live in the same house you live?

Q16. What language do you prefer to write something? (check one box)

$\square$ i Only Creole

$\square 2 \quad$ More Creole than English

$\square$ Both equally 
$\square_{4} \quad$ More English than Creole

$\square 5 \quad$ Only English

Q17. What language do you prefer to speak with someone? (check one box)

$\square$ - Only Creole

$\square_{2}$ More Creole than English

$\square_{3}$ Both equally

$\square_{4}$ More English than Creole

$\square$ Only English

Q18. What language do you prefer to read with something? (check one box)

$\square$ i Only Creole

$\square 2$ More Creole than English

$\square 3$ Both equally

$\square$ More English than Creole

$\square_{5}$ Only English

Q19. Your smoking habit. (check one box)

$\square_{1} \quad$ Never smoked cigarettes, cigars or a pipe

$\square_{2}$ I quit smoking cigarettes/cigars/pipes at least one year ago

$\square$ I I smoke cigarettes: cigarettes per day

$\square 4$ I smoke cigar: cigars per day 
$\square$ I smoke pipe:

pipes per day

$\square$ 6 I chew tobacco: times per day

Q20. In general, would you say your health is: (check one box)<smiles>C1CCC1</smiles>

Excellent<smiles>C1CCCC1</smiles>

Very Good<smiles>C1CCC1</smiles>

Good

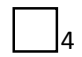

Fair

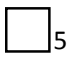

Poor

\section{Section II - Medication History}

Q21. Are you currently (in last 6 months) prescribed any medicine for the treatment of diabetes by your physician? (check one box)

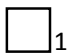

No
Yes

If "yes" check all the medication(s) that apply: 
- ORAL DIABETES MEDICATION(S): $\square_{1}$ No $\square_{2}$ Yes

d If "yes" How many oral diabetes medication(s) you take?

- INSULIN:

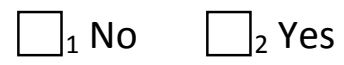

Q22. Are you currently (in last 6 months) prescribed any other medicine prescribed by your physician? (check one box)

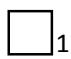

No

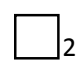

Yes

If "yes" check all the medication(s) that apply:

Cholesterol: $\square_{1}$ No $\quad \square_{2}$ Yes $\quad$ Hypertension: $\square_{1}$ No $\quad \square 2$ Yes

Diuretics: $\square_{1}$ No $\quad \square_{2}$ Yes $\quad$ Depression: $\square_{1}$ No $\quad \square_{2}$ Yes

Aspirin: $\square_{1}$ No $\quad \square_{2}$ Yes $\quad$ Pain Relievers: $\square_{1}$ No $\quad \square$ Yes

Estrogen Replacement Therapy: $\quad \square$ No $\quad \square 2$ Yes

Other(s): 
Q23. Are you currently (in last 6 months) taking any other non-prescription medication (over-the-counter)?

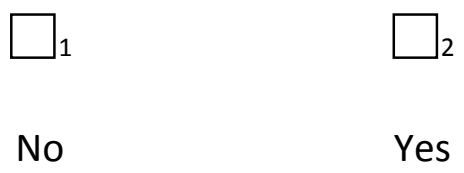

If "yes" check all the medication(s) that apply:

Antacids and Acid Reducers: $\square_{1}$ No $\quad \square_{2}$ Yes

Antidiarrheals: $\quad \square_{1}$ No $\quad \square_{2}$ Yes

Antiemetic Medicines: $\quad \square_{1}$ No $\quad \square_{2}$ Yes

Antihistamines: $\quad \square_{1}$ No $\quad \square_{2}$ Yes

Cough Medicines: $\quad \square_{1}$ No $\quad \square_{2}$ Yes

Decongestants: $\quad \square_{1}$ No $\quad \square_{2}$ Yes

Laxatives:

$\square_{1}$ No $\quad \square_{2}$ Yes

Pain Relievers: $\quad \square_{1}$ No $\quad \square_{2}$ Yes 
If "yes" check all the medication(s) that apply:

Aspirin (Bayer, St. Joseph) $\quad \square_{1}$ No $\square_{2}$ Yes $\quad$ Ibuprofen (Advil, Motrin) $\square_{1}$ No $\square_{2}$ Yes

Ketoprofen (Orudis KT) $\quad \square_{1}$ No $\square_{2}$ Yes $\quad$ Naproxen (Aleve) $\square_{1}$ No $\square_{2}$ Yes

Other(s):

\section{Section III - Family History}

Q24. Family history of diabetes (check all that apply)

$\square_{1} \quad$ Your mother has diabetes

$\square_{2} \quad$ Your father has diabetes

$\square_{3} \quad$ Your son has diabetes

$\square 4 \quad$ Your daughter has diabetes

$\square_{5} \quad$ You have no family history of diabetes

$\square_{6} \quad$ You don't know your family history of diabetes

Q25. Family history of premature coronary heart disease (check all that apply) 
$\square$ Your mother had coronary heart disease before age 65 years old

$\square 2$ Your sister had coronary heart disease before age 65 years old

$\square$ 3 Your father had coronary heart disease before age 55 years old

$\square_{4} \quad$ Your brother had coronary heart disease before age 55 years old

$\square_{5}$ You have no family history of coronary heart disease

$\square$ You don't know your family history of coronary heart disease 


\section{Section IV - Support}

Q1. I want a lot of help and support from my family or friends in:

(circle one answer for each line)

\begin{tabular}{|c|c|c|c|c|c|c|}
\hline & $\begin{array}{r}\text { Strongly } \\
\text { Disag } \\
\text { ree }\end{array}$ & $\begin{array}{c}\text { Somewhat } \\
\text { Disagree }\end{array}$ & Neutral & $\begin{array}{c}\text { Somewhat } \\
\text { Agree }\end{array}$ & $\begin{array}{c}\text { Strongly } \\
\text { Agree }\end{array}$ & $\begin{array}{r}\text { Does } \\
\text { Not } \\
\text { Apply }\end{array}$ \\
\hline $\begin{array}{l}\text { following my meal } \\
\text { plan. }\end{array}$ & 1 & 2 & 3 & 4 & 5 & N/A \\
\hline $\begin{array}{l}\text { taking my } \\
\text { medicine. }\end{array}$ & 1 & 2 & 3 & 4 & 5 & N/A \\
\hline $\begin{array}{l}\text { taking care of my } \\
\text { feet. }\end{array}$ & 1 & 2 & 3 & 4 & 5 & N/A \\
\hline $\begin{array}{l}\text { getting enough } \\
\text { physical activity. }\end{array}$ & 1 & 2 & 3 & 4 & 5 & N/A \\
\hline testing my sugar. & 1 & 2 & 3 & 4 & 5 & N/A \\
\hline $\begin{array}{l}\text { handling my } \\
\text { feelings about } \\
\text { diabetes. }\end{array}$ & 1 & 2 & 3 & 4 & 5 & N/A \\
\hline
\end{tabular}


Q2. My family or friends help and support me a lot to:

(circle one answer for each line)

\begin{tabular}{|c|c|c|c|c|c|c|}
\hline & $\begin{array}{l}\text { Strongly } \\
\text { Disagree }\end{array}$ & $\begin{array}{c}\text { Somewhat } \\
\text { Disagree }\end{array}$ & Neutral & $\begin{array}{c}\text { Somewhat } \\
\text { Agree }\end{array}$ & $\begin{array}{c}\text { Strongly } \\
\text { Agree }\end{array}$ & $\begin{array}{l}\text { Does } \\
\text { Not } \\
\text { Apply }\end{array}$ \\
\hline $\begin{array}{l}\text { a) follow my meal } \\
\text { plan. }\end{array}$ & 1 & 2 & 3 & 4 & 5 & $\mathrm{~N} / \mathrm{A}$ \\
\hline b) take my medicine. & 1 & 2 & 3 & 4 & 5 & $\mathrm{~N} / \mathrm{A}$ \\
\hline $\begin{array}{l}\text { c) take care of my } \\
\text { feet. }\end{array}$ & 1 & 2 & 3 & 4 & 5 & $\mathrm{~N} / \mathrm{A}$ \\
\hline $\begin{array}{l}\text { d) get enough } \\
\text { physical activity. }\end{array}$ & 1 & 2 & 3 & 4 & 5 & $\mathrm{~N} / \mathrm{A}$ \\
\hline e) test my sugar. & 1 & 2 & 3 & 4 & 5 & $\mathrm{~N} / \mathrm{A}$ \\
\hline $\begin{array}{l}\text { f) handle my feelings } \\
\text { about diabetes. }\end{array}$ & 1 & 2 & 3 & 4 & 5 & N/A \\
\hline
\end{tabular}


Q3. My family or friends: (circle one answer for each line)

\begin{tabular}{|c|c|c|c|c|c|}
\hline & Strongly & Somewhat & & Somewhat & Strongly \\
\hline & Disagree & Disagree & Neutral & $\underline{\mathrm{Ag}}$ & Agree \\
\hline $\begin{array}{l}\text { a) accept me and my } \\
\text { diabetes. }\end{array}$ & 1 & 2 & 3 & 4 & 5 \\
\hline $\begin{array}{l}\text { b) feel uncomfortable about } \\
\text { me because of my } \\
\text { diabetes. }\end{array}$ & 1 & 2 & 3 & 4 & 5 \\
\hline $\begin{array}{l}\text { c) encourage or reassure me } \\
\text { about my diabetes. }\end{array}$ & 1 & 2 & 3 & 4 & 5 \\
\hline $\begin{array}{l}\text { d) discourage or upset me } \\
\text { about my diabetes. }\end{array}$ & 1 & 2 & 3 & 4 & 5 \\
\hline $\begin{array}{l}\text { e) listen to me when I want } \\
\text { to talk about my diabetes. }\end{array}$ & 1 & 2 & 3 & 4 & 5 \\
\hline f) nag me about diabetes. & 1 & 2 & 3 & 4 & 5 \\
\hline
\end{tabular}

Q4. Who helps you the most in caring for your diabetes? (check only one box)

$\square$ Spouse

$\square_{2}$ Other family members

$\square_{3}$ Friends

$\square_{4}$ Paid helper 
$\square_{5}$ Doctor

$\square_{6}$ Nurse

$\square_{7}$ Case manager

$\square_{8}$ Other health care professional

$\square$ No one 


\section{Section V - Diet Adherence Scale}

Q1. Has any health care provider or nurse $\square_{1}$ No $\quad \square$ Yes $\quad \square$ Not sure told you to follow a meal plan or diet?

Never Sometimes Always

Q2. How often do you follow a meal plan

1

2

3

45

or diet?

Q3. Have you been told to follow a schedule for

$\square_{1}$ No $\quad \square_{2}$ Yes your meals and snacks?

Q4. Have you been told to weigh or measure

$\square_{1}$ No $\quad \square_{2}$ Yes your food?

Q5. Have you been told to use exchange lists or

$\square_{1}$ No $\quad \square_{2}$ Yes food group lists to plan your meals?

\begin{tabular}{|llllllc|}
\hline & Never & Sometimes & Always \\
\hline Q6. & $\begin{array}{l}\text { How often do you follow the schedule } \\
\text { for your meals and snacks? }\end{array}$ & 1 & 2 & 3 & 4 & 5 \\
\hline Q7. & $\begin{array}{l}\text { How often do you weigh or measure } \\
\text { your food? }\end{array}$ & 1 & 2 & 3 & 4 & 5 \\
\hline Q8. & $\begin{array}{l}\text { How often do you (or the person who } \\
\text { cooks your food) use the exchange } \\
\text { lists or food group lists to plan your } \\
\text { meals? }\end{array}$ & 1 & 2 & 3 & 4 & 5 \\
\hline
\end{tabular}

\section{Section VI - Exercise Barriers Scale}


For the following questions, please circle the appropriate response.

(circle one answer for each line)

\begin{tabular}{|c|c|c|c|c|c|c|}
\hline Q1. & $\begin{array}{l}\text { How often do you have trouble getting } \\
\text { enough exercise because: }\end{array}$ & Rarely & & Sometimes & & Often \\
\hline & a) it takes too much effort? & 1 & 2 & 3 & 4 & 5 \\
\hline & b) you don't believe it is useful? & 1 & 2 & 3 & 4 & 5 \\
\hline & c) you don't like to do it? & 1 & 2 & 3 & 4 & 5 \\
\hline & d) you have a health problem? & 1 & 2 & 3 & 4 & 5 \\
\hline & $\begin{array}{l}\text { e) it makes your diabetes more } \\
\text { difficult to control? }\end{array}$ & 1 & 2 & 3 & 4 & 5 \\
\hline
\end{tabular}

\section{Section VII - Education / Advice Received}

Q1. Has your health care provider or nurse ever told you to take special care of your feet?

(check one box)

$\square_{1}$ No $\square_{2}$ Yes $\square$ Not Sure

Q2. Has your health care provider or nurse ever told you to follow an exercise program?

(check one box)

$\square_{1}$ No $\square_{2}$ Yes $\square 3$ Not Sure 
Q3. Has your health care provider or nurse ever told you to follow a meal plan or diet?

(check one box)

$\square_{1}$ No $\square_{2}$ Yes $\square_{3}$ Not Sure

Q4. Have you ever received diabetes education? (for example: attended a series of classes or

series of meetings with a diabetes educator) (check one box)

$\square_{1}$ No $\square_{2}$ Yes $\square_{3}$ Not Sure 


\section{Section VIII - Long-Term Care Benefits Scale}

For the following questions, please circle the appropriate response.

(circle one answer for each line)

\begin{tabular}{|lcccccc|}
\hline $\begin{array}{l}\text { Q1. Taking the best possible care } \\
\text { of diabetes will delay or } \\
\text { prevent: }\end{array}$ & $\begin{array}{l}\text { Strongly } \\
\text { Disagree }\end{array}$ & Disagree & Neutral & $\begin{array}{c}\text { Strongly } \\
\text { Agree }\end{array}$ \\
\hline a) eye problems & 1 & 2 & 3 & 4 & 5 \\
\hline b) kidney problems & 1 & 2 & 3 & 4 & 5 \\
\hline c) foot problems & 1 & 2 & 3 & 4 & 5 \\
\hline d) hardening of the arteries & 1 & 2 & 3 & 4 & 5 \\
\hline e) heart disease & 1 & 2 & 3 & 4 & 5 \\
\hline
\end{tabular}




\begin{tabular}{|c|c|c|c|c|c|c|}
\hline Q1. & $\begin{array}{l}\text { How do you rate your understanding } \\
\text { of: (circle one answer for each } \\
\text { line) }\end{array}$ & Poor & & Good & & Excellent \\
\hline & a) overall diabetes care & 1 & 2 & 3 & 4 & 5 \\
\hline & b) coping with stress & 1 & 2 & 3 & 4 & 5 \\
\hline & c) diet for blood sugar control & 1 & 2 & 3 & 4 & 5 \\
\hline & d) the role of exercise in diabetes & 1 & 2 & 3 & 4 & 5 \\
\hline & e) medications you are taking & 1 & 2 & 3 & 4 & 5 \\
\hline & $\begin{array}{l}\text { f) how to use the results of blood } \\
\text { sugar monitoring }\end{array}$ & 1 & 2 & 3 & 4 & 5 \\
\hline & $\begin{array}{l}\text { g) how diet, exercise, and } \\
\text { medicines affect blood sugar } \\
\text { levels }\end{array}$ & 1 & 2 & 3 & 4 & 5 \\
\hline & $\begin{array}{l}\text { h) prevention and treatment of high } \\
\text { blood sugar }\end{array}$ & 1 & 2 & 3 & 4 & 5 \\
\hline & $\begin{array}{l}\text { i) prevention and treatment of low } \\
\text { blood sugar }\end{array}$ & 1 & 2 & 3 & 4 & 5 \\
\hline & $\begin{array}{l}\text { j) prevention of long-term } \\
\text { complications of diabetes }\end{array}$ & 1 & 2 & 3 & 4 & 5 \\
\hline & k) foot care & 1 & 2 & 3 & 4 & 5 \\
\hline & $\begin{array}{l}\text { 1) benefits of improving blood } \\
\text { sugar control }\end{array}$ & 1 & 2 & 3 & 4 & 5 \\
\hline & m) pregnancy and diabetes & 1 & 2 & 3 & 4 & 5 \\
\hline
\end{tabular}




\section{Section X - Self-Care Adherence:}

For the following questions, please circle the appropriate response.

(circle one answer for each line)

\begin{tabular}{|c|c|c|c|c|c|c|}
\hline & & Never & & Sometimes & & Always \\
\hline Q1. & $\begin{array}{l}\text { I keep my blood sugar in good } \\
\text { control. }\end{array}$ & 1 & 2 & 3 & 4 & 5 \\
\hline Q2. & $\begin{array}{l}\text { I keep my glycated hemoglobin } \\
\left(\mathrm{HbA}_{1 \mathrm{C}}\right) \text { in good control. }\end{array}$ & 1 & 2 & 3 & 4 & 5 \\
\hline Q3. & I keep my weight under control. & 1 & 2 & 3 & 4 & 5 \\
\hline Q4. & $\begin{array}{l}\text { I do the things I need to do for my } \\
\text { diabetes (diet, medicine, exercise). }\end{array}$ & 1 & 2 & 3 & 4 & 5 \\
\hline
\end{tabular}




\section{APPENDIX H}


ID \#

\section{CVD RISK STUDY: \\ HAITIAN \& AFRICAN AMERICAN}

Weight:

lb

Height:

in

BMI:

Waist circumference: in
Weight: kg

Height: cm

\section{Blood Pressure: 1}

Systolic: mm Hg

Diastolic: mm Hg

Blood Pressure: 2

Systolic: mm Hg

Diastolic: mm Hg

\section{Average Blood Pressures}

Average Systolic: mm Hg

Average Diastolic mm Hg 
APPENDIX I 


\begin{tabular}{|c|c|c|c|}
\hline Aim & Hypotheses & Variables & Test \\
\hline $\begin{array}{l}\text { 1. To determine } \\
\text { differences in } \\
\text { Serum MnSOD } \\
\text { and } 8 \mathrm{OHdG} \text { by } \\
\text { diabetes status and } \\
\text { ethnicity. }\end{array}$ & $\begin{array}{l}\text { 1a: Serum levels of } \\
\text { MnSOD will be lower } \\
\text { in participants with } \\
\text { T2D as compared with } \\
\text { those without T2D, } \\
\text { independent of } \\
\text { ethnicity. } \\
\text { 1b: Serum levels of } \\
8 \text { OHdG will be higher } \\
\text { in participants with } \\
\text { T2D when compared to } \\
\text { those without T2D, } \\
\text { independent of } \\
\text { ethnicity. } \\
\text { 1c: There will be an } \\
\text { inverse relationship } \\
\text { between serum levels } \\
\text { of MnSOD and } \\
8 O H d G \text { in participants } \\
\text { with T2D, independent } \\
\text { of ethnicity. }\end{array}$ & $\begin{array}{l}\text { Dependent Variables } \\
\text { 1a: MnSOD } \\
\text { 1b: 8OHdG } \\
\text { Independent Variables } \\
\text { Diabetes status, } \\
\text { ethnicity } \\
\text { Covariates } \\
\text { Age, gender, smoking, } \\
\text { education, BMI, } \\
\text { energy intakes }\end{array}$ & $\begin{array}{l}\text { 1a: ANCOVA } \\
\text { 1b: ANCOVA } \\
\text { 1c: Pearson's } \\
\text { correlation and } \\
\text { multiple linear } \\
\text { regression }\end{array}$ \\
\hline
\end{tabular}




\begin{tabular}{|c|c|c|c|}
\hline $\begin{array}{l}\text { 2. To examine the } \\
\text { relationships of } \\
\text { serum MnSOD } \\
\text { and } 8 \mathrm{OHdG} \text { with } \\
\text { various dietary } \\
\text { antioxidants by } \\
\text { diabetes status and } \\
\text { ethnicity. }\end{array}$ & $\begin{array}{l}\text { 2a: Serum } 8 \mathrm{OHdG} \\
\text { levels will be } \\
\text { negatively associated } \\
\text { with dietary intake of } \\
\text { antioxidants, } \\
\text { independent of } \\
\text { diabetes status and } \\
\text { ethnicity. } \\
\text { 2b: MnSOD levels } \\
\text { will be negatively } \\
\text { associated with dietary } \\
\text { intake of antioxidants, } \\
\text { independent of } \\
\text { diabetes status and } \\
\text { ethnicity }\end{array}$ & $\begin{array}{l}\text { Dependent Variables } \\
\text { 2a: } 8 \text { OHdG } \\
\text { 2b: MnSOD } \\
\text { Independent Variables } \\
\text { Dietary intake of } \\
\text { antioxidants (Vit E, } \\
\text { Vit C, Vit D, } \\
\text { carotenoids) } \\
\text { Diabetes status, } \\
\text { ethnicity } \\
\text { Covariates } \\
\text { Age, gender, smoking, } \\
\text { education, BMI, } \\
\text { energy Intakes }\end{array}$ & $\begin{array}{l}\text { 2a: Pearson's } \\
\text { correlation and } \\
\text { multiple linear } \\
\text { regression. } \\
\text { 2b: Pearson's } \\
\text { correlation and } \\
\text { multiple linear } \\
\text { regression. }\end{array}$ \\
\hline $\begin{array}{l}\text { 3. To examine the } \\
\text { relationships of } \\
\text { glycemic control } \\
\text { (A1C and FPG) } \\
\text { with various } \\
\text { dietary } \\
\text { antioxidants in } \\
\text { T2D by ethnicity. }\end{array}$ & $\begin{array}{l}\text { 3a: There will be no } \\
\text { relationship between } \\
\text { serum A1C and dietary } \\
\text { antioxidants in } \\
\text { participants with T2D } \\
\text { independent of } \\
\text { ethnicity. } \\
\text { 3b: There will be no } \\
\text { relationship between } \\
\text { fasting plasma glucose } \\
\text { level and any of the } \\
\text { dietary antioxidant } \\
\text { intakes in T2D } \\
\text { independent of } \\
\text { ethnicity. }\end{array}$ & $\begin{array}{l}\text { Dependent Variables } \\
\text { 3a: A1C } \\
\text { 3b: FPG } \\
\text { Independent Variables } \\
\text { Dietary intake of } \\
\text { antioxidants (Vit E, } \\
\text { Vit C, Vit D, } \\
\text { carotenoids) } \\
\text { ethnicity } \\
\text { Covariates } \\
\text { Age, gender, smoking, } \\
\text { education, BMI, } \\
\text { energy intakes }\end{array}$ & $\begin{array}{l}\text { 3a: Pearson's } \\
\text { correlation and } \\
\text { multiple linear } \\
\text { regression } \\
\text { 3b: Pearson's } \\
\text { correlation and } \\
\text { multiple linear } \\
\text { regression }\end{array}$ \\
\hline
\end{tabular}


VITA

MICHAEL ANDREW MCLEAN

Born, Spanish Town, Jamaica

1984-1986

Pre-Medicine

Broward College

Hollywood, Florida

1986-1989

B.Sc., Biology

Florida International University

Miami, Florida

1986-2001

Medical Laboratory Supervisor/Manager

American Medical Testing Laboratory

Hollywood, Florida

1986-Present

State of Florida Laboratory License

Clinical Laboratory Supervisor

1994-2012

Medical Lab Technologist

Solstas Lab Partners

Miami Lakes, Florida

1996-2002

M.Sc. - Dietetics \& Nutrition

Florida International University

Miami, Florida

2001-2010

Medical Laboratory Supervisor/Manager

Signet Diagnostic Corporation

Riviera Beach, FL

2004-Present

American Society of Clinical Pathologist Clinical Laboratory Technologist

2007-2014

Doctoral Candidate, Dietetics and Nutrition Florida International University Miami, Florida 


\section{PUBLICATIONS AND PRESENTATIONS}

McLean, M. A. (2014). The Relationship among Serum Levels of Manganese Superoxide Dismutase and mtDNA 8-hydroxy-2'-deoxyguanosine, and Dietary Antioxidants Intake in Type 2 Diabetes. Ph.D. Dissertation. College of Urban and Public Affairs, Department of Dietetics and Nutrition, Florida International University, Miami, Florida, 33199

Zarini, G.G., Sheban, L., Exebio, J.C., McLean, M., Huffman, F.G. (2013). Relationship between 25-hydroxyvitamin D and adiponectin levels in Blacks. The FASEB Journal, 27:841.4

Cuervo, J., Zarini, G.G., Exebio, J.C., McLean, M., and Huffman, F.G. (2012).

Hypertension, glycemic control and microalbuminuria in Haitian Americans and African Americans. The FASEB Journal, 26:876.3

Huffman, F.G., Knight-Sepulveda, K., McLean, M., Vaccaro, J.A., Zarini, G.G. (2010). Serum Adiponectin and Ghrelin, Metabolic Syndrome and Diabetes Status in Cuban Americans. International Journal of Health Research, 3(2): 93-103

Karina Knight Sepulveda, Fatma G. Huffman, Michael McLean and Gustavo G. Zarini. (2009). Increased Adiponectin Among Cuban American Type 2 Diabetics with Metabolic Syndrome. The FASEB Journal, 23:547.8

McLean, M. A. (2002). The Correlation between Dehydroepiandrosterone Sulfate (DHEA-S) and Cardiovascular Risk Factors in Tri-Ethnic Population. M.Sc. Thesis. College of Urban and Public Affairs, Department of Dietetics and Nutrition, Florida International University, Miami, Florida, 33199 